\title{
Reprogramming of protein-targeted small molecule medicines to RNA by ribonuclease recruitment
}

Authors: Peiyuan Zhang ${ }^{1, \#}$, Xiaohui Liu ${ }^{1, \#}$, Daniel Abegg ${ }^{1}$, Toru Tanaka ${ }^{1}$, Yuquan Tong ${ }^{1}$, Raphael I. Benhamou ${ }^{1}$, Jared Baisden ${ }^{1}$, Gogce Crynen ${ }^{1}$, Samantha M. Meyer ${ }^{1}$, Michael D.

Cameron $^{1}$, Arnab K. Chatterjee ${ }^{2}$, Alexander Adibekian ${ }^{1}$, Jessica L. Childs-Disney ${ }^{1}$, and Matthew D. Disney ${ }^{1, *}$.

\author{
Affiliations: \\ ${ }^{1}$ Department of Chemistry, Scripps Research, Jupiter, FL, 33458 USA \\ ${ }^{2}$ California Institute for Biomedical Research (CALIBR), Scripps Research, La Jolla, CA 92037 \\ USA \\ *Correspondence to: disney@scripps.edu \\ \#These authors contributed equally to this work.
}

This PDF file includes:

Materials and Methods

Supplementary Text

Figures S1 to S29

Tables S1

Synthetic experimental procedures

Synthetic schemes, methods, and characterization

Other Supplementary Materials for this manuscript include the following:

Data S1: Results of global proteomic analysis of MDA-MB-231 cells treated with 1 (1 $\mu \mathrm{M}), \mathbf{4}(1 \mu \mathrm{M})$, or LNA-21 $(0.1 \mu \mathrm{M})$ and untreated cells.

Data S2: Results of RNA-seq analysis of MDA-MB-231 cells treated with $1(1 \mu \mathrm{M}), 4(1$ $\mu \mathrm{M})$, or LNA-21 $(0.1 \mu \mathrm{M})$, and untreated cells. 


\section{Materials and Methods}

General Nucleic Acids Methods. All DNA oligonucleotides were purchased from Integrated DNA Technologies, Inc. (IDT). They were prepared by dissolving in Nanopure water and used without further purification. A locked nucleic acid (LNA) oligonucleotide targeting miR-21-5p (LNA-21, YI04100689-DFA) or a scrambled LNA control (LNA-Scramble, YI00199006-DFA) were purchased from QIAGEN, Inc. The RNase L-targeting siRNA-1 (sc-45965) and control siRNA-1 (sc-37007) were purchased from Santa Cruz Biotechnology. RNase L-targeting siRNA2 (SMARTpool: ON-TARGETplus RNASEL siRNA) and control siRNA-2 (ON-TARGETplus Non-targeting siRNA) were purchased from GE Healthcare Dharmacon, Inc.

Compound Libraries. The 9300-member ReFRAME (Repurposing, Focused Rescue, and Accelerated Medchem) small molecule compound collection was provided in 2016 by the California Institute for Biomedical Research (Calibr) in 1536-well format. This compound collection is a drug repurposing library containing only small molecules that have reached clinical trials or undergone significant preclinical profiling. ${ }^{1}$ Hit compounds were re-purchased in larger quantities for testing. Compound 1 was purchased from LC Laboratories.

PCR Amplification and In Vitro Transcription. DNA templates encoding the RNA library, premiR-21, or mutant pre-miR-21 were amplified in $1 \times$ PCR Buffer $(10 \mathrm{mM}$ Tris, $\mathrm{pH} 9.0,0.1 \%$ (v/v) Triton $\mathrm{X}-100$ and $50 \mathrm{mM} \mathrm{KCl}$ ), containing $2 \mu \mathrm{M}$ forward primer and $2 \mu \mathrm{M}$ reverse primer (Table 1), $330 \mu \mathrm{M}$ of each dNTP, $4.25 \mathrm{mM} \mathrm{MgCl}_{2}$ and $1 \mu \mathrm{L}$ of Taq DNA polymerase in a $50 \mu \mathrm{L}$ reaction. The conditions for PCR amplification were as follows: initial denaturing at $95^{\circ} \mathrm{C}$ for $90 \mathrm{~s}$, followed by 35 cycles of $95^{\circ} \mathrm{C}$ for $30 \mathrm{~s}, 55^{\circ} \mathrm{C}$ for $30 \mathrm{~s}$ and $72{ }^{\circ} \mathrm{C}$ for $60 \mathrm{~s}$. The PCR product was directly used for in vitro transcription as described previously. ${ }^{2}$ Briefly, the PCR product was added with $2 \mathrm{mM}$ of each rNTP, $10 \mathrm{mM} \mathrm{MgCl} 2$ and T7 polymerase into $1 \times$ Transcription Buffer $(40 \mathrm{mM}$ Tris$\mathrm{HCl}, \mathrm{pH}$ 8.1, $10 \mathrm{mM}$ DTT, $1 \mathrm{mM}$ spermidine, and 0.001\% (v/v) Triton X-100 and), and the sample was incubated at $37^{\circ} \mathrm{C}$ overnight. RQ1 DNase (Promega) was then added for $30 \mathrm{~min}$. The RNA product was purified by polyacrylamide gel electrophoresis (PAGE). RNA concentration was quantified using Beer's Law $(\mathrm{A}=\varepsilon \mathrm{lc})$. RNA absorbance was measured at $260 \mathrm{~nm}$ using a Beckman Coulter DU800 UV/vis spectrophotometer. The RNA's extinction coefficient was calculated by the IDT Oligo Analyzer Tool.

Solution-Based Dye Displacement Assay. The solution-based dye displacement assay was completed as previously described ${ }^{3}$ except the dye used was TO-PRO-3, as it has less spectral overlap with compounds in the ReFRAME library. ${ }^{1}$ The $3 \times 2$ internal loop library $(\mathbf{3} \times \mathbf{2}$ ILL) has five random nucleotides and thus has total 1024 unique members. Briefly, the $\mathbf{3} \times \mathbf{2}$ ILL $(0.25 \mu \mathrm{M})$ was folded in 1× Assay Buffer 1 (AB1: $8 \mathrm{mM} \mathrm{Na}_{2} \mathrm{HPO}_{4}$, $\mathrm{pH} 7.0,185 \mathrm{mM} \mathrm{NaCl}, 1 \mathrm{mM}$ EDTA) by heating at $65^{\circ} \mathrm{C}$ for $5 \mathrm{~min}$ followed by slowly cooling to room temperature. Bovine serum albumin (BSA) was then added to a final concentration of $40 \mu \mathrm{g} / \mathrm{mL}$ to afford $1 \times$ Assay Buffer 2 (AB2:

$8 \mathrm{mM} \mathrm{Na}_{2} \mathrm{HPO}_{4}, \mathrm{pH} 7.0,185 \mathrm{mM} \mathrm{NaCl}, 1 \mathrm{mM}$ EDTA, and $\left.40 \mu \mathrm{g} / \mathrm{mL} \mathrm{BSA}\right)$. The folded $\mathbf{3} \times \mathbf{2}$ ILL was then added to a solution of $0.025 \mu \mathrm{M}$ TO-PRO-3, prepared in $1 \times \mathrm{AB} 2$, and the solution was incubated at room temperature for $15 \mathrm{~min}$. Then, $4.92 \mu \mathrm{L}$ of this solution was dispensed into each well of a black 384-well plate (Greiner Low-Volume 784076) using an Aurora Discovery FRD1B liquid dispenser. A $10 \mathrm{~nL}$ aliquot of each small molecule from the ReFRAME library (stock concentration: $333.3 \mu \mathrm{M}$ ) was then pinned into each well eight times, using a Biomek NXP Laboratory Automation Workstation equipped with a 384-pin head, to obtain a final small 
molecule concentration of $5.3 \mu \mathrm{M}$. The solution was incubated at room temperature for $30 \mathrm{~min}$ in the dark. Fluorescence intensity was then measured on an Envision 2104 Multilabel Plate Reader (Perkin Elmer) with an excitation wavelength of $620 \mathrm{~nm}$ and an emission wavelength of $665 \mathrm{~nm}$. DMSO and a nonspecific RNA binder, mitoxantrone, were used as negative and positive controls, respectively, for the assay. The change in fluorescence was normalized to a percentage (\% Fluorescence Change) according to Equation 1:

$$
\% \text { Fluorescence Change }=100-\left(\frac{\tilde{I}_{N C}-I}{\tilde{I}_{N C}} \times 100\right)
$$

where $I$ represents fluorescence of each sample and $\tilde{\mathrm{I}}_{\mathrm{NC}}$ represents the average fluorescence value for all negative controls. If the standard deviation (SD) of all negative control raw fluorescence values is equal to $I$, then by equation 1 the resulting \% Fluorescence Change is $\sigma$. Compounds were considered as hit compounds if they have \% Fluorescence Change greater than 3 times the value of $\sigma($ or $3 \sigma)$. The $\mathrm{Z}$-factor ${ }^{4}$ for the dye displacement assay is $0.63 \pm 0.08$.

Construction of AbsorbArray Small Molecule Microarrays. Microarrays were constructed as previously reported. ${ }^{5}$ Briefly, a $1 \%(\mathrm{w} / \mathrm{v})$ agarose solution was poured onto a glass slide and dried on the benchtop. A $200 \mathrm{~nL}$ aliquot of 68 hit compounds (10 $\mathrm{mM}$ in DMSO) was pinned onto the array from a 384-well plate using a Biomek NXP Laboratory Automation Workstation. Slides were then dried overnight to obtain a thin, invisible agarose layer. Slides were washed three times with $1 \times$ PBST (phosphate buffered saline containing $0.1 \%(\mathrm{v} / \mathrm{v})$ Tween- 20$)^{6}$ and then three times with Nanopure water. Slides were dried completely by air before RNA selection, completed by Two-Dimensional Combinatorial Screening (2DCS) (see below).

RNA Selection and Screening by 2 DCS. The $3 \times 2$ RNA ILL was 5 '-end ${ }^{32} \mathrm{P}$-labeled as previously described, ${ }^{7}$ and 2DCS selections were also completed as previously described. ${ }^{5}$ Briefly, all oligonucleotides were folded as described in "Solution-Based Dye Displacement Assay". Small molecule microarrays were pre-equilibrated with $3 \mathrm{~mL}$ of $1 \times \mathrm{AB} 2$ for $5 \mathrm{~min}$. After removing the pre-equilibration buffer, the folded 5 '-end labeled $\mathbf{3} \times \mathbf{2}$ RNA ILL $(\sim 50,000 \mathrm{cpm})$ was added in $3 \mathrm{~mL}$ of $1 \times \mathrm{AB} 2$ containing $1 \mathrm{mM} \mathrm{MgCl} 2$ and $100 \mu \mathrm{M}$ each of eight competitor oligonucleotides (Figure S1). The oligonucleotide solution was evenly distributed across the microarray surface with a custom-cut piece of Parafilm. After incubating for $30 \mathrm{~min}$ at room temperature, the Parafilm was removed, and the slide was washed gently by submersion in $1 \times \mathrm{AB} 2$ for $30 \mathrm{~s}$. This washing step was repeated three additional times, and the array was dried on the benchtop for $1 \mathrm{~h}$. After drying, the selection was imaged using a Molecular Devices Typhoon phosphorimager, which revealed the locations (small molecules) that bound the ${ }^{32} \mathrm{P}$-labeled RNA. To harvest and collect the bound RNAs, $1 \mu \mathrm{L}$ of Nanopure water was added to each spot with signal on the slide. After $30 \mathrm{~s}$, the water drop was absorbed into the agarose gel, hydrating it such that it could be excised with a toothpick. The RNAs from each excised spot were eluted from the agarose by simple incubation with water and then treated with RNase-free DNase I. A unique barcode for each small molecule was installed by reverse transcription (RT). Barcoded RNAs were amplified by PCR, purified, and identified by next-generation sequencing (NGS) using an Ion Proton deep sequencer using PI chips (60-80 million reads) as previously described. ${ }^{3}$ The RNA-seq data were analyzed by High Throughput Structure-Activity Relationships Through Sequencing (HiT-StARTS) to identify the most statistically significantly enriched RNAs, that is the highest affinity RNA-small molecule binding pairs, as described. ${ }^{6}$

Supporting Information Page 3 
LOGOS Analysis. $Z_{\text {obs }}$ scores corresponding to the top $0.5 \%$ (enriched) and bottom $0.5 \%$ (discriminated) RNAs for each compound were subjected to LOGOS analysis. ${ }^{8}$ The sequences were converted separately to position weight matrix (PWM) lists for each compound using JMP ${ }^{\circledR}$, Version $<13.2 .1>$. SAS Institute Inc., Cary, NC, 1989-2007. The R package DiffLogo, ${ }^{9}$ part of Bioconductor, was utilized to create the sequence logos from PWM lists for each compound and visually compare the differences between them in RStudio (version 1.2.5042, RStudio Team 2020) with R 3.6.3. ${ }^{10}$

Principal Component Analysis (PCA). Proteomics data were subjected to PCA, which 2965 proteins that were detected in all samples after the technical replicates were averaged to visualize overall differences across the samples. $\mathrm{R}$ build in package prcomp ${ }^{10}$ was used to perform the analysis, where scale was set to TRUE.

Fluorescent Binding Affinity Measurements. Binding assays were completed as previously described. ${ }^{6}$ Briefly, the RNA of interest was folded as described in "Solution-Based Dye Displacement Assay", including the addition of BSA. Then, 1 was added to the RNA solution to a final concentration of $0.5 \mu \mathrm{M}$. The solution was serial diluted with $1 \times \mathrm{AB} 2$ containing $0.5 \mu \mathrm{M}$ of 1. The solutions were incubated at room temperature in the dark for $30 \mathrm{~min}$ and then transferred to a black 384-well plate (Greiner Low-Volume 784076). Fluorescence intensity was measured using a Tecan Plate Reader (Gain: 100, Integration time: $40 \mu \mathrm{s}$ ) with excitation wavelength of 355 $\mathrm{nm}$ and emission wavelength of $535 \mathrm{~nm}$. The change in fluorescence was normalized to samples lacking RNA. Binding affinity was calculated using Equation 2, as previously described: ${ }^{6}$

$I=I_{0}+0.5 \Delta \varepsilon\left\{\left([F L]_{0}+[R N A]_{0}+K_{d}\right)-\left(\left([F L]_{0}+[R N A]_{0}+K_{d}\right)^{2}-4[F L]_{0}[R N A]_{0}\right)^{0.5}\right\}$

where $I$ and $I_{0}$ are the measured fluorescence intensity of compound with or without RNA, respectively, $\Delta \varepsilon$ is the difference between the fluorescence intensity with infinite concentration of RNA or without RNA, $[F L]_{0}$ and $[\mathrm{RNA}]_{0}$ are the concentrations of small molecule and RNA, respectively, and $K_{d}$ is the dissociation constant.

Binding Affinity Measurements by Microscale Thermophoresis (MST). MST binding assays were performed using a Monolith NT. 115 system (NanoTemper Technologies) with a Cy5-labeled RNA displaying pre-miR-21's A-bulge (5'-Cy5-GUUGACUGUUGAAUCUCAUGG_CAAC). The RNA $(10 \mathrm{nM})$ was prepared in $1 \times \mathrm{AB} 1$ and folded by heating at $65^{\circ} \mathrm{C}$ for $5 \mathrm{~min}$ followed by slowly cooling to room temperature and supplemented with $0.1 \%$ (v/v Tween 20$)$. Compound 1 or 8 was prepared in $1 \times \mathrm{AB} 1$ to a final concentration of 15 or $30 \mu \mathrm{M}$, followed by $2: 3$ serial dilutions in $1 \times \mathrm{AB} 1$. The RNA solution and the compound solutions were then mixed 1:1 (v/v) for a total volume of $20 \mu \mathrm{L}$. The samples were incubated at room temperature for $30 \mathrm{~min}$ then loaded into premium coated capillaries (NanoTemper Technologies). MST curves were generated using the following parameters: $80 \%$ MST power, 5-20\% LED, Laser-On time $=30 \mathrm{~s}$, Laser-off time $=5 \mathrm{~s}$. The excitation and emission wavelengths for fluorescence detection were $605-645 \mathrm{~nm}$ and 680-685 nm, respectively. The results were analyzed using NanoTemper's MST analysis software, generating both thermophoresis analysis and curve fitting using a quadratic binding equation. Average $\mathrm{K}_{d} \mathrm{~s}$ from three independent experiments were reported. 
NMR Spectroscopy. All NMR spectra were acquired on a Bruker Avance III 600 spectrometer equipped with a cryoprobe. NMR samples were dissolved in $95 \% \mathrm{H}_{2} \mathrm{O}$ and $5 \% \mathrm{D}_{2} \mathrm{O}$, and all experiments were performed at $25^{\circ} \mathrm{C}$. $1 \mathrm{D}{ }^{1} \mathrm{H}$ experiments and water-ligand observed gradient spectroscopy (WaterLOGSY) experiments were collected on $300 \mu \mathrm{M}$ of 1a only. An excitation sculpted pulse was used to suppress water in the $1 \mathrm{D}{ }^{1} \mathrm{H}$ experiment. Next, WaterLOGSY spectra were recorded upon addition of $3 \mu \mathrm{M}$ of WT miR-21 or $3 \mu \mathrm{M}$ of $\Delta \mathrm{A}$ (adenine bulge deletion) to the 1a sample, or a 1:100 RNA:compound ratio. WaterLOGSY spectra were phased to ensure negative nuclear Overhauser effects (NOEs) for water. The frequency of water was used as an internal reference for proton chemical shift. NMR data were processed and exported using TopSpin (Bruker).

In Vitro RNase L Oligomerization. To a solution of RNase L ( $3 \mu \mathrm{M})$ in $1 \times$ RNase L Buffer $(25$ $\mathrm{mM}$ Tris- $\mathrm{HCl}, \mathrm{pH} 7.4$, and $100 \mathrm{mM} \mathrm{KCl}$ ) was added $\mathrm{MgCl}_{2}$, freshly prepared $\beta$-mercaptoethanol, and ATP to final concentrations of $10 \mathrm{mM}, 7 \mathrm{mM}$, and $50 \mu \mathrm{M}$, respectively. The dimerization of RNase L induced by small molecules was assessed as previously reported. ${ }^{2}$ Briefly, compounds in $1 \times$ RNase L Buffer were added to the sample at the indicated concentration. After incubation at room temperature for $5 \mathrm{~min}, 1 \mu \mathrm{L}$ of $44 \mathrm{mM}$ of dimethyl suberimidate (Thomas Scientific) was added. The samples were incubated at room temperature for $2 \mathrm{~h}$, followed by the addition of 3.6 $\mu \mathrm{L}$ of $6 \times$ Laemmli buffer $(375 \mathrm{mM}$ Tris- $\mathrm{HCl}, \mathrm{pH} 6.8,60 \%$ glycerol, $12 \%$ SDS, $0.6 \% \beta-$ mercaptoethanol, $0.03 \%$ bromophenol blue). The samples were denatured at $95{ }^{\circ} \mathrm{C}$ for $5 \mathrm{~min}$ and diluted 1:90 in 1× Laemmli buffer. Monomeric and oligomeric RNase L protein were resolved by Western blot by using by SDS-PAGE ( $8 \%$ polyacrylamide in the separating layer) at $150 \mathrm{~V}$ for 80 min and detected using an RNase L primary antibody (1:6000 dilution; Cell Signaling Technology, D4B4J). The blot was incubated with the antibody in $1 \times$ TBST (Tris-buffered saline supplemented with $0.1 \%(\mathrm{v} / \mathrm{v})$ Tween-20) and $5 \%(\mathrm{w} / \mathrm{v})$ nonfat dry milk at $4{ }^{\circ} \mathrm{C}$ overnight. After washing, the blot was incubated with 1:12000 anti-rabbit IgG, HRP-linked Antibody (Cell Signaling Technology, 7074S) in $1 \times$ TBST with $5 \%(\mathrm{w} / \mathrm{v})$ nonfat dry milk for $1 \mathrm{~h}$ at room temperature. The blot was washed with $1 \times$ TBST three times for 10 min each, followed by detection of monomeric and oligomerized RNase L protein using SuperSignal West Pico Chemiluminescent Substrate (Pierce Biotechnology). ImageJ software was used for quantification.

In vitro Dicer Processing. The pre-miR-21 WT RNA or pre-miR-21 Dicer site base pair mutant (see RNA structures in Figure S6) were 5'-end labeled with T4 polynucleotide kinase and $\left[\gamma-{ }^{32} \mathrm{P}\right]$ ATP as described previously. ${ }^{7}$ The RNA was folded in $1 \times$ Reaction Buffer (Genlantis) by heating at $65^{\circ} \mathrm{C}$ for $5 \mathrm{~min}$ and cooling slowly to room temperature on the benchtop. The mixture was then supplemented with $2.5 \mathrm{mM} \mathrm{MgCl}$ and $1 \mathrm{mM}$ ATP. The Dicer processing reaction was performed as described previously. ${ }^{2}$ Briefly, compound was added into reaction mixture and incubated at room temperature for $15 \mathrm{~min}$. Recombinant human Dicer enzyme (Genlantis) was added to a final concentration of $0.01 \mathrm{U} / \mu \mathrm{L}$, and the samples were incubated at $37{ }^{\circ} \mathrm{C}$ for $30 \mathrm{~min}$. The cleavage reaction was stopped by addition of an equal volume of $2 \times$ Gel Loading Buffer ( $8 \mathrm{M}$ Urea, $50 \mathrm{mM}$ EDTA, $0.05 \%(\mathrm{w} / \mathrm{v})$ bromophenol blue, $0.05 \%(\mathrm{w} / \mathrm{v})$ xylene cyanol) and resolved on a denaturing $15 \%$ polyacrylamide gel for $2 \mathrm{~h}$ at $70 \mathrm{~W}$. The gel was imaged using a Molecular Dynamics Typhoon phosphorimager and quantified with QuantityOne software from Bio-Rad.

In vitro RNA Cleavage. Pre-miR-21 RNA labeled with $\left[\gamma^{32} \mathrm{P}\right]$ ATP was folded in $1 \times$ RNase $\mathrm{L}$ Buffer by heating at $65^{\circ} \mathrm{C}$ for $5 \mathrm{~min}$ and slowly cooling to room temperature on the benchtop. To 
this solution was added $\mathrm{MgCl}_{2}, \beta$-mercaptoethanol, and ATP to final concentrations of $10 \mathrm{mM}, 7$ $\mathrm{mM}$ and $50 \mu \mathrm{M}$, respectively. Compound was then added to the folded RNA solutions at the indicated concentrations. The samples were incubated at room temperature for $15 \mathrm{~min}$, followed by the addition of tRNA to a final concentration of $10 \mu \mathrm{M}$. After another 15 min incubation at room temperature, RNase $\mathrm{L}$ was added to the samples to a final concentration of $25 \mathrm{nM}$. The samples were incubated at room temperature for $12 \mathrm{~h}$ and the cleavage products were resolved on a denaturing $15 \%$ polyacrylamide gel for $2 \mathrm{~h}$ at $70 \mathrm{~W}$. The gel was imaged and quantified as described in "In vitro Dicer Processing” section, using Bio-Rad's QuantityOne software.

In Vitro Chemical Cross-linking and Isolation by Pull Down (Chem-CLIP) and Competitive Chem-CLIP (C-Chem-CLIP). Growth medium [RPMI 1640 medium with L-glutamine \& 25 mM HEPES (Corning)] was inactivated by heating at $95^{\circ} \mathrm{C}$ for $15 \mathrm{~min}$ and slowly cooling to room temperature on the benchtop. Pre-miR-21 labeled with ${ }^{32} \mathrm{P}$ at the $5^{\prime}$-end $(\sim 10,000$ counts) was folded in growth medium by heating at $65^{\circ} \mathrm{C}$ for $5 \mathrm{~min}$ and slowly cooling to room temperature. Chem-CLIP probe $2(1,5,20$ or $100 \mu \mathrm{M})$ or negative control probe $\mathbf{3}(1,5,20$ or $100 \mu \mathrm{M})$ was then mixed with the folded RNA solution and the mixtures were incubated at $37^{\circ} \mathrm{C}$ for $1 \mathrm{~h}$. The samples were then cross-linked by irradiation with $365 \mathrm{~nm}$ light for $10 \mathrm{~min}$. The Chem-CLIP probe $\mathbf{2}$ or control probe $\mathbf{3}$, whether or not cross-linked to the RNA, was then clicked to disulfide biotin azide (10 mM in DMSO; $10 \mu \mathrm{L}$ per sample; 1168-10, Click Chemistry Tools). After addition of $25 \mathrm{mM}$ HEPES, $\mathrm{pH} 7$, a mixture of $30 \mu \mathrm{L}(\mathrm{v} / \mathrm{v} / \mathrm{v}=1: 1: 1)$ sodium ascorbate $(250 \mathrm{mM}$ in $\left.\mathrm{H}_{2} \mathrm{O}\right), \mathrm{CuSO}_{4}\left(10 \mathrm{mM}\right.$ in $\left.\mathrm{H}_{2} \mathrm{O}\right)$ and THPTA $\left(50 \mathrm{mM}\right.$ in $\left.\mathrm{H}_{2} \mathrm{O}\right)$ was added, and the samples were incubated for $2 \mathrm{~h}$ at $37^{\circ} \mathrm{C}$. Streptavidin beads (Invitrogen; loading; $10 \mu \mathrm{L}$ per sample) were then added to the samples to pull-down the cross-linked RNA, and the samples were shaken for $20 \mathrm{~min}$ at room temperature. The samples were washed three times with $1 \times$ PBST (phosphate buffered saline containing $0.1 \%(\mathrm{v} / \mathrm{v})$ Tween-20). The wash steps were collected and pooled. The radioactive signal from bound RNAs (on the beads) and unbound RNAs (from the wash steps) was measured by using a Beckman Coulter LS6500 Liquid Scintillation Counter as $\mathrm{C}_{\text {bound }}$ and $\mathrm{C}_{\text {unbound. }}$ Enrichment of RNAs was calculated as percentage of radiolabeled RNA captured by beads calculated, or $\mathrm{C}_{\text {bound }} /\left(\mathrm{C}_{\text {bound }}+\mathrm{C}_{\text {unbound }}\right)$. In vitro $\mathrm{C}$-Chem-CLIP was completed by pre-treatment of the RNA with $1(1,5,20$ or $100 \mu \mathrm{M})$. Sample preparation and data analysis were completed as described above for in vitro Chem-CLIP studies.

Cell Culture. Cells were cultured at $37{ }^{\circ} \mathrm{C}$ with 5\% $\mathrm{CO}_{2}$. MDA-MB-231 cells (HTB-26, ATCC) were cultured in RPMI 1640 medium with L-glutamine and $25 \mathrm{mM}$ HEPES supplemented with $1 \times$ Antibiotic/Antimycotic solution (Corning) and 10\% fetal bovine serum (FBS; Sigma, catalog \#12003C). MCF-7 (HTB-22, ATCC), A549 (CCL-185, ATCC), A375 (CRL-1619, ATCC), and MDA-LM2 were cultured in $1 \times$ Dulbecco's modified eagle medium (DMEM) (high glucose) containing $1 \times$ Antibiotic/Antimycotic solution, $1 \times$ Glutagro (Corning), and 10\% FBS. MCF-10A cells (CRL-10317, ATCC) were cultured in 1× DMEM/F12 with L-glutamine \& 15 mM HEPES (Corning) supplemented with 20\% FBS, $1 \times$ Antibiotic/Antimycotic solution, $20 \mathrm{ng} / \mathrm{mL}$ human epidermal growth factor (Pepro Tech, Inc.), $10 \mu \mathrm{g} / \mathrm{mL}$ insulin (Sigma-Aldrich), and $0.5 \mathrm{mg} / \mathrm{mL}$ hydrocortisone (Pfaltz \& Bauer). For compound treatment, compound stocks prepared in DMSO were diluted in growth medium ( $<1 \%$ DMSO final concentration) and added to cells at around $60 \%$ confluency. After $24 \mathrm{~h}$, the medium was removed, and compound of interest prepared in medium was added for the indicated length of time, typically $24 \mathrm{~h}$. For experiments that required 
treatment for 72 and $96 \mathrm{~h}$ (Figure S15A), compounds were added to the cells when they reached $\sim 30 \%$ confluency to avoid overgrowing.

Plasmid DNA to overexpress pre-miR-21 (Addgene 21114) or a plasmid encoding the pre-miR21 mutant (custom purchased from GenScript USA, Inc.) was transfected with jetPRIME per the manufacturer's protocol (250 ng of total plasmid were transfected into each well of 24-well plate for $4 \mathrm{~h}$ ). After transfection, the medium was replaced with growth medium containing the compound of interest, prepared as described above. The RNase L-targeting siRNA or a control siRNA were transfected with Lipofectamine RNAiMAX reagent (Invitrogen) per the manufacturer's protocol to final concentration of $0.1 \mu \mathrm{M}$.

Potential Reactivity of 4, as Determined by Mass Spectrometry. To study the potential reactivity of 4 in cell culture medium, the amount remaining after incubation in growth medium (1× RPMI 1640 with L-glutamine and 25 mM HEPES + 10\% FBS; Condition 1) and growth medium supplemented with an additional $5 \mathrm{mM}$ glutathione (Condition 2) was measured at $37^{\circ} \mathrm{C}$ / $5 \% \mathrm{CO}_{2}$ at the indicated time points. Note, RPMI medium contains $3.25 \mu \mathrm{M}$ glutathione. Mass spectra were collected using an ABSciex 5500 mass spectrometer using multiple reaction monitoring. The percentage of intact 4 was calculated using the mass transition $1006 \rightarrow 559$. The results were reported as quantity of intact compound $\mathbf{4}$ normalized to time equals to zero under Condition 1 and Condition 2.

RNA Isolation and Quantitative Real-Time PCR (RT-qPCR). After treatment, total RNA was extracted and purified using the Zymo Quick-RNA mini prep kit per the manufacturer's protocol. Reverse transcription (RT) for mature miRNAs, as well as pri- and pre-miR-21, was completed using $200 \mathrm{ng}$ of total RNA with the miScript II RT kit (Qiagen), according to manufacturer's protocol. Manufacturer-provided HiSpec Buffer was used for mature miRNAs and pre-miR-21 while HiFlex Buffer was used for pri-miR-21. RT for mature miRNA was also completed using 200 ng of total RNA with the Taqman MicroRNA Assays Kit (Applied Biosystems) according to manufacturer's protocol. RT of mRNAs were performed using the qScript cDNA Synthesis kit (QuantaBio). An Applied Biosystems QS5 384-well PCR system was used to complete qPCR experiments with Power SYBR Green Master Mix (Life Technologies) or TaqMan as described previously. ${ }^{2}$ Validation experiments of miScript (pre- and mature miR-21) and Taqman (mature miR-21) primers are shown in Figure S29.

Western Blotting. MDA-MB-231 cells were plated in 6-well plates. After reaching $\sim 60 \%$ confluency, they were treated with vehicle (DMSO), compound, or LNA-21. After $24 \mathrm{~h}$, the medium was removed, compound prepared in growth medium was added, and the cells were incubated for another $24 \mathrm{~h}$. After removing the medium, the cells were washed with $1 \times$ DPBS and harvested by trypsinization. Total protein was extracted with Mammalian Protein Extraction Reagent (M-PER, Thermo Scientific) as previously described, ${ }^{2}$ and protein concentrations were determined using a Pierce Micro BCA Protein Assay Kit (Fisher Scientific). Approximately 10 $\mu \mathrm{g}$ of total protein from each sample obtained above were resolved on an SDS-polyacrylamide gel $(10 \%)$, followed by protein transfer to a PVDF $(0.45 \mu \mathrm{m})$ membrane. After blocking the membrane in $1 \times$ TBST with $5 \%(\mathrm{w} / \mathrm{v})$ nonfat milk for $60 \mathrm{~min}$, the membrane was incubated with $1 \times$ TBST containing 5\% milk and PDCD4 (Cell Signaling Technology, 9535S) primary antibody (1:1000 dilution) at $4{ }^{\circ} \mathrm{C}$ overnight. The membrane was washed three times with $1 \times$ TBST for 10 
min each and then incubated with 1:2000 anti-rabbit IgG horseradish-peroxidase secondary antibody conjugate (Cell Signaling Technology, 7074S) in $1 \times$ TBST containing $5 \%(\mathrm{w} / \mathrm{v})$ milk for about $2 \mathrm{~h}$. After three more washes with $1 \times$ TBST for $10 \mathrm{~min}$ each, PDCD4 protein was detected using SuperSignal West Pico Chemiluminescent Substrate (Pierce Biotechnology). After imaging, the membrane was stripped with $1 \times$ Stripping Buffer $(200 \mathrm{mM}$ glycine with $0.1 \% \mathrm{SDS}, \mathrm{pH} 2.2)$ for $90 \mathrm{~min}$ at room temperature, and $\beta$-actin levels were detected as described for PDCD4, except using a $\beta$-actin primary antibody (1:5000 dilution; Cell Signaling Technology catalog \#3700S). ImageJ software was used for quantification of the protein bands.

Western blots for pERK, ERK, FLT3, RNase L and PPAR $\alpha$ were performed as described for PDCD4, using the following primary antibodies: pERK (Cell Signaling Technology, catalog \#9101S) primary antibody (1:1000 dilution), ERK primary antibody (1:2000 dilution; Cell Signaling Technology catalog \# 9102S), FLT3 primary antibody (1:1000 dilution; Cell Signaling Technology catalog \# 3462S), RNase L (1:1000 dilution; Cell Signaling Technology catalog \# D4B4J), and PPAR $\alpha$ primary antibody (1:1000 dilution; Abcam catalog \# ab215270)). In each case, the secondary antibody was diluted 2-fold more than the primary antibody. Carfilzomib as a protease inhibitor was purchased from Adipogen Corporation (PR-171).

Cellular Chem-CLIP and C-Chem-CLIP to Study Occupancy of pre-miR-21. MDA-MB-231 cells in $100 \mathrm{~mm}$ diameter dishes ( $\sim 60 \%$ confluency) were treated with $\mathbf{2}$ or $\mathbf{3}$ for $12 \mathrm{~h}$ at $37^{\circ} \mathrm{C}$ and $5 \% \mathrm{CO}_{2}$. The cells were then washed with $1 \times$ DPBS and cross-linked under $365 \mathrm{~nm}$ light for 10 min in ice cold $1 \times$ DPBS. The cells were harvested by scraping and pelleted by centrifugation. Total RNA was extracted using the miRNeasy Mini Kit (Qiagen) per the manufacturer's protocol. Approximately $50 \mu \mathrm{g}$ of total RNA was clicked to disulfide biotin azide as described in "In Vitro Chem-CLIP and Competitive Chem-CLIP (C-Chem-CLIP)". Streptavidin beads (10 $\mu \mathrm{L})$ were added, and the samples were incubated, with shaking, for $2 \mathrm{~h}$ at $37^{\circ} \mathrm{C}$. The beads were then washed with $1 \times$ Wash Buffer (10 mM Tris-HCl, $\mathrm{pH}$ 7.0, $4 \mathrm{M} \mathrm{NaCl}, 1 \mathrm{mM}$ EDTA) three times and then once with Nanopure water. Bound RNAs were cleaved from the beads by incubating with $200 \mu \mathrm{L}$ of 1:1 TCEP $(200 \mathrm{mM})$, pre-reduced with $600 \mathrm{mM}$ of $\mathrm{K}_{2} \mathrm{CO}_{3}$, for $30 \mathrm{~min}$ at $37^{\circ} \mathrm{C}$. The reaction was quenched by treatment with an equal volume of $400 \mathrm{mM}$ iodoacetamide for $30 \mathrm{~min}$ at room temperature. The supernatant was collected, and the beads were washed once with Nanopure water; the water was added to the eluant. The combined eluant was cleaned up using RNAClean XP beads according to the manufacturer's protocol. The obtained RNA was then subjected to RT-qPCR. Relative fold enrichment of pre-miR-21 before and after pull-down was calculated using Equation 3, as previously described (2):

\section{Relative Fold Enrichment $=2^{-\left(\Delta C_{t} \text { before pull-down- } \Delta C_{t} \text { after pull-down }\right)}$}

where " $\Delta \mathrm{C}_{\mathrm{t}}$ before pull-down" is the difference between the $\mathrm{C}_{\mathrm{t}}$ values for the pre-miR-21 and 18S in total RNA from cells and " $\Delta \mathrm{C}_{t}$ after pull-down" is the difference between the $\mathrm{C}_{t}$ values for the pre-miR-2 1 and $18 \mathrm{~S}$ in RNA after pull-down. Cellular C-Chem-CLIP was completed by pretreating MDA-MB-231 cells with 1,5 or $7(1$ or $5 \mu \mathrm{M})$ for $6 \mathrm{~h}$, followed by dosing with $2(5 \mu \mathrm{M})$ for $6 \mathrm{~h}$. Sample preparation and data analysis were completed as described above for cellular Chem-CLIP studies. 
Cellular Chem-CLIP and C-Chem-CLIP to Study Occupancy of an RTK. Compound treatment and isolation of cells were completed as described for cellular occupancy studies of premiR-21. Total protein was extracted and quantified as described in "Western Blotting". Approximately $1 \mathrm{mg}$ of total protein was used for pull-down experiments, using a protocol adapted from a previously published method. ${ }^{11}$ Protein cross-linked to the probe were clicked to disulfide biotin azide, as described above, except the amount of each reagent was doubled for the process (20 $\mu \mathrm{L} /$ sample). Then, a 4:1 ice-cold mixture of methanol/chloroform $(2.5 \mathrm{~mL})$ was added to the mixture, followed by $1 \mathrm{~mL}$ of ice-cold $1 \times$ DPBS. The mixture was centrifuged at $5000 \times \mathrm{g}$ for 10 $\min$ at $4{ }^{\circ} \mathrm{C}$ to fractionate a protein interphase between organic and aqueous layers. After carefully removing the two layers, the protein disc was collected and washed with an ice-cold mixture of 1:1 methanol/chloroform $(1 \mathrm{~mL})$ three times, followed by sonication in an ice-cold mixture of $4: 1$ methanol/chloroform $(3 \mathrm{~mL})$. The washed protein mixture was centrifuged at $5000 \times \mathrm{g}$ for $10 \mathrm{~min}$ at $4{ }^{\circ} \mathrm{C}$ to pellet the protein. The pellet was dissolved in $\mathrm{H}_{2} \mathrm{O}$, and to this solution was added 20 $\mu \mathrm{L}$ of streptavidin beads. The mixture was incubated for $30 \mathrm{~min}$ at room temperature. The solution was then removed, and the beads were washed once with $0.2 \%$ SDS in $1 \times$ DPBS, twice with detergent-free $1 \times$ DPBS, and twice with Nanopure water. After these washing steps, protein was cleaved from the beads as described above. The supernatant was collected, and protein concentration was determined using a Pierce Micro BCA Protein Assay kit (Thermo Scientific).

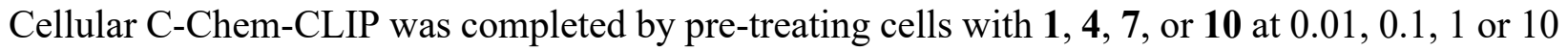
$\mu \mathrm{M}$, respectively for $6 \mathrm{~h}$, followed by dosing with $2(1 \mu \mathrm{M})$ for $1 \mathrm{~h}$. Sample preparation was completed as described above for cellular Chem-CLIP studies. Western blotting was performed on total protein $(10 \mu \mathrm{g})$ before or after pull-down, indicated as "Input" or "Output", as described in "Western Blotting".

PTEN Luciferase Assay. To study de-repression of PTEN, a luciferase-based cellular assay was performed as previously described. ${ }^{2}$ Briefly, MDA-MB-231 cells ( $\sim 60 \%$ confluency) in 48 -well plates were co-transfected with $40 \mathrm{ng}$ of a plasmid encoding Renilla luciferase (for normalization) and $200 \mathrm{ng}$ of a plasmid encoding firefly luciferase fused to the 3' UTR of PTEN using Lipofectamine 2000 (Life Technologies), according to the manufacturer's protocol. After $5 \mathrm{~h}$, the cells were treated with compounds diluted in growth medium as described in "Cell Culture". Luciferase assay were then completed as previously described. ${ }^{5,12}$ Briefly, luminescence signals of PTEN and Renilla were measured on a Biotek Flx800 plate reader as LucPTEN and LucRenilla. The ratio $\mathrm{Luc}_{\mathrm{PTEN}} / \mathrm{Luc}_{\mathrm{Renilla}}$ of compound was normalized to DMSO vehicle.

Boyden Chamber Invasion Assay. MDA-MB-231 or MCF-10A cells $\left(5 \times 10^{4}\right)$ in serum free growth medium with or without compound treatment were seeded into hanging cell culture inserts (for 24-well plates) pre-coated with Matrigel. Complete growth medium was added to the bottom well. After 16-24 h, the medium was removed, and the hanging inserts were washed with $1 \times$ DPBS twice and then fixed with $4 \%(\mathrm{w} / \mathrm{v})$ paraformaldehyde in $1 \times$ DPBS at room temperature for 20 min. Next, the inserts were washed twice with $1 \times$ DPBS and stained with $0.1 \%(\mathrm{w} / \mathrm{v})$ crystal violet in $1 \times$ DPBS for 20 min. The inserts were washed twice with Nanopure water and once with $1 \times$ DPBS. Cells on the surface of the Matrigel (non-invasive) were removed with cotton swabs, and invading cells were counted and imaged under a Leica DMI3000 B upright fluorescent microscope. 
RNase L Immunoprecipitation. MDA-MB-231 cells were seeded in 6-well plates and were treated with vehicle, 4,6 , or $7(1 \mu \mathrm{M})$ when the cells reached $\sim 60 \%$ confluency. After $24 \mathrm{~h}$, the medium was removed, and the compound of interest prepared in medium was added. The samples were then incubated for another $24 \mathrm{~h}$. The cells were harvested and lysed for $20 \mathrm{~min}$ on ice using $100 \mu \mathrm{L}$ of M-PER buffer (Thermo Scientific) containing $1 \times$ Protease Inhibitor Mixture III for Mammalian Cells (Research Products International Corp.) and $80 \mathrm{U}$ RNaseOUT recombinant Ribonuclease Inhibitor (Invitrogen). The lysate was centrifuged at $13000 \times \mathrm{g}$ for $15 \mathrm{~min}$, and the supernatants were incubated with Dynabeads Protein A $(10 \mu \mathrm{L}$ per sample; Life Technologies) bound to RNase L mouse primary antibody or $\beta$-actin mouse primary antibody overnight at $4{ }^{\circ} \mathrm{C}$. After incubation, the beads were washed with $1 \times$ DPBS containing $0.02 \%(\mathrm{v} / \mathrm{v})$ Tween-20, and RNA was extracted using a miRNeasy Mini Kit (Qiagen) per the manufacturer's instructions. RTqPCR was performed as described above. Relative RNA levels were determined by $\Delta \Delta \mathrm{C}_{\mathrm{t}}$ analysis and normalization to $18 S$ rRNA levels. Normalized fold change was calculated using Equation 4, as previously described ${ }^{2}$ :

$$
\text { Normalized Fold Change }=\frac{\text { Relative RNA Expression in RNase } L \text { fraction }}{\text { Relative RNA Expression in } \beta \text {-actin fraction }}
$$

(Eq. 4)

Construction of RNase L Knockout MDA-MB-231 Cells. To establish the optimal conditions for lentiviral transductions, MDA-MB-231 cells were plated at three different densities $\left(1 \times 10^{5}\right.$, $2 \times 10^{5}$, and $4 \times 10^{5}$ cells per $9.6 \mathrm{~cm}^{2}$ well) and puromycin solution (GenDEPOT, catalog \# CR026$001)$ and treated with six puromycin concentrations $(0$ to $4 \mu \mathrm{g} / \mathrm{mL}) 48 \mathrm{~h}$ later. Cells were cultured for an additional $72 \mathrm{~h}$ and counted using a TC20 automated cell counter (Bio-Rad) to determine the optimal plating density and $\mathrm{IC}_{95}$ for puromycin.

Lentiviral constructs containing Cas9 and gRNAs against RNASEL or a negative control were purchased from Transomic Technologies, Inc. [catalog \# TEVH-1249025-pCLIP-ALL-hCMVPuro (KO+) and TELA1015 (KO-)] and packaged by transfecting HEK293T cells (ATCC, catalog \# CRL-11268) using Lipofectamine 2000 transfection reagent (Invitrogen, catalog \# 11668500) and Cellecta packaging mix (Cellecta, catalog \# CPCP-K2A) in Opti-MEM (Gibco, catalog \# 31985070). Virus supernatants were harvested $72 \mathrm{~h}$ post-transfection, filtered with $0.45 \mu \mathrm{m}$ PES filters (mdi Membrane Technologies Inc., catalog \# SYPL0602MNXX204), and used to transduce MDA-MB-231 cells in the presence of $6 \mu \mathrm{g} / \mathrm{mL}$ polybrene (Millipore, catalog \# TR-1003-G).

Kinase Selectivity Profiling. A Kinase Selectivity Profiling System (Promega, catalog \#V6929) was used to evaluate the selectivity of $\mathbf{1}$ and $\mathbf{4}$ per the manufacturer's recommended protocol. Briefly, $2 \mu \mathrm{L}$ of $2.5 \times$ Kinase Working Stocks (supplied with the kit) was added to $1 \mu \mathrm{L}$ of 1 (5 $\mu \mathrm{M}), 4(5 \mu \mathrm{M})$, or vehicle prepared in $1 \times$ Kinase Buffer (supplied with the kit), in white 384-well plates (Greiner Low-Volume 784075). After centrifugation, mixing well with an orbital shaker, and incubation at room temperature for $10 \mathrm{~min}, 2 \mu \mathrm{L}$ of ATP/Substrate Working Stocks (supplied with the kit) were added. The solution was mixed well with an orbital shaker and incubated at room temperature for $60 \mathrm{~min}$.

ADP levels, indicative of kinase activity, were detected by an ADP-Glo ${ }^{\text {TM }}$ Kinase Assay (supplied with the Kinase Selectivity Profiling System). Briefly, to the $5 \mu \mathrm{L}$ kinase reactions were added 5 $\mu \mathrm{L}$ of ADP-Glo ${ }^{\mathrm{TM}}$ Reagent. After mixing well with an orbital shaker, the reactions were incubated 
at room temperature for $40 \mathrm{~min}$. Then, $10 \mu \mathrm{L}$ of Kinase Detection Reagent (supplied with the kit) were added to each sample, which were then incubated at room temperature for an additional 30 min. Finally, luminescence signals were measured using a Tecan Plate Reader (Gain: 100, Integration time: $500 \mathrm{~ms}$ ). Percent change in luminescence was calculated and compared to vehicle treatment.

Global Proteomics Profiling Using LC-MS/MS. MDA-MB-231 cells ( $\sim 60 \%$ confluency) were treated as described in "Cell Culture" with $1(1 \mu \mathrm{M}), \mathbf{4}(1 \mu \mathrm{M})$, LNA-21 $(0.1 \mu \mathrm{M})$, or vehicle. After washing with $1 \times$ DPBS, the cells were harvested by scraping and resuspended in $1 \times$ DPBS. They were lysed by sonication and centrifuged at $14,000 \times \mathrm{g}$ for $15 \mathrm{~min}$. Protein concentrations were determined using a Bradford assay (Bio-Rad). Protein samples $(340 \mu \mathrm{g})$ were denatured with $6 \mathrm{M}$ urea in $50 \mathrm{mM} \mathrm{NH}_{4} \mathrm{HCO}_{3}, \mathrm{pH} 8$, reduced with $10 \mathrm{mM}$ TCEP for $30 \mathrm{~min}$, and alkylated with $25 \mathrm{mM}$ iodoacetamide for $30 \mathrm{~min}$ in the dark. The samples were diluted to a final concentration of $2 \mathrm{M}$ urea with $50 \mathrm{mM} \mathrm{NH}_{4} \mathrm{HCO}_{3}, \mathrm{pH} 8$, and $\mathrm{CaCl}_{2}$ was added to a final concentration of $1 \mathrm{mM}$. The protein mixture was digested with trypsin $(1.5 \mu \mathrm{L}$ of $0.5 \mu \mathrm{g} / \mu \mathrm{L})$ overnight at $37{ }^{\circ} \mathrm{C}$. The digested protein samples were acidified with acetic acid and desalted over a self-packed $\mathrm{C} 18$ spin column. After lyophilization, the samples were analyzed by LC-MS/MS as described below.

LC-MS/MS Analysis and MaxQuant Analysis. The lyophilized protein obtained above was resuspended in $0.1 \%$ formic acid in water and analyzed using an EASY-nLC 1200 nano-UHPLC coupled to Q Exactive HF-X Quadrupole-Orbitrap mass spectrometer (Thermo Scientific) as previously reported. ${ }^{2}$ Obtained spectra were then analyzed with MaxQuant (V1.6.1.0). Spectra were searched against the human proteome (Uniprot) and common contaminants. The search tolerance was set to $20 \mathrm{ppm}$ for the first peptide search and $10 \mathrm{ppm}$ for the main peptide search. The false discovery rate (FDR) for proteins, peptides and site identification was set at 5\%. All parameters were set as previously reported. ${ }^{2}$

RNA-seq. MDA-MB-231 cells ( $\sim 60 \%$ confluency) were treated as described in "Cell Culture" for $48 \mathrm{~h}$ with $1(1 \mu \mathrm{M}), 4(1 \mu \mathrm{M})$, or LNA-21 $(0.1 \mu \mathrm{M})$. Total RNA was extracted using a miRNeasy Mini Kit (Qiagen) per the manufacturer's protocol. RNA concentration was quantified using a Qubit 2.0 Fluorometer (Invitrogen), and RNA quality was assessed using an Agilent Technologies 2100 Bioanalyzer and an RNA nano chip. Samples were used only when the RNA Integrity Number (RIN, an algorithm for assigning integrity values to RNA measurements) was $>8.0$.

Next, rRNA was depleted from 500 ng of total RNA using NEBNext rRNA depletion modules (E6310L, New England Biosciences) according to the manufacturer's protocol. RNA samples were chemically fragmented and primed with random hexamers for reverse transcription into first strand cDNA. Then, the RNA template was removed, after which dUTP was incorporated in place of dTTP. The second strand of cDNA was then synthesized by end repair, followed by adenylation at the 3' end. A hairpin loop adaptor with corresponding T nucleotides was ligated to the doublestranded cDNA. The dUTP in the loop and other incorporated U's in the second strand were removed by using uracil-specific excision reagent enzyme. PCR amplifying adaptor ligated DNA with Illumina barcoding primers were used to generate the final libraries. Only fragments with both 5' and 3' adaptors were enriched in the PCR step. After validation by a Bioanalyzer DNA chip, the final libraries were prepared to $2 \mathrm{nM}$; the libraries were pooled equally and then 
sequenced on a NextSeq 500 v2.5 flow cell $(1.8 \mathrm{pM})$ using paired-end chemistry $(2 \times 40 \mathrm{bp})$. For each sample, $\sim 20-25$ million reads were generated with a base quality score $>Q 30$. RNA-seq data were analyzed as previously reported. ${ }^{14}$

Quantitation of 1 and 4 in Mouse Plasma and Tissue. Male C57BL/6 mice ( $\mathrm{n}=3$ per dose; 57 weeks) were intraperitoneally (i.p.) injected with $1(24,49$ or $81 \mathrm{mg} / \mathrm{kg})$ or $4(17,34$ or 56 $\mathrm{mg} / \mathrm{kg}$ ) in a formulation of DMSO/Tween-80/ $\mathrm{H}_{2} \mathrm{O}(10 / 10 / 80)$. After $48 \mathrm{~h}$, mice were euthanized, and blood, lung, and kidney were collected. Tissues were immediately frozen. Blood was centrifuged to generate plasma and immediately frozen. On the day of analysis, tissues were homogenized, mixed with 5-times volume of acetonitrile and filtered. Drug levels were determined by mass spectrometry using an ABSciex 5500 mass spectrometer with multiple reaction monitoring. Compound 1 was detected using the mass transition $393 \rightarrow 322$, and 4 was detected using the mass transition $1006 \rightarrow 559$.

In Vivo Studies to Assess Metastasis of Breast Cancer to the Lung. Female NOD/SCID mice ( $\mathrm{n}=10 ; 5-7$ weeks) were used for in vivo breast cancer metastasis studies as previously reported. ${ }^{2}$ Briefly, mice purchased from Jackson Laboratory were intravenously injected (tail vein) with MDA-MB-231-Luc cells $\left(0.8 \times 10^{6}\right.$ cells/mice $)$. Luciferase activity was monitored every other day to determine when to initiate treatment [averaged luciferase signal is ten times higher than the background as measured by LagoX (Spectral Instruments)]. After 5 days, the mice were split into three groups, with each group having the same luciferase signal. The mice in the vehicle group were i.p. injected with DMSO/Tween-80/ $\mathrm{H}_{2} \mathrm{O}(10: 10: 80)$ while treated groups were i.p. injected with $81 \mathrm{mg} / \mathrm{kg}$ of 1 or $56 \mathrm{mg} / \mathrm{kg}$ of 4 in the same formulation every other day (q.o.d.). After 30 days, the mice were euthanized (in accordance with guidelines provided by the American Veterinarian Medical Association), the lungs were perfused with PBS, harvested, and immediately fixed in Bouin's solution (Sigma, HT10132-1L) for $24 \mathrm{~h}$ to image nodules. After counting the nodules, the fixed lungs were washed in $60 \mathrm{~mL}$ of $10 \%$ formalin solution eight times over $48 \mathrm{~h}$ to remove Bouin's solution. Paraffin-embedded sections of the lungs were then generated by the Histology Core at Scripps Research Florida. Briefly, lungs were first embedded in paraffin using a Sakura Tissue-Tek VIP5 paraffin processor, then mounted on positively charged slides for further staining.

Lung Tissue Histology. All histological analyses were performed as previously reported. ${ }^{2}$ The slides were stained on a Leica BondMax Immunostaining platform by using a DAB refine kit. H\&E staining and PDCD4, pERK and ERK IHC were performed by the Histology Core at Scripps Research Florida. All antibodies were used at a 1:100 dilution: anti-PDCD4 (Abcam, ab51495); anti-pERK (Cell Signaling Technology, 4370S); and ERK (Cell Signaling Technology, 9102S). The primary antibodies were detected using a DAB Substrate Kit (Vector Laboratories, Inc.) per the manufacturer's protocol.

To visualize miR-21 and pre-miR-21 by fluorescence in situ hybridization (FISH), the paraffinembedded sections were incubated at $56{ }^{\circ} \mathrm{C}$ overnight and cleaned with xylenes three times, followed by washing with serially diluted concentrations of ethanol $(100 \%, 95 \%, 90 \%$, and $85 \%)$. The slides were then washed with MilliQ water three times and immersed in $0.3 \%(\mathrm{v} / \mathrm{v}) \mathrm{H}_{2} \mathrm{O}_{2}$ for $30 \mathrm{~min}$ at room temperature. The slides were then washed with MilliQ water three times and digested with proteinase $\mathrm{K}(400 \mu \mathrm{g} / \mathrm{mL}$, QIAGEN $)$ at $37^{\circ} \mathrm{C}$ for $15 \mathrm{~min}$. After washing three times 
with MilliQ water, the slides were dehydrated with 95\% ethanol and air-dried completely at room

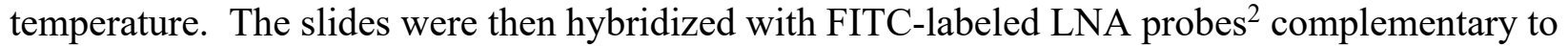
mature miR-21 (CAACATCAGTCTGATAAGCT*/36-FAM) or pre-miR-21 (ATTCAACAGTCAACATCAGTCT/36-FAM) at $37{ }^{\circ} \mathrm{C}$ overnight. After hybridization, the slides were washed with $2 \times \mathrm{SSC}$ (saline sodium citrate buffer) three times and then $1 \times$ DPBS three times, each at room temperature. The slides were then incubated with an anti-FITC horseradish peroxidase-conjugated antibody (Abcam) for $2 \mathrm{~h}$ at room temperature (1:100 dilution). The slides were washed with $1 \times$ TBST three times.

After staining of interest was completed, the slides were dehydrated, cover-slipped with Cytoseal 60, and imaged with a Leica DMI3000 B upright fluorescent microscope.

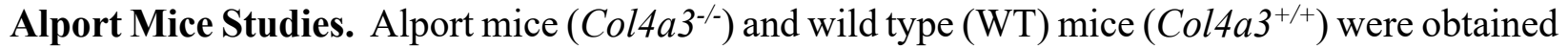
from the breeding of heterozygous $\left(\mathrm{Col}_{4} \mathrm{a}^{+/}\right)$mice. Urine was collected 1 day before compound treatment on what was considered Day 1. Compound treatment started on Day 2, with mice around 4 weeks of age. Alport mice were treated with vehicle or 4 as described for NOD/SCID mice in "In Vivo Studies to Assess Metastasis of Breast Cancer to the Lung”. Urine was collected every other day for analysis of albumin or creatine levels. After 6 weeks of treatment, the mice were euthanized on Day 43. The kidneys were harvested, and one kidney was frozen at $-80{ }^{\circ} \mathrm{C}$ for Western blotting and RT-qPCR analyses. The other kidney was fixed in formalin for paraffinembedding sectioning and further staining.

Evaluation of Kidney Function. The concentration of urine albumin was determined using a Mouse Albumin ELISA Kit (Bethyl Laboratories Inc, E99-134) per the manufacturer's protocol. Urine creatinine levels were measured using a Urinary Creatinine Assay Kit (Fisher Scientific, 50673-569) per the manufacturer's protocol.

Kidney Tissue Histology. Silver staining, Periodic Acid Schiff (PAS) staining, and PPAR $\alpha$ staining were performed by the Histology Core at Scripps Research Florida. Briefly, silver staining and PAS staining were performed using Gomori Stain Kit (Newcomer Supply, catalog \# 9167A) and PAS Stain Kit (Newcomer Supply, 9162A) per manufacturer's protocols. The antiPPAR $\alpha$ antibody (Abcam, catalog \# ab215270) was used at 1:1000 dilution. PPAR $\alpha$ IHC and FISH imaging of miR-21 and pre-miR-21 were completed as described in "Lung Tissue Histology".

Computational Methods. The three-dimensional structures of Dovitinib with ionization states at $\mathrm{pH} 7.0 \pm 2.0$ in Figure 1B were generated with LigPrep (Schrodinger, Inc.). A model of pre-miR21 bound to a previously reported compound ${ }^{2}$ was processed and minimized using the Protein Preparation Wizard (Schrodinger, Inc.) to assign bond orders and add missing hydrogens. Docking was carried out with Induced Fit Docking (Schrodinger, Inc.), where the ligand and receptor are flexible, and no imposed constraints. Docking poses were ranked by Prime energy.

Statistical Analysis. All plots show means of data with error bars representing standard deviation (SD). Data were plotted and analyzed using commercially available software (Perseus, GraphPad prism, ImageJ). Comparisons of two groups were made with the statistical test indicated in each figure legend, typically a two-tailed Student's t-test. Perseus was used to calculate the FDR for 
the Volcano plots of global miRNA profiling and proteomics data. A two-tailed KolmogorovSmirnov test was used to calculate the p-value between distributions. Unless otherwise specified, significance was accepted at $\mathrm{p}<0.05$. 


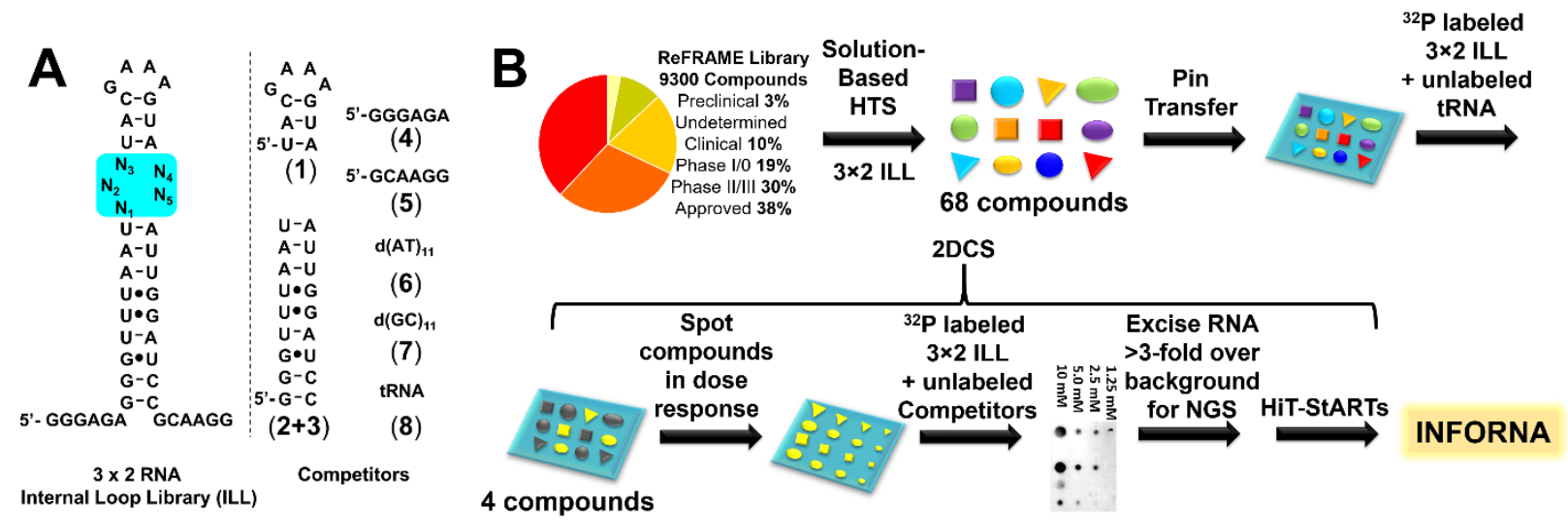

Figure S1. Execution of a high-throughput screen (HTS) identifies medicines that bind RNA and mining those interactions across the human transcriptome to identify potential RNA targets for reprogrammed medicines. (A) Secondary structures of the $3 \times 2$ RNA internal loop library $(\mathbf{3} \times \mathbf{2} \mathbf{I L L})$ and competitor oligonucleotides used in solution-based HTS ( $\mathbf{3} \times \mathbf{2}$ ILL only) and selection by two-dimensional combinatorial screening (2DCS; library and competitor oligonucleotides). (B) Solution-based screen followed by AbsorbArray-enabled 2DCS identified four compounds that bind selectively to members of the $\mathbf{3} \times \mathbf{2}$ ILL. The secondary structural elements from disease-associated miRNAs were extracted and compared with RNA motif-small molecule interactions housed in our Inforna database. ${ }^{15}$ 


\section{A}

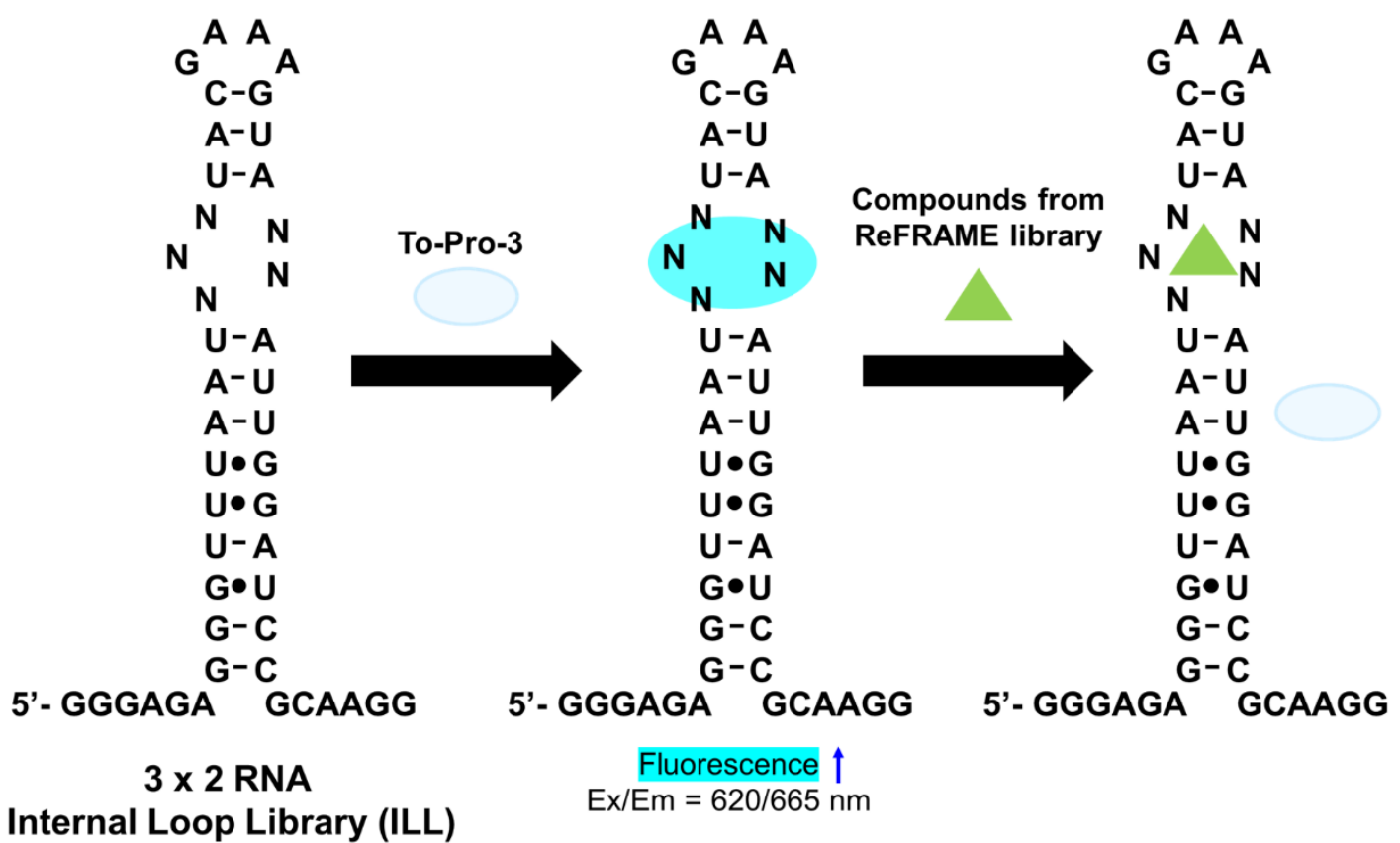

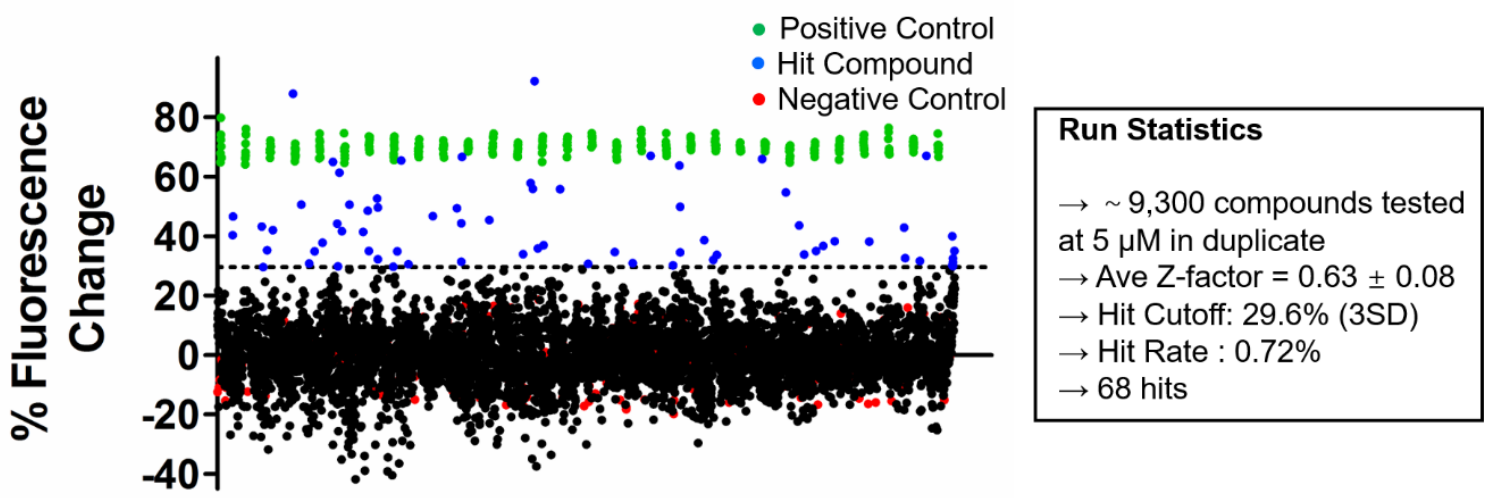

Figure S2. A dye displacement assay identified 68 compounds that bind to $3 \times 2$ RNA ILL avidly. (A) Scheme of solution-based HTS, completed as previously described. ${ }^{2}$ Briefly, the fluorescence intensity of TO-PRO-3 is enhanced when bound to RNA. Displacement of TO-PRO-3 by binding ${ }^{16}$ compounds results in decreased fluorescence signal. (B) Distribution of the percent change in fluorescence induced by 9,300 ReFRAME and control compounds, revealing that 68 compounds reduce fluorescence by $>3 \sigma(n=3)$, which were carried forward to 2DCS selections. 


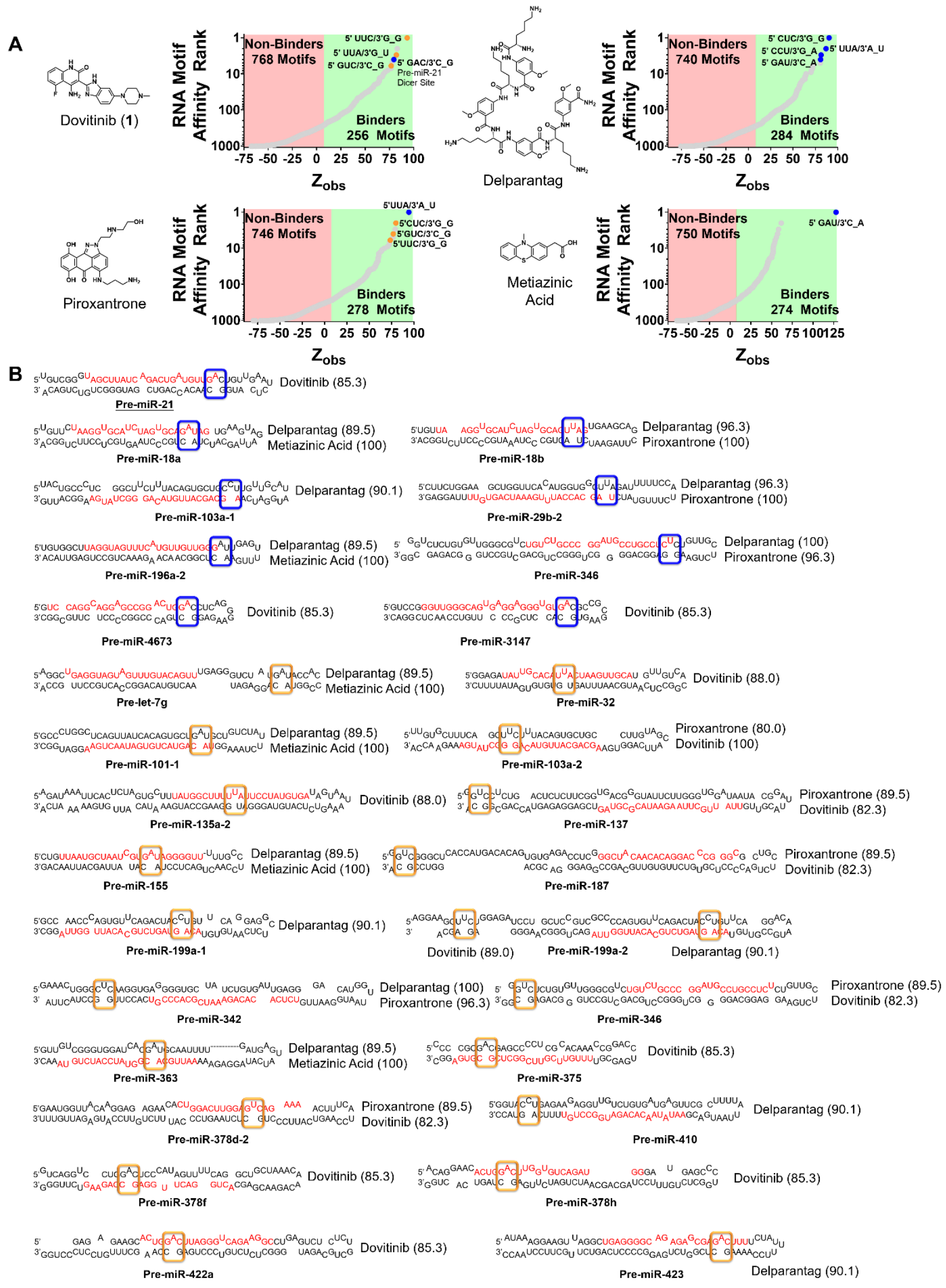

Supporting Information Page 17 
Figure S3. Inforna generated fitness plots showing four different medicines bound RNA targets avidly. (A) $Z_{\mathrm{obs}}$ is a parameter of statistical confidence. RNA motifs with $Z_{\mathrm{obs}}>8(\mathrm{p}<0.0001)$ are avid binders, whereas RNAs with $\mathrm{Z}_{\mathrm{obs}}<8$ are non-binders. ${ }^{6}$ This analysis afforded 256 binding motifs for Dovitinib (1), 278 motifs for Piroxantrone, 284 motifs for Delparantag, and 274 motifs for Metiazinic Acid. Notably, Dovitinib only binds the Drosha or Dicer site in three miRNAs, pre-miR-21, pre-miR-4673, and pre-miR-3147. The mature miRNAs derived from the latter two were not detected in miRNA profiling studies, whether treated or untreated cells (Figure S10A). Fitness scores were calculated by normalizing $Z_{\text {obs }}$ value to the most statistically significant RNA motif binder (Fitness score $=100$ ). ${ }^{6}$ Blue dots indicate that the compound binds to the RNA motif in a Dicer or Drosha functional site with Fitness Scores $>80$, whereas orange dots indicate RNA motifs are present in non-functional sites. Among, the 256 motifs for Dovitinib (1), an A-bulge ( $\left.5^{\prime} \mathrm{GAC} / 3^{\prime} \mathrm{C} \_\mathrm{G}\right)$ in the Dicer processing site of pre-miR-21, is the most fit with a score of 85. (B) All interactions between miRNA precursors and compounds with fitness score over 80. Binding sites are indicated in boxes (blue: Dicer or Drosha sites; orange: non-functional sites); Fitness Scores are provided in parentheses. 


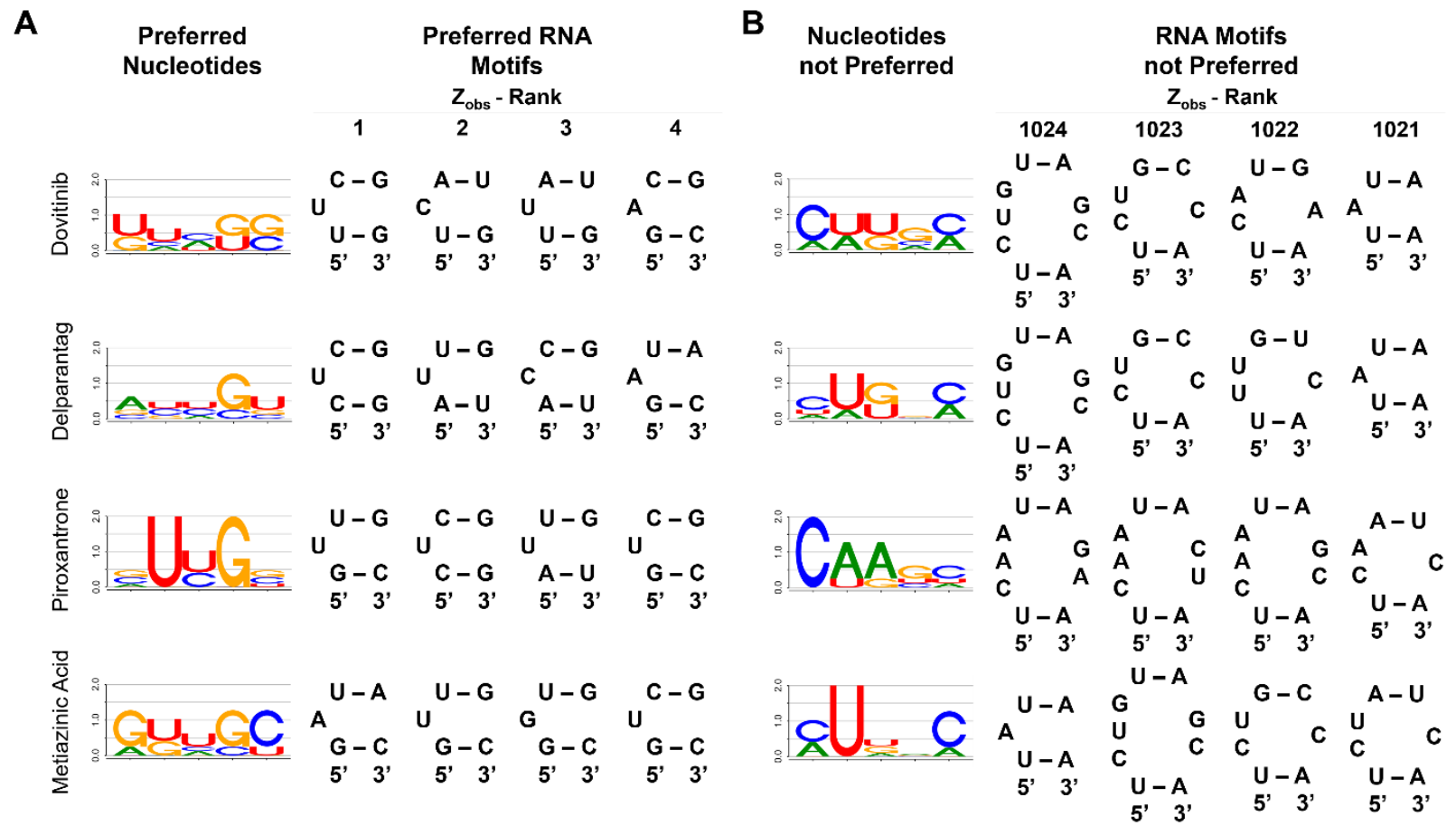

Figure S4. LOGOS analysis reveals the RNA 3D folds preferred and discriminated against by four medicines. (A) RNA 3D folds in the $\mathbf{3} \times \mathbf{2}$ ILL that are preferentially bound by each compound, showing a high preference for guanine and uridine nucleotides in the RNAs they bind. (B) RNA 3D folds that are preferentially discriminated against by each compound. These molecules show low propensity to bind loops with AU closing pairs. 


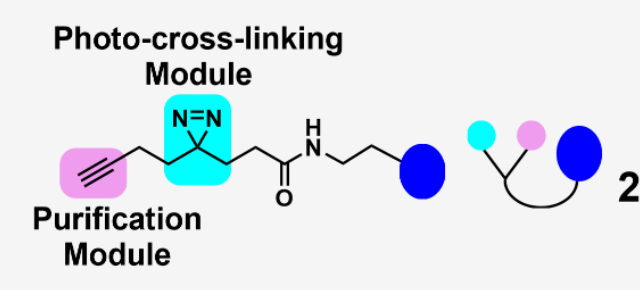

2
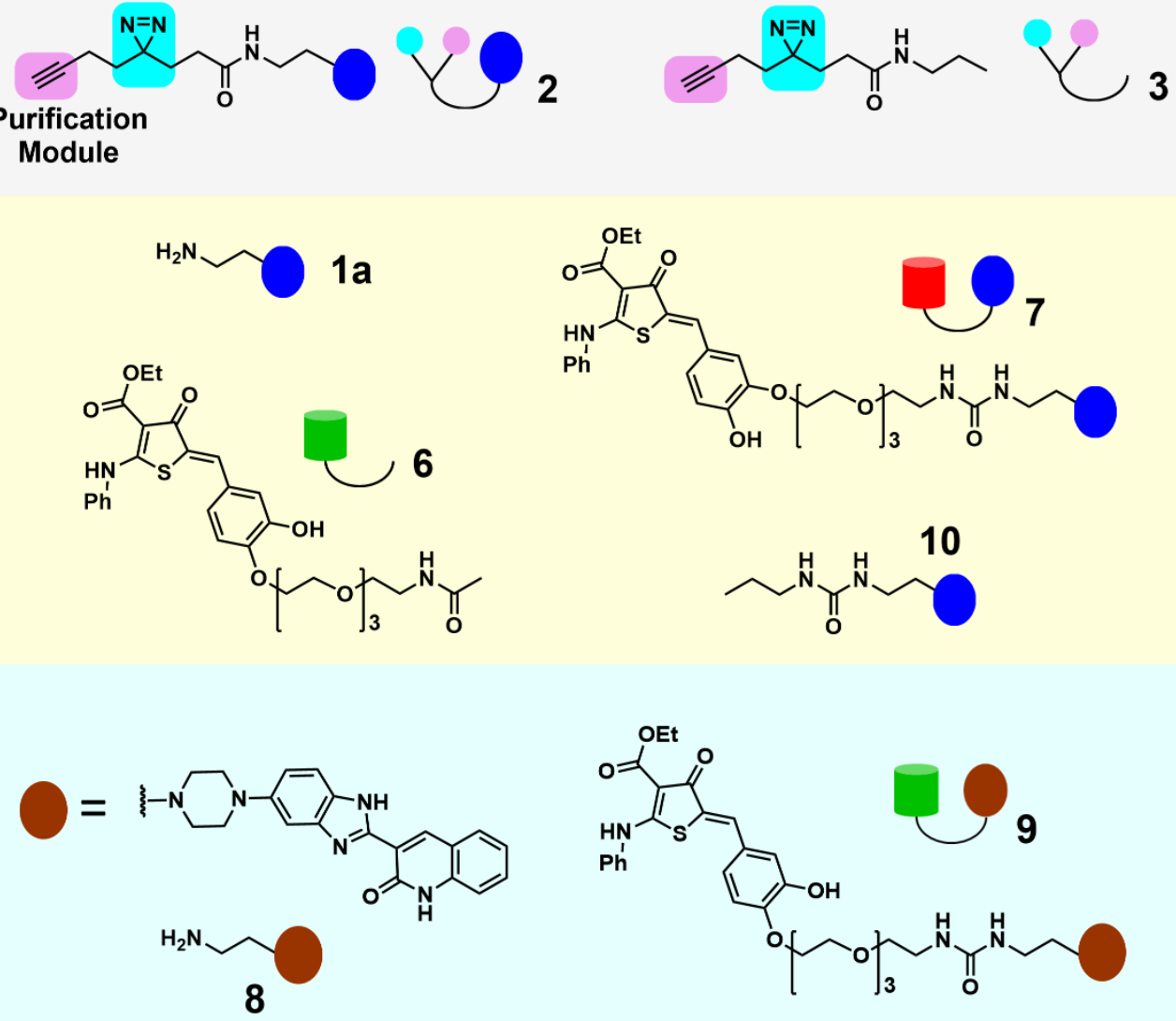

Figure S5. Chemical structures of compounds used in this study. Parent compound 1, RIBOTAC 4, and PROTAC 5 have been shown in main text. Chem-CLIP probe 2 comprises the RNA-binding module 1, an alkyne purification module, and a cross-linking diazirine module. Compound 1a was used for the synthesis of the reprogrammed RIBOTAC and for NMR studies as it has superior solubility than $\mathbf{1}$. Control Chem-CLIP probe $\mathbf{3}$ lacks RNA-binding module 1. Negative control compound $\mathbf{6}$ is RIBOTAC $\mathbf{2}$ without RNA-binding module $\mathbf{1}$. Negative control compound $\mathbf{7}$ is a regioisomer of RIBOTAC $\mathbf{2}$ in which the RNase $\mathrm{L}$ recruiter has much reduced activity. Compound $\mathbf{8}$ is an inactive RNA-binding analog of $\mathbf{1}$, used as a negative control. Compound $\mathbf{9}$ is $\mathbf{8}$ attached to the RNase L recruiter. Control compound $\mathbf{1 0}$ is $\mathbf{1}$ with a urea linker. 

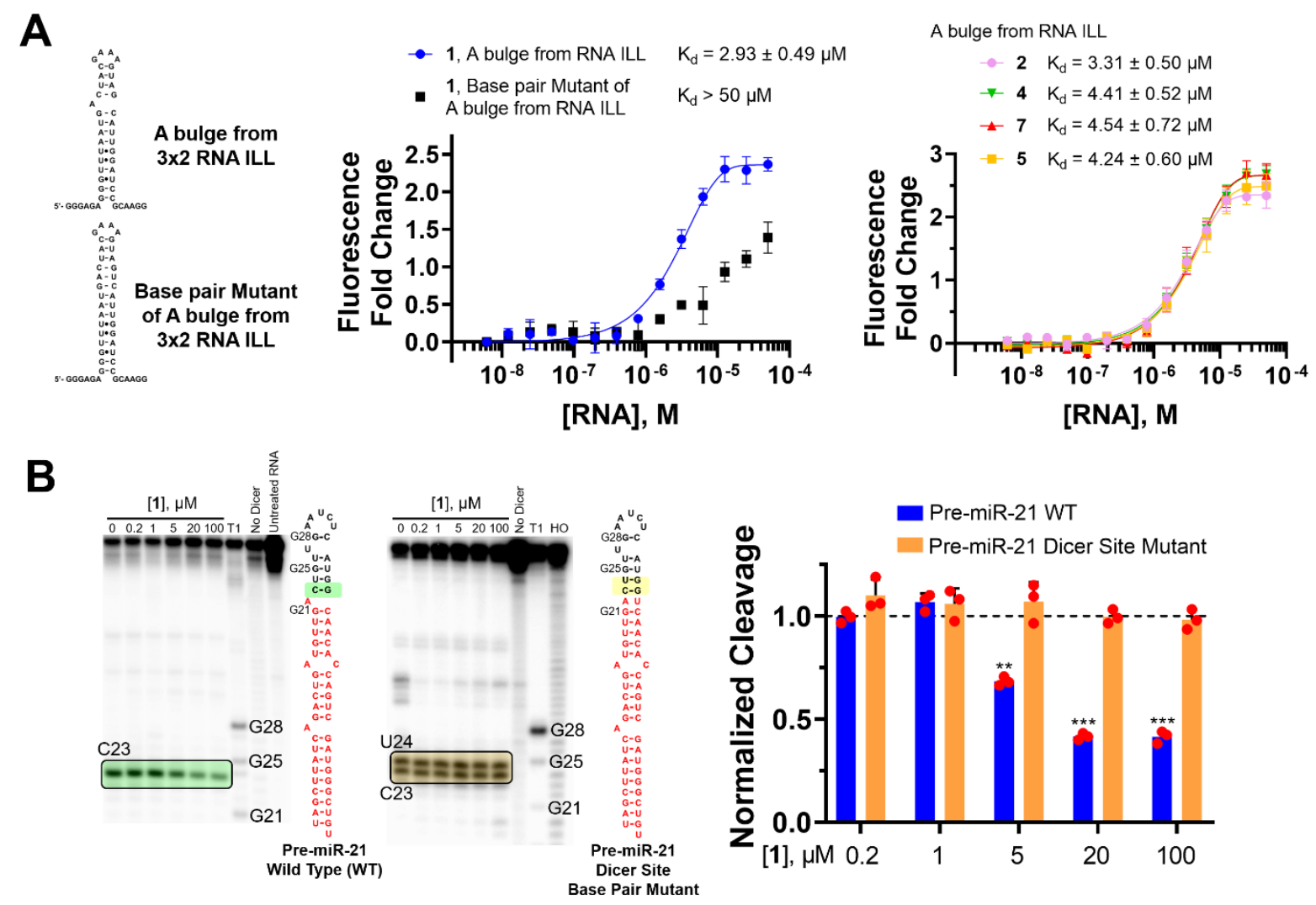

Figure S6. In vitro characterization of compounds shows that 1 and various derivatives bind to premiR-21's A-bulge avidly and selectively. (A) Left, Secondary structure of the A-bulge RNA from $\mathbf{3} \times \mathbf{2}$ ILL and its base pair mutant. Middle, binding curves of fluorescent binding assay between $\mathbf{1}$ and the Abulge and 1 and the base pair mutant $(n=3)$. No saturable binding was observed with the addition of up to $40 \mu \mathrm{M}$ of the mutant RNA. Right, binding curves of fluorescent binding assay between $2,4,5$, and 7 and pre-miR-21's A-bulge $(\mathrm{n}=3)$. (B) In vitro Dicer inhibition assay. Left, representative gel autoradiogram of the inhibition of Dicer processing of pre-miR-21 and the pre-miR-21 mutant by $\mathbf{1}$. Compound 1 inhibited the Dicer processing of pre-miR-21 with an $\mathrm{IC}_{50}$ of $5 \mu \mathrm{M}$ but was unable to inhibit Dicer processing of mutant, which lacks a 1 binding site. Green and yellow boxes indicate Dicer cleavage sites. "OH" indicates a hydrolysis ladder in which every base is cleaved; "T1" indicates cleavage of the RNA at G residues by T1 endonuclease under denaturing conditions. Right, quantification of inhibition of Dicer processing with 1 treatment ( $\mathrm{n}=3$ independent experiments). ${ }^{* *}, \mathrm{p}<0.01 ; * * * \mathrm{p}<0.001$, as determined by a paired twotailed Student's t-test. 


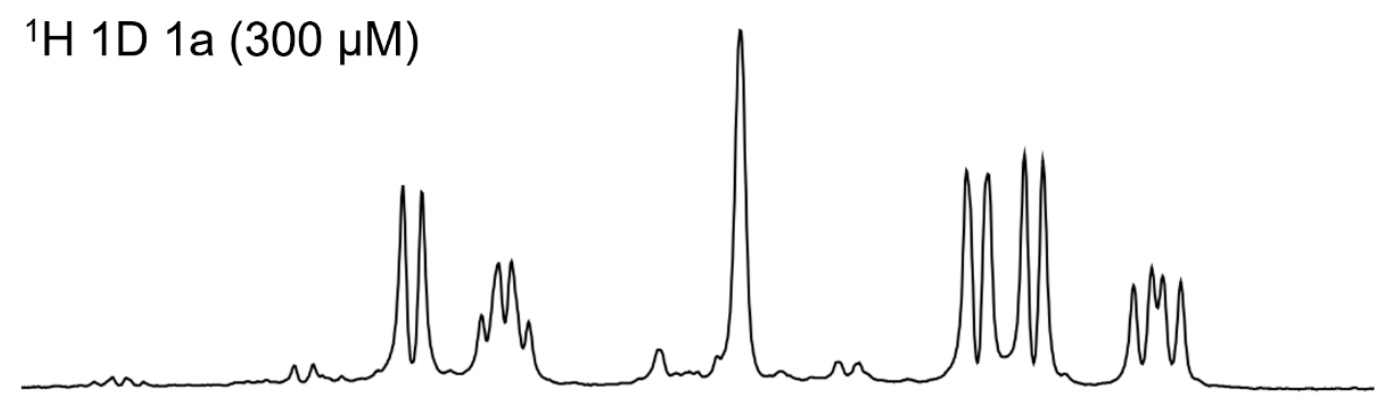

WaterLOGSY 1a
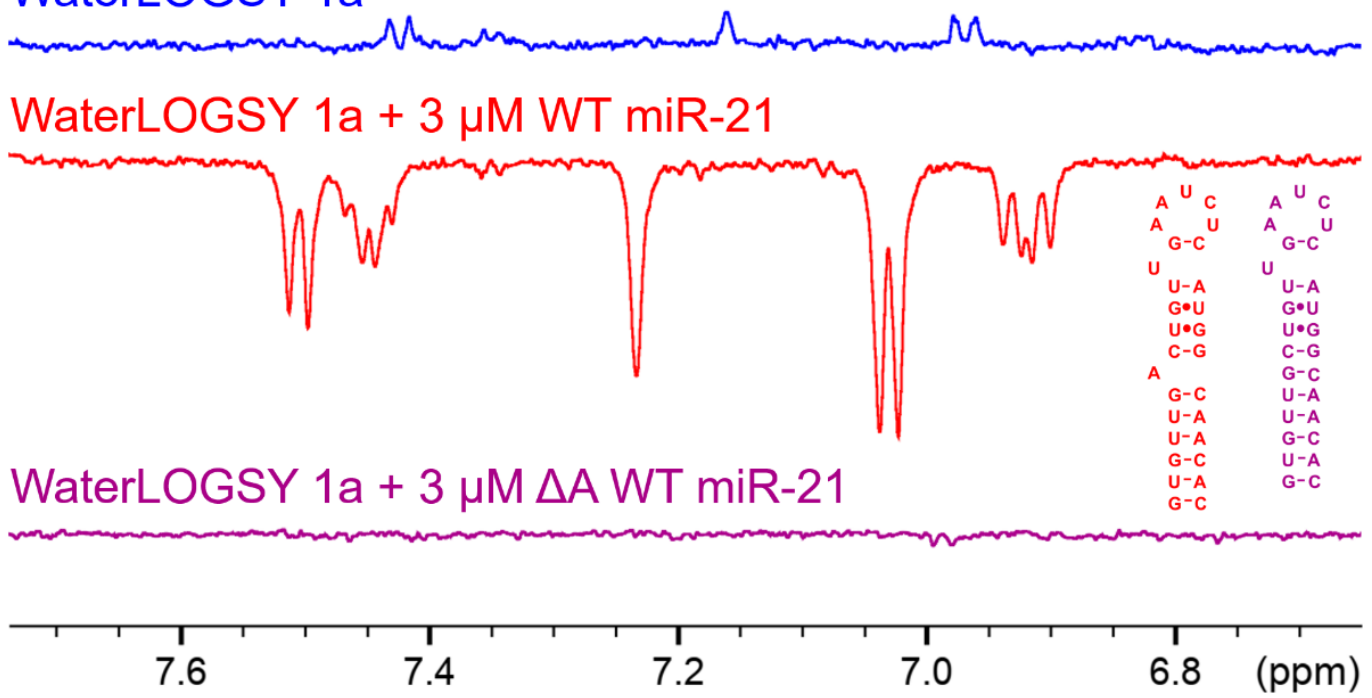

Figure S7. NMR spectroscopic analysis of a model of the Dicer site in pre-miR-21 (WT) and $\Delta \mathrm{A}$ mutant with 1a. In black, the $1 \mathrm{D}{ }^{1} \mathrm{H}$ NMR spectrum shows the chemical shifts for aromatic region of $\mathbf{1 a}$. In blue, a WaterLOGSY experiment of 1a showed weak, positive signal, indicating compound solubility. Upon addition of a $3 \mu \mathrm{M}(1 / 100$ ratio) of WT miR-21 (red), NOE transfer from RNA binding inverted the signal of compound 1a peaks. Addition of a $3 \mu \mathrm{M}$ of WT miR-21 $\Delta \mathrm{A}$ RNA (A-bulge deletion, purple) did not invert the signal (no binding), collectively showing the selectivity of 1a for the WT pre-miR-21 over the $\triangle \mathrm{A}$ RNA construct. 
A Scheme of the Chem-CLIP Methodology to pull down pre-miR-21

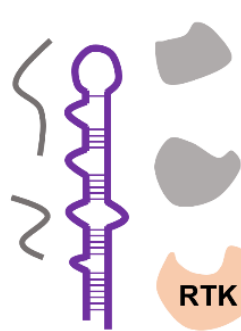

Pre-miR-21

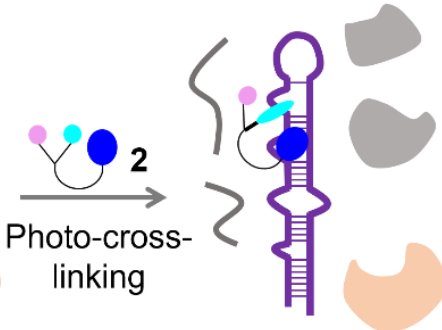

$-\mathrm{N}_{3}$ Disulfide Biotin Azide

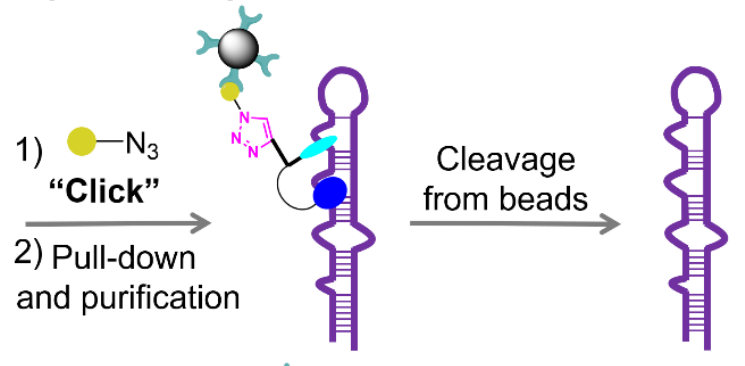

2. Streptavidin beads

RT-qPCR
B

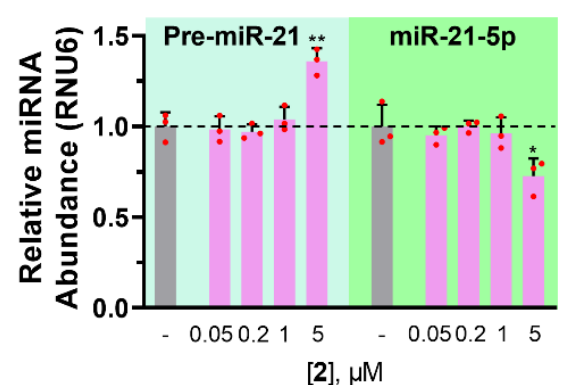

D

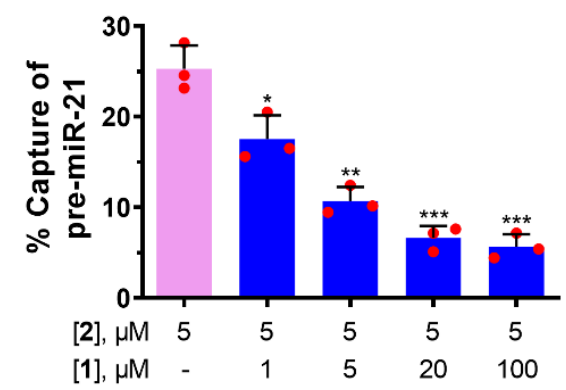

C

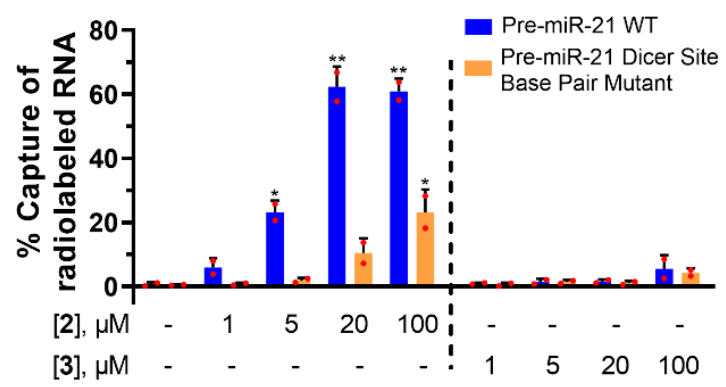

$\mathbf{E}$

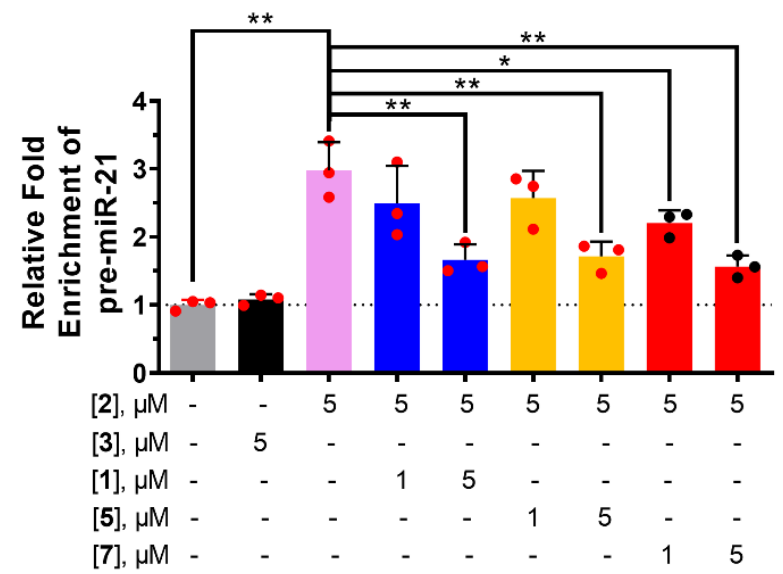

Figure S8. Chem-CLIP and C-Chem-CLIP demonstrate direct target engagement of pre-miR-21 by 1, 5, and 7. (A) Scheme of Chem-CLIP probe 2 reacting with pre-miR-21 in cells to validate target engagement. (B) Chem-CLIP probe 2 retains the activity of 1, which decreases mature miR-21 levels and increases pre-miR-21 levels $(\mathrm{n}=3)$. (C) In vitro Chem-CLIP of ${ }^{32} \mathrm{P}-$ labeled pre-miR-21 WT RNA and mutant $(\mathrm{n}=2)$. Probe 2 dose-dependently enriched pre-miR-21 WT but not the mutant, except at $100 \mu \mathrm{M}$ where non-specific reaction was observed. Control probe $\mathbf{3}$ did not enrich either RNA. (D) In vitro CChem-CLIP shows that the enrichment of pre-miR-21 by $\mathbf{2}$ can be competed by parent compound $\mathbf{1}$ in a dose dependent manner $(\mathrm{n}=3)$. (E) In MDA-MB-231 cells, probe 2 reacted with pre-miR-21 whereas control probe 3 did not. C-Chem-CLIP studies showed that when cells were incubated with increasing concentrations of $\mathbf{1}, \mathbf{5}$, or $\mathbf{7}$, the pull-down of pre-miR-21 with 2 (constant concentration of $5 \mu \mathrm{M}$ ) was similarly diminished and in a dose dependent manner $(\mathrm{n}=3){ }^{*}, \mathrm{p}<0.05 ; * *, \mathrm{p}<0.01,{ }^{* * *} \mathrm{p}<0.001$, as determined by a two-tailed Student's t-test. 


\section{A Scheme of the Chem-CLIP Methodology to pull down RTK}

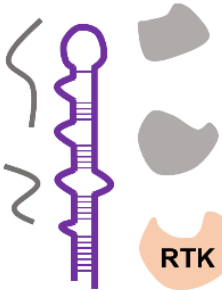

Pre-miR-21

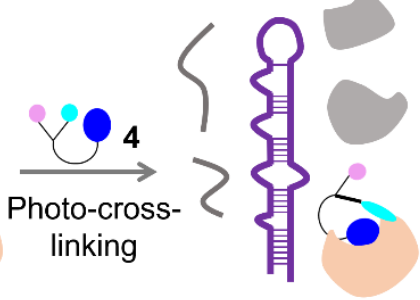

$-\mathrm{N}_{3}$ Disulfide Biotin Azide

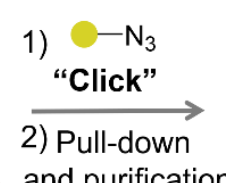
and purification

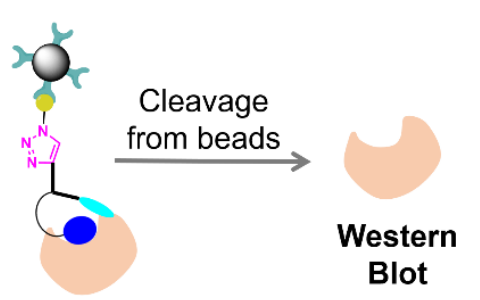

Streptavidin beads

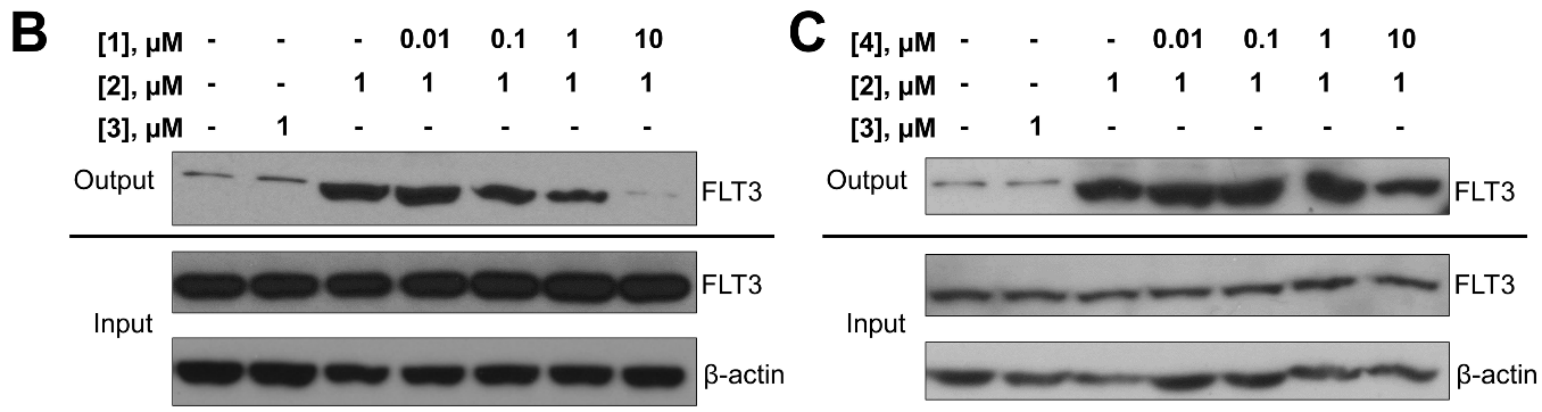

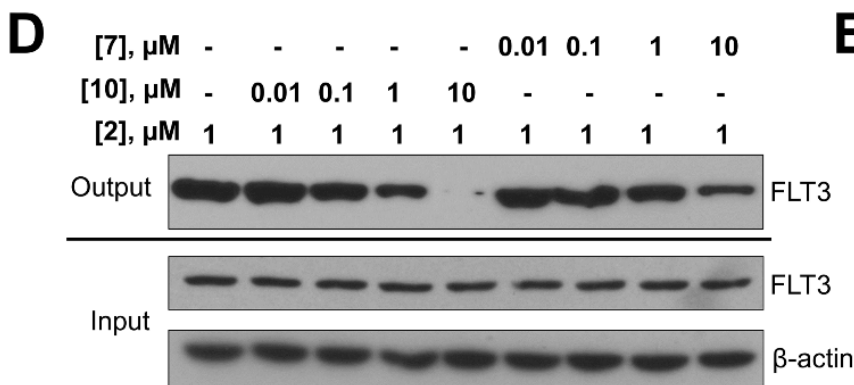

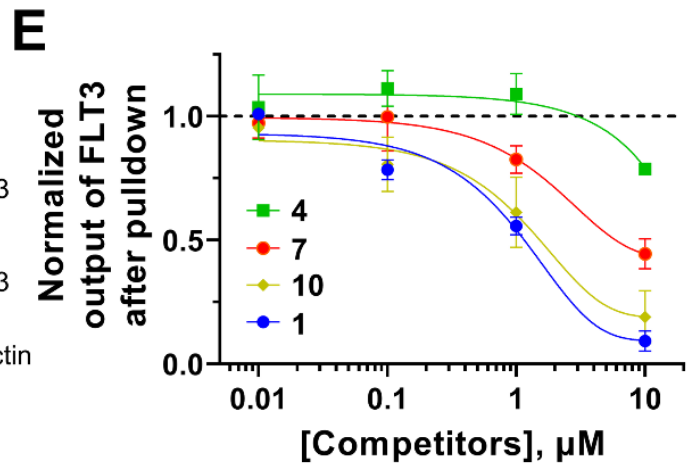

Figure S9. Chem-CLIP and C-Chem-CLIP shows direct target engagement of an RTK by 1, 4, 7, and 10. (A) Scheme of Chem-CLIP probe 2 reacting with an RTK in cells to validate target engagement. (B, C, D) Chem-CLIP probe 2 enriched RTK FLT3 from MDA-MB-231 cells, and this enrichment can be competed off by $\mathbf{1}$ (B), 4(C), 7 and 10 (D) in a dose dependent manner. Control probe 3, which lacks the RNA-binding module, did not enrich FLT3. All compounds have no effect on FLT3 expression, as indicated by Western blotting (labeled "Input"). (E) Quantification of the experiments from (B), (C) and (D) $(\mathrm{n}=3)$. RIBOTAC 4 at $10 \mu \mathrm{M}$ competed with probe $2(1 \mu \mathrm{M})$ to the same extent as $\mathbf{1}$ at $0.1 \mu \mathrm{M}$, indicating a 100-fold difference cellular protein occupancy between $\mathbf{1}$ and $\mathbf{2}$. The extent of depletion by 7 was between those observed for 1 and $\mathbf{4}$, suggesting that both chemical modification of 1 by attaching the recruiter and its recruitment of RNase $L$ contribute to the 100 -fold lower protein binding of 4 . Competition by $\mathbf{1 0}$ was similar to $\mathbf{1}$, indicating that the urea linker has no effect on protein binding. 
A
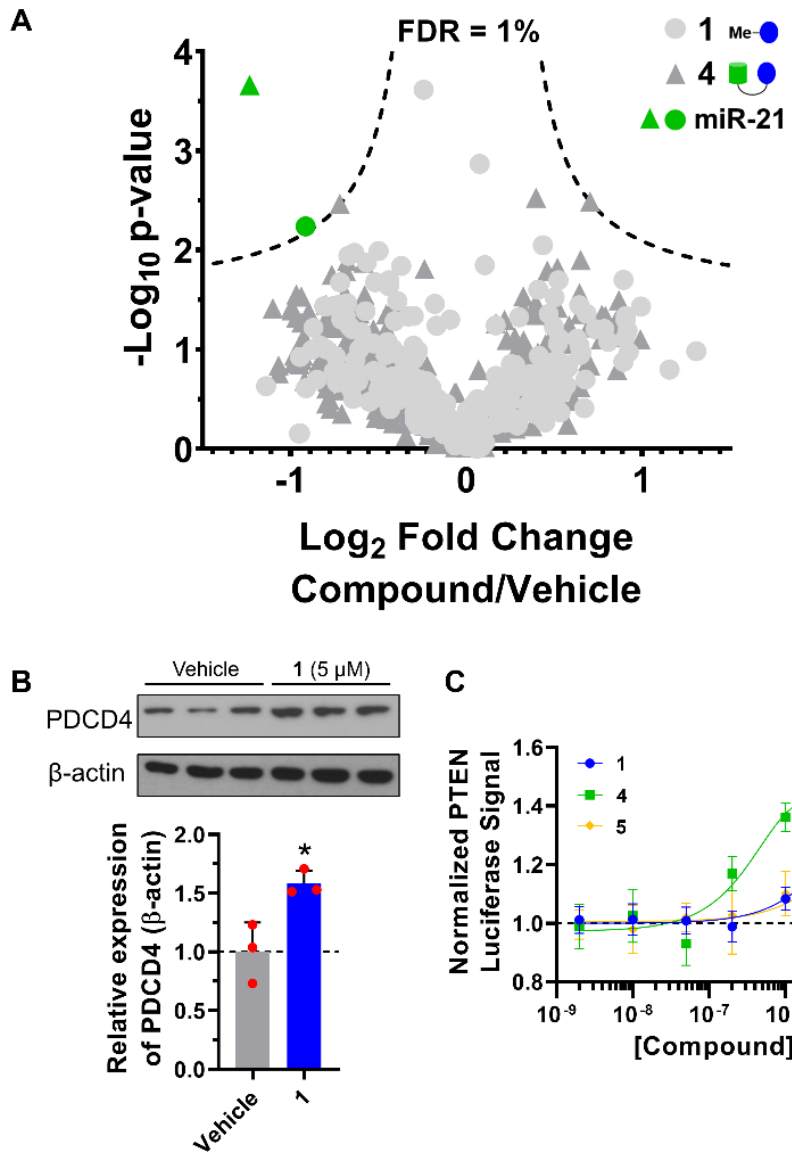

C

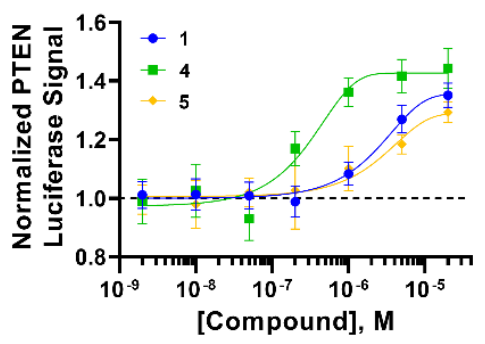

Figure S10. Cellular characterization of 1 and its derivatives. (A) Global miRNA profiling of $1(5 \mu \mathrm{M})$ and $4(1 \mu \mathrm{M})$ in MDA-MB-231 cells, with 4 showing greater selectivity $(\mathrm{n}=3)$. Dotted lines indicate an FDR equal to $1 \%$ and a group variance of S0 (0.1). (B) Representative Western blot and quantification thereof of to assess the effect of $\mathbf{1}(5 \mu \mathrm{M})$ on PDCD4 expression in MDA-MB-231 cells $(\mathrm{n}=3)$. (C) Effect of $\mathbf{1}, \mathbf{4}$, and $\mathbf{5}$ on PTEN protein expression, as determined using a luciferase reporter fused to the PTEN 3 ' UTR $(\mathrm{n}=3){ }^{*}, \mathrm{p}<0.05 ; * *, \mathrm{p}<0.01, * * * \mathrm{p}<0.001$, as tested by a two-tailed Student's t-test. 

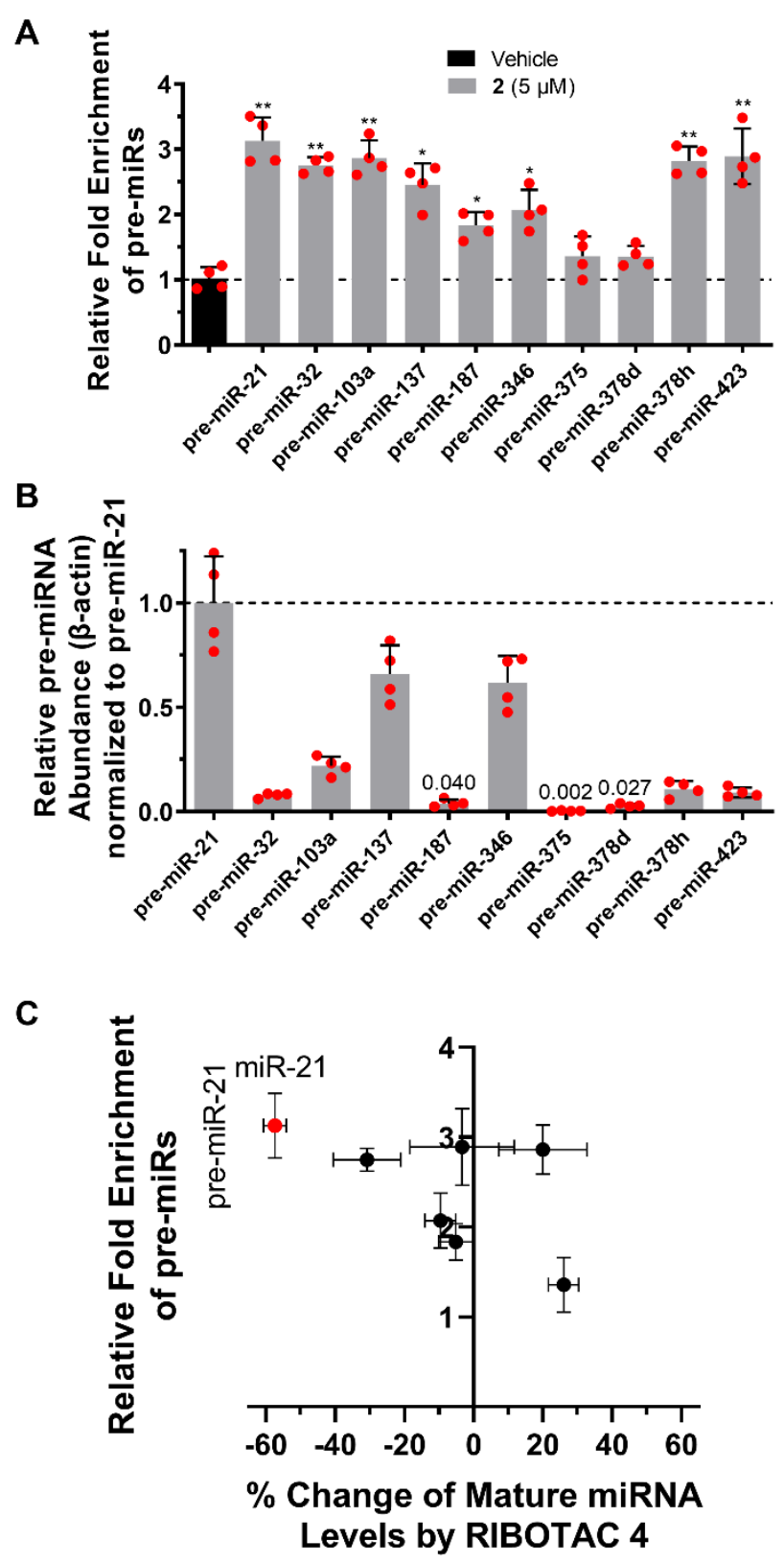

Figure S11. Enrichment of pre-miRNAs predicted to bind 1 (Figure S3) by Chem-CLIP. (A) Occupancy of miRNAs predicted to bind 1 by Inforna. Of the fourteen pre-miRNAs that have Fitness Scores $>80$, ten are detectable in MDA-MB-231 cells. Among these ten pre-miRNAs, eight are pulled down by Chem-CLIP probe 2. Note, that 1's binding site within these other miRNA precursors are not harbored in Drosha or Dicer processing sites. (B) Relative expression levels of pre-miRNAs shown in panel A in MDA-MB-231 cells, as normalized to pre-miR-21, which is the most abundant. (C) Effect of RIBOTAC 4 on levels of mature miRNAs processed from precursors predicted to bind $\mathbf{1}$ (as reported in Figure S10A) as a function of pre-miRNA fold enrichment in Chem-CLIP cellular occupancy studies (as reported in panel A). Three of the mature miRNAs (miR-375, miR-378d, and miR-378h) were not detected in miRNA profiling experiment $\left(\mathrm{C}_{\mathrm{t}}>30\right)$ and thus were not included in the plot. ${ }^{*}, \mathrm{p}<0.05 ;{ }^{* *}, \mathrm{p}<0.01$, $* * * \mathrm{p}<0.001$, as determined by a two-tailed Student's t-test. 
A

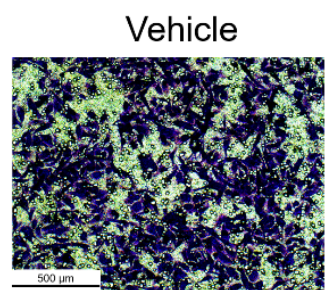

D

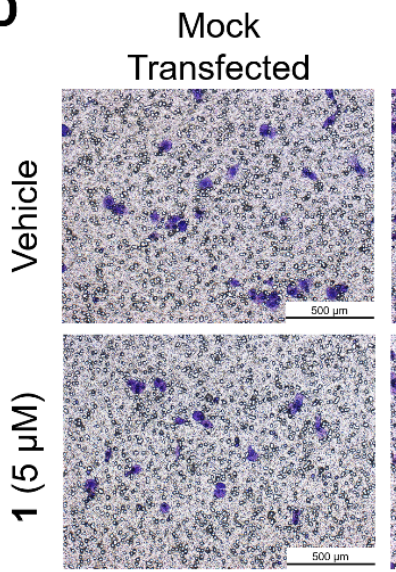

B
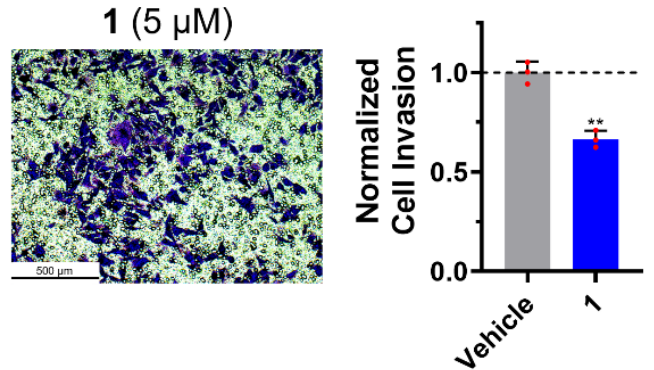

Pre-miR-21 WT Transfected

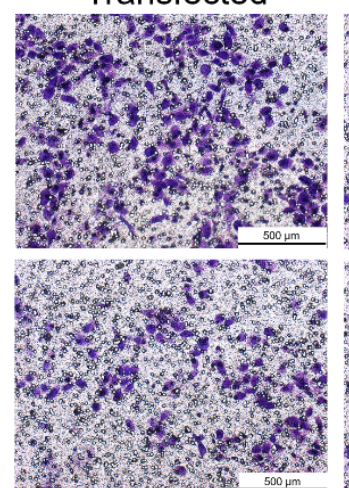

Pre-miR-21 Mutant Transfected

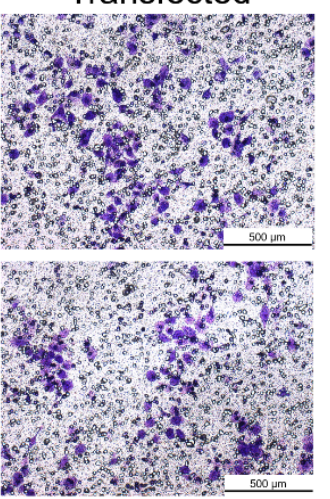

C

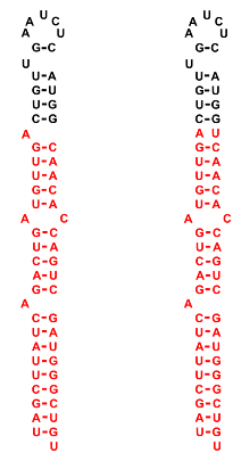

Pre-miR-21 Pre-miR-21 Wild Type (WT) Dicer Site
Base Pair Mutant

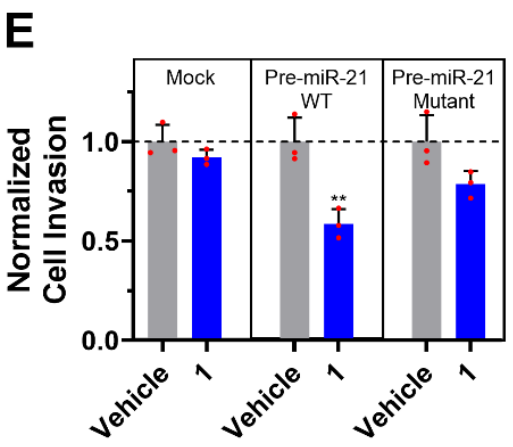

Figure S12. Compound 1 reduced invasion (miR-21-mediated phenotype) of MDA-MB-231 and MCF-10A cells forced to express the miR-21 precursor. (A) Representative microscopic images of the effect of $1(5 \mu \mathrm{M})$ on the invasive character of MDA-MB-231 cells. (B) Quantification of the MDA-MB231 cell invasion from $\mathbf{A}(\mathrm{n}=3)$. (C) Secondary structures of pre-miR-21 and its mutant encoded by two different plasmids. (D) Compound 1 inhibited the invasive phenotype of MCF-10A cells acquired by transfection of wild type (WT) pre-miR-21 but not that of mutant pre-miR-21, which lacks the $\mathbf{1}$ binding site. (E) Quantification of the MCF-10A cell invasion images from $(\mathbf{D})(\mathrm{n}=3){ }^{* *}, \mathrm{p}<0.01$, as tested by a two-tailed Student's t-test. 


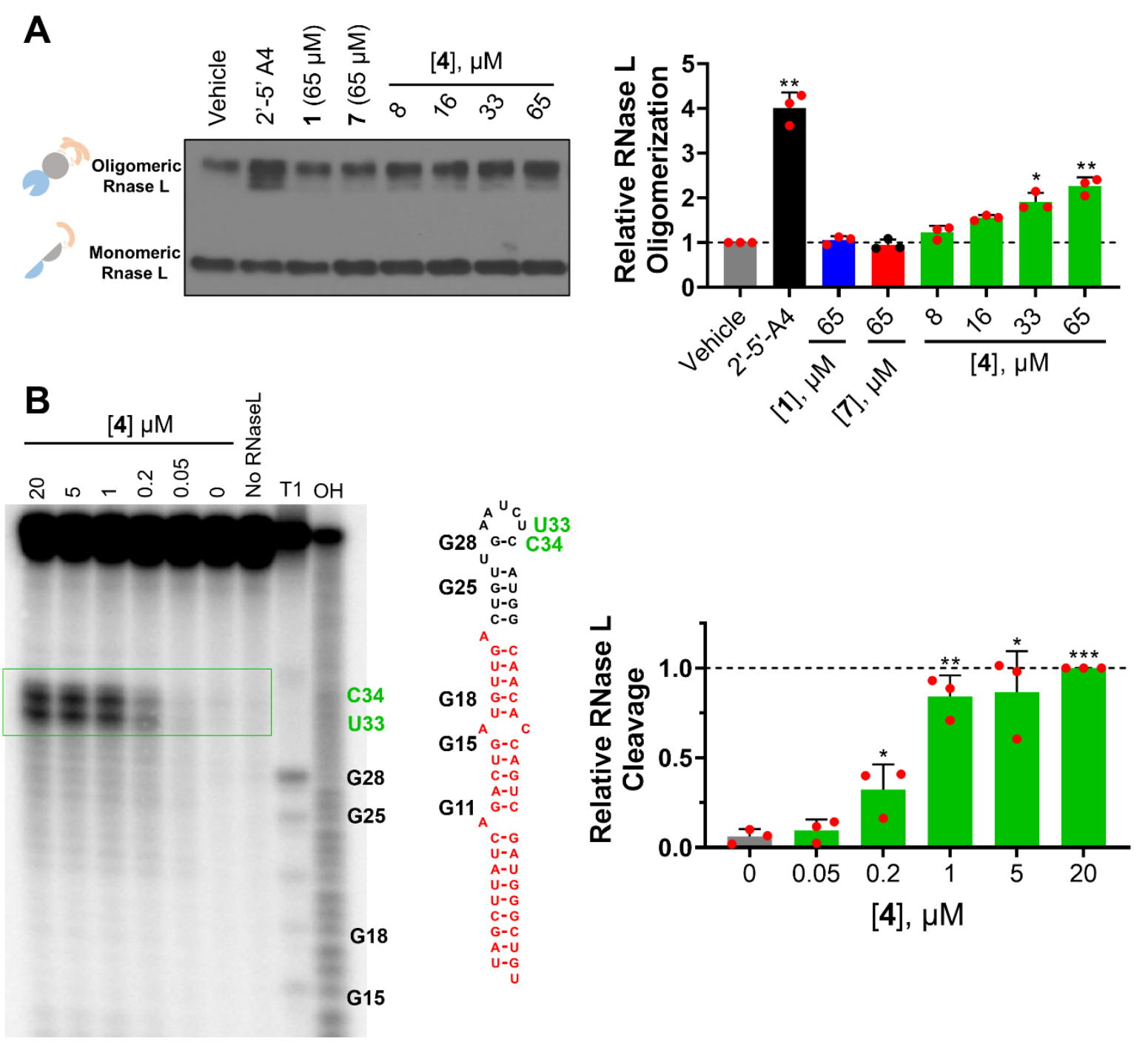

Figure S13. RIBOTAC 4 recruited and activated RNase $L$ to cleave pre-miR-21 in vitro. (A) Left: representative gel showing that RIBOTAC 4, but not parent compound $\mathbf{1}$ or control compound $\mathbf{7}$, oligomerized RNase $\mathrm{L}$ in a dose dependent manner. Right, quantification of the RNase L oligomerization $(\mathrm{n}=3)$. (B) Left, representative gel autoradiogram of the in vitro cleavage of pre-miR-21 WT RNA by RNase L, recruited by RIBOTAC 4. The green box indicates the RNase L cleavage sites at U33 and C34. "OH" indicates a hydrolysis ladder in which every base is cleaved; "T1" indicates all G residues, identified by cleaved by $\mathrm{T} 1$ endonuclease under denaturing conditions. Right, quantification of RNase L cleavage by recruitment with $4(\mathrm{n}=3) .{ }^{*}, \mathrm{p}<0.05 ;{ }^{* *}, \mathrm{p}<0.01,{ }^{* * *} \mathrm{p}<0.001$, as tested by a paired two-tailed Student's t-test. 


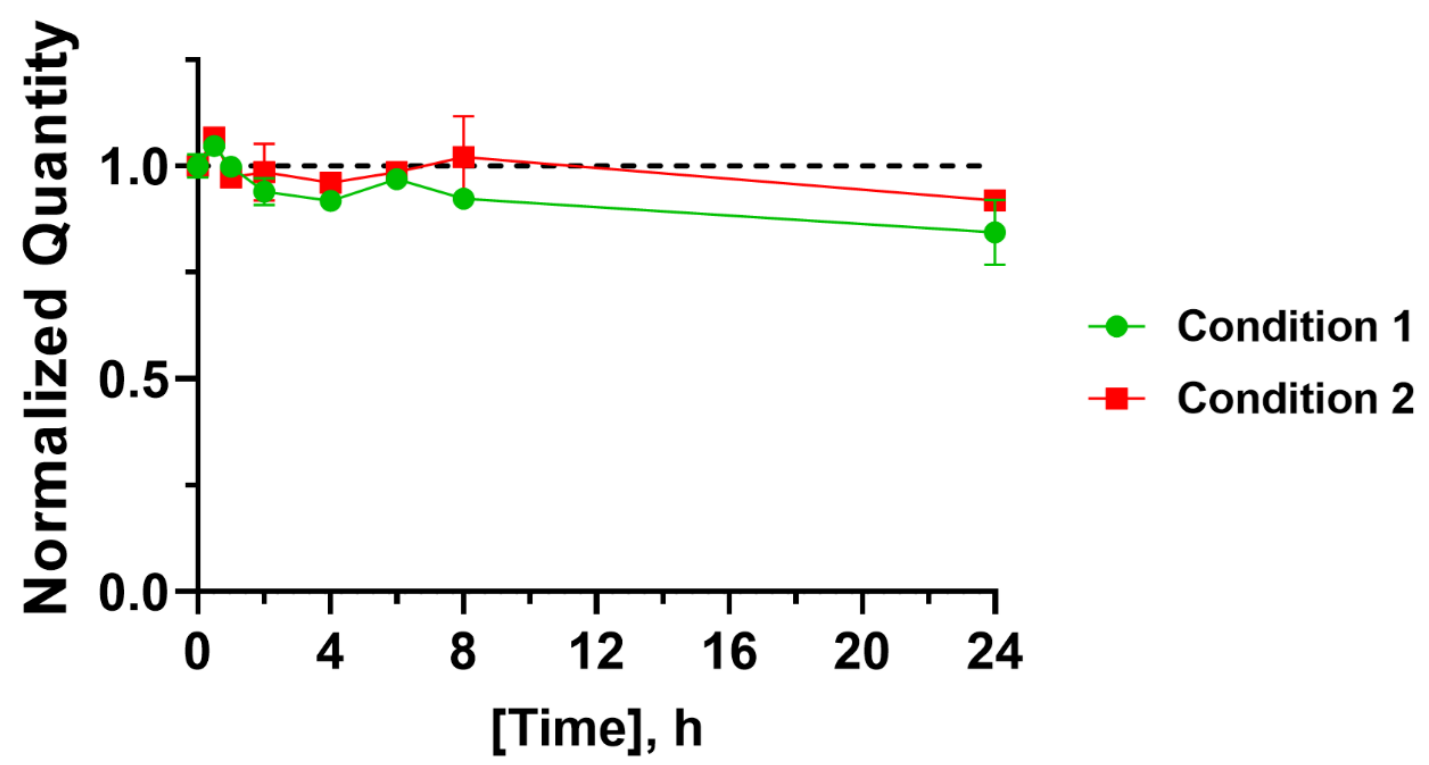

Figure S14. RIBOTAC 4 is not electrophilically reactive in cell culture medium, as assessed by addition of glutathione in cell culture medium. The amounts of $\mathbf{4}$ remaining after incubation at the designated time points, as determined by mass spectrometry. Condition 1 is $\mathbf{4}$ in growth medium $(1 \times \mathrm{RPMI}$ 1640 with L-glutamine and $25 \mathrm{mM}$ HEPES $+10 \% \mathrm{FBS})$ at $37{ }^{\circ} \mathrm{C} / 5 \% \mathrm{CO}_{2}(\mathrm{n}=2)$. Note, RPMI medium contains $3.25 \mu \mathrm{M}$ glutathione. Condition 2 is 4 in growth medium in the presence of an additional $5 \mathrm{mM}$ glutathione at $37{ }^{\circ} \mathrm{C} / 5 \% \mathrm{CO}_{2}(\mathrm{n}=2)$. 
A

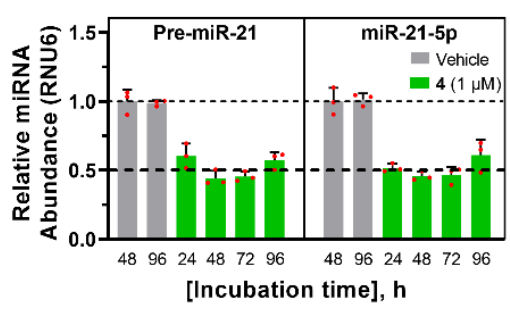

D

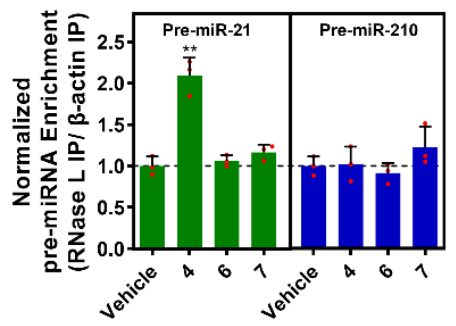

G

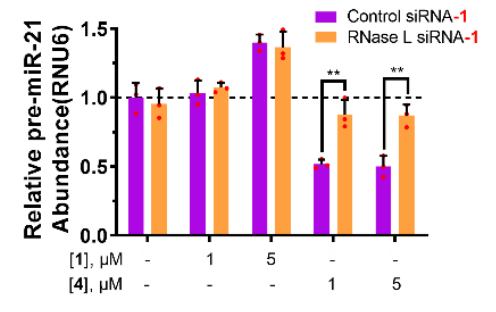

H
B

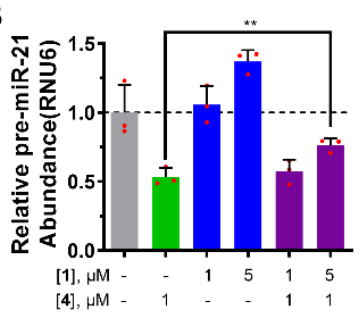

E

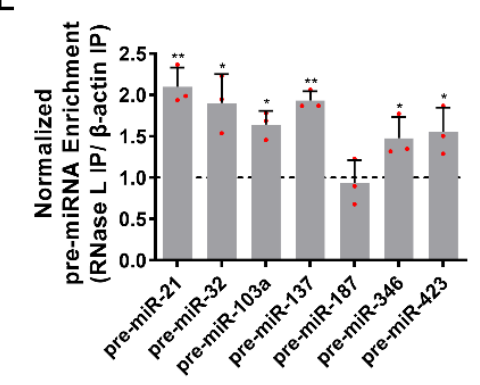

C

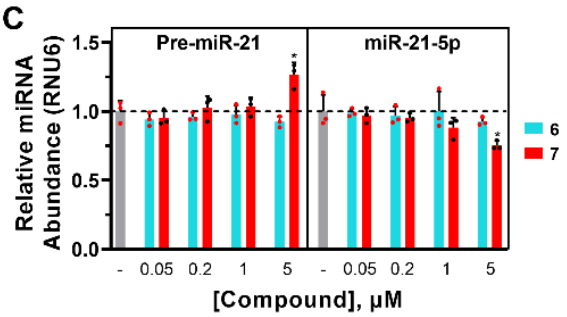

$\mathbf{F}$

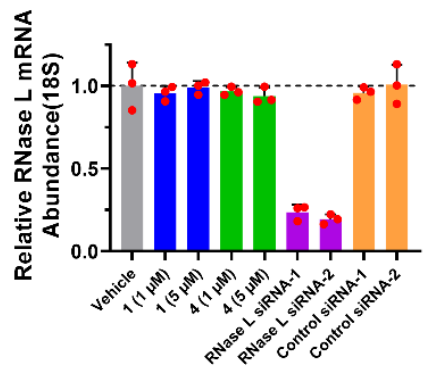

I

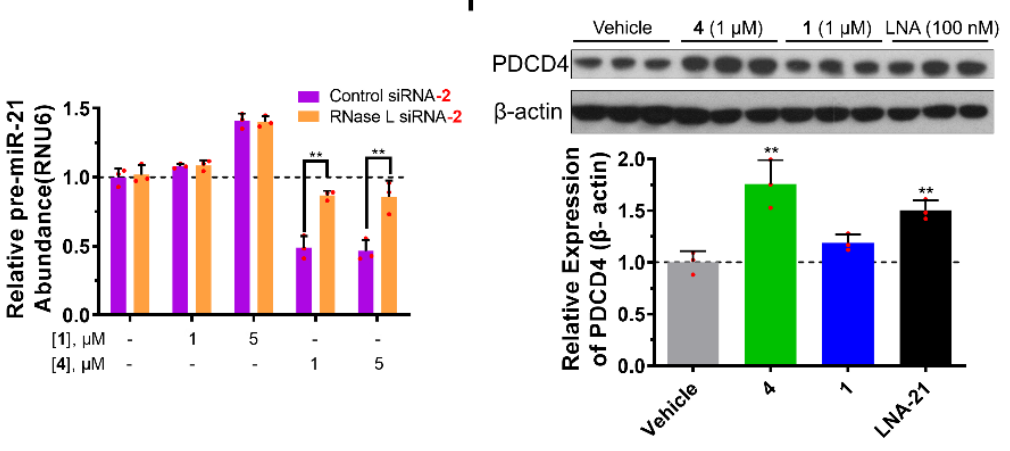

$\mathbf{J}$
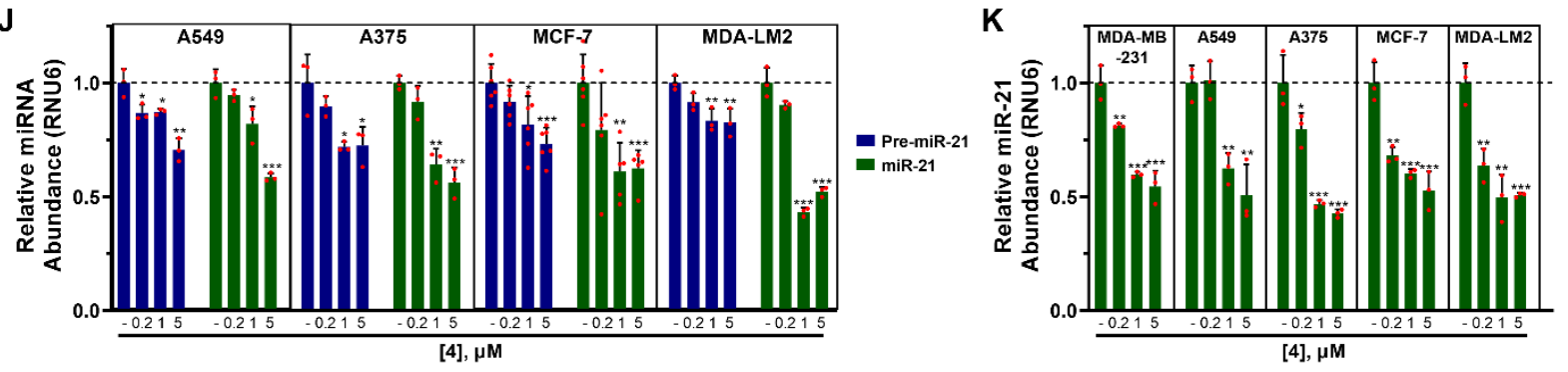

Figure S15. RIBOTAC 4 selectively cleaved pre-miR-21 in cells. (A) Effect of $1(1 \mu \mathrm{M})$ on pre- and mature miR-21 levels in MDA-MB-231 cells at different time points, as determined by RT-qPCR $(n=3)$. RIBOTAC 4 induced maximum cleavage of the RNA target at $48 \mathrm{~h}$. Therefore, all subsequent experiments were completed at the $48 \mathrm{~h}$ time point unless specifically indicated. (B) Effect of $\mathbf{1}$ and $\mathbf{4}$ on pre-miR-21 levels in MDA-MB-231 cells, as determined by RT-qPCR $(n=3)$. Consistent with their modes of action, RIBOTAC 4 reduced pre-miR-21 levels while $\mathbf{1}$ enhanced them. Addition of $\mathbf{1}$ in the presence of a constant concentration of $4(1 \mu \mathrm{M})$ competed away cleavage of pre-miR-21 by the RIBOTAC. (C) Negative control compound 6, which lacks the RNA-binding module, had no effect on pre-miR-21 levels, as determined by RT-qPCR $(\mathrm{n}=3)$. Negative control compound 7, which contains 1 but an inefficient RNase L-recruiting module, acts like simple binding compound 1, increasing pre-miR-21 levels $(\mathrm{n}=3)$. Immunoprecipitation of RNase L from MDA-MB-231 cells treated with $4(1 \mu \mathrm{M})$, but not 6 or $7(1 \mu \mathrm{M})$, 
enriched pre-miR-21 ( $\mathrm{n}=3$ ). Importantly, 4 did not enrich a different pre-miRNA, pre-miR-210, that does not contain a 1-binding site. (E) Assessment of ternary complex formation between 4 and pre-miRNAs occupied by Chem-CLIP probe $\mathbf{2}$ with detectable mature miRNA levels (Figure S11A) via immunoprecipitation of RNase L from MDA-MB-231 cells treated with $1 \mu \mathrm{M}$ of $4(\mathrm{n}=3)$. (F) Compounds $\mathbf{1}$ and $\mathbf{4}$ as well as control siRNAs had no effect on RNase L mRNA levels while RNase L-targeting siRNAs knocked the mRNA down, as expected $(n=3)$. $(\mathbf{G}, \mathbf{H})$ Knock down of RNase $\mathrm{L}$ with two different siRNAs repressed cleavage of pre-miR-21 by $4(\mathrm{n}=3)$. (I) RIBOTAC $4(1 \mu \mathrm{M})$ and LNA-21 $(0.1 \mu \mathrm{M})$ de-repressed PDCD4 expression while $\mathbf{1}$ was unable to do so at the same concentration of $\mathbf{4}(n=3)$. (J) Mature miR-21 and pre-miR-21 levels upon 4 treatment in various cancer cell lines, as measured by RT-qPCR $(n=3)$ : A549, lung carcinoma; A375, melanoma; MCF-7, breast cancer; and MDA-LM2, lung metastatic breast cancer. (K) Further confirmation of the reduction of mature miR-21 levels upon 4-treatment in all cell lines by RT-qPCR $(\mathrm{n}=3)$ using Taqman primers. *, $\mathrm{p}<0.05$; **, $\mathrm{p}<0.01,{ }^{* *} \mathrm{p}<0.001$, as tested by a twotailed Student's t-test. 

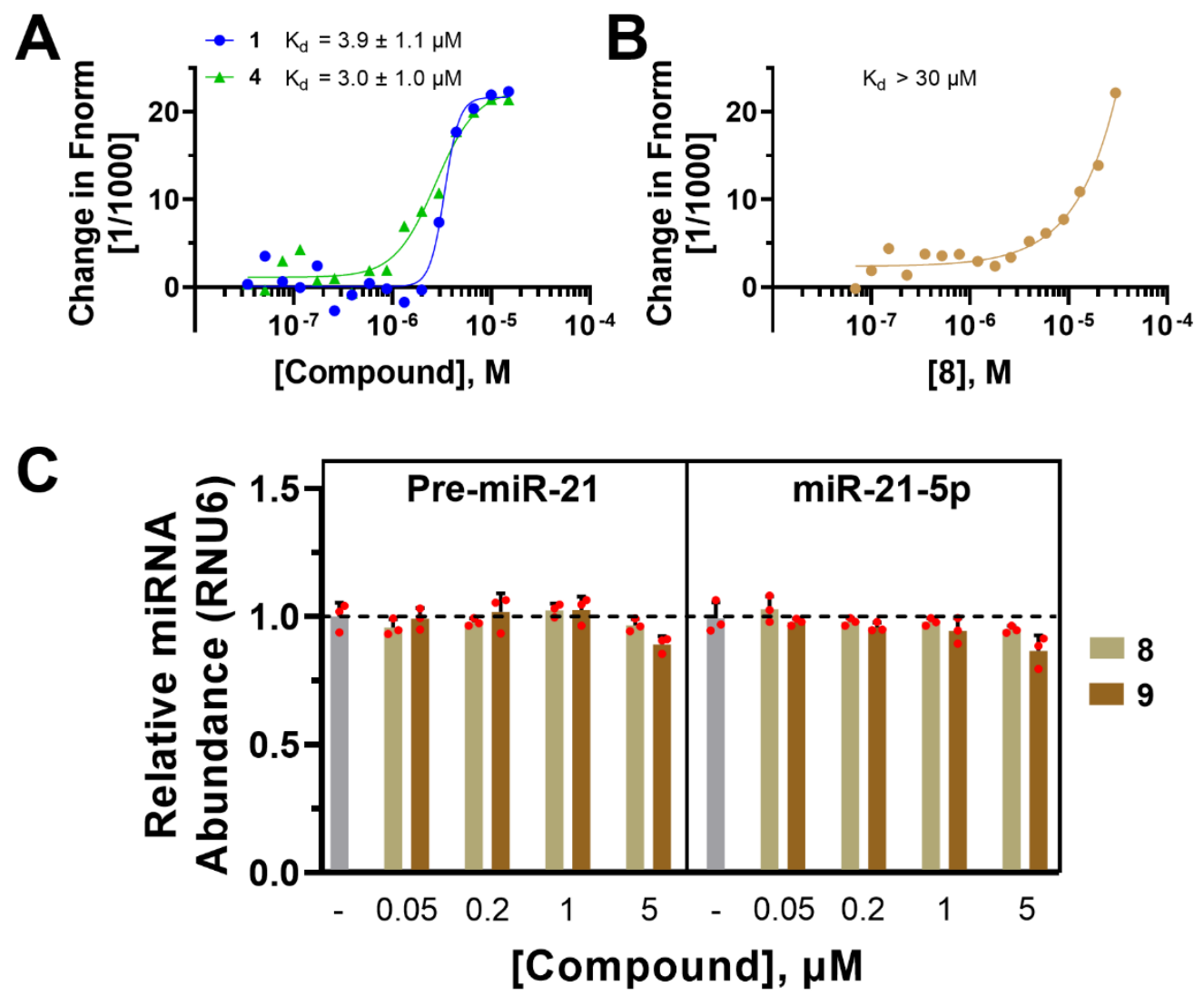

Figure S16. Analog 8, which binds to pre-miR-21 with 10-fold less avidity than 1, and its RIBOTAC (9) are inactive at the same concentrations where 4-activity is observed. (A, B) Representative MST binding affinity curves for $\mathbf{1}$ and $\mathbf{4}(\mathrm{A})$ and $\mathbf{8}$ (B) to the A-bulge present in pre-miR-21 (see sequences in "Microscale Thermophoresis (MST)") $(n=3)$. Binding affinities $\left(\mathrm{K}_{d} \mathrm{~S}\right)$ were calculated by fitting the curve to a single site model. Compound $\mathbf{8}$ is 10 -fold less avid for pre-miR-21 than $\mathbf{1}$. (C) Less active control compounds 8 and its RIBOTAC 9 had no effect on pre- and mature miR-21 levels, as determined by RT-qPCR $(\mathrm{n}=3)$. 
A

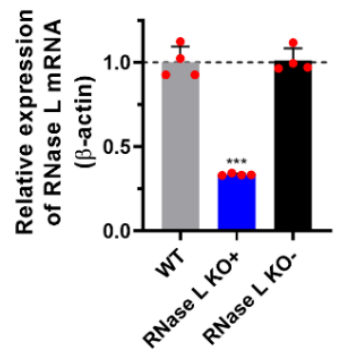

B
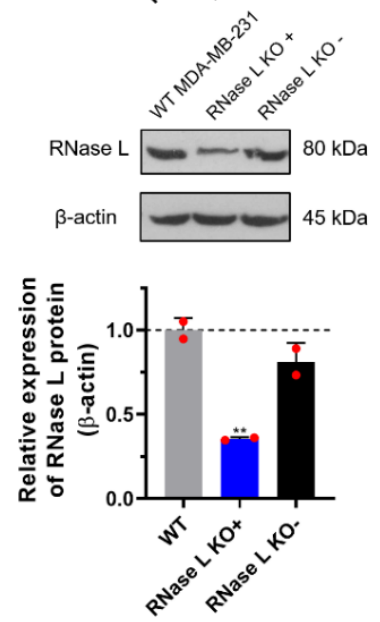

C
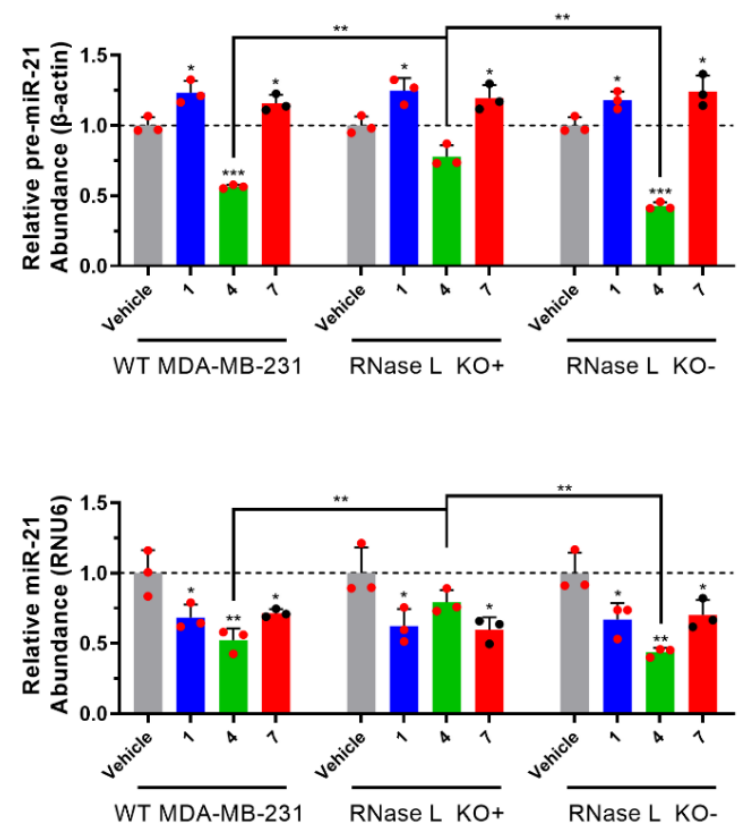

D
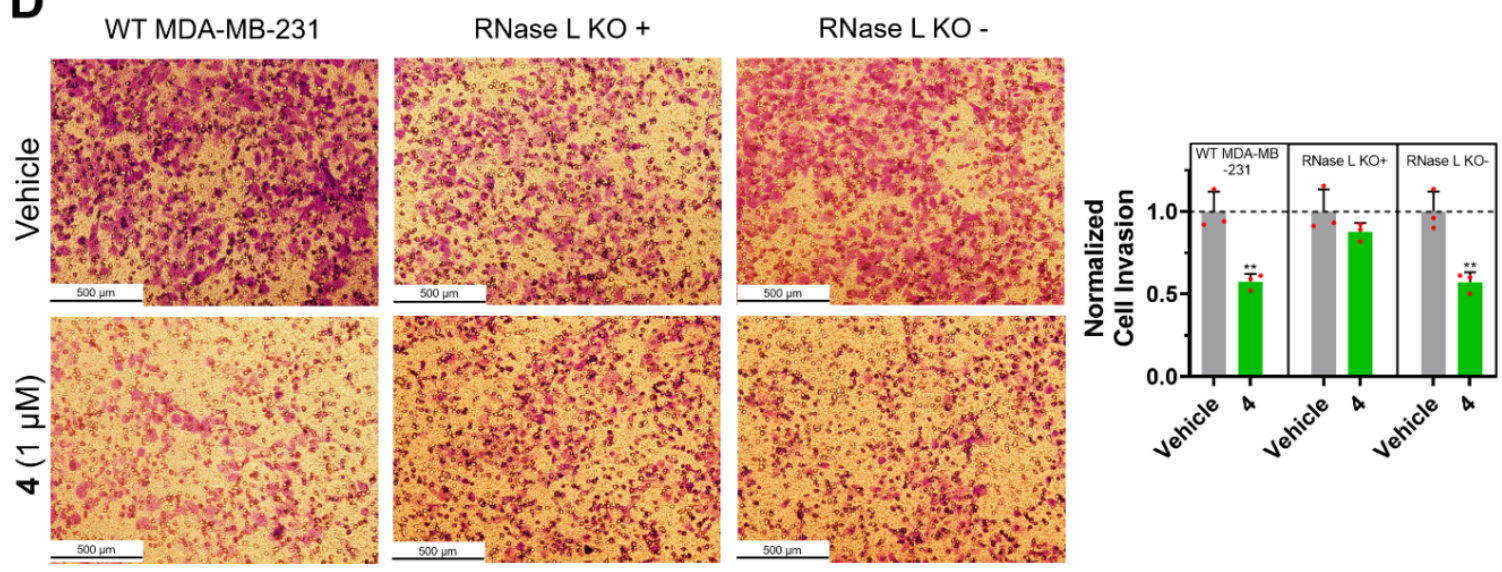

Figure S17. RIBOTAC 4's activity is abated in MDA-MB-231 cells in which RNase $\mathrm{L}$ is knocked out by CRISPR. (A) RNase L mRNA levels were significantly reduced in MDA-MB-231 cells in which RNase L was knocked out by CRISPR (RNase L KO+; Transomic Technologies, Inc.; catalog \# TEVH1249025-pCLIP-ALL-hCMV-Puro) as compared to WT MDA-MB-231 cells and negative control cells (RNase L KO-; Transomic Technologies, Inc.; cat\# TELA1015). (B) RNase L protein levels were significantly reduced in RNase $\mathrm{L} \mathrm{KO}+$ cells as compared to WT MDA-MB-231 cells and RNase L KOcells. (C) Compounds 1 (Dovitinib), 4 (RIBOTAC), and 7 (reduced ability to recruit RNase L) have similar effect on pre-miR-21 (top) and mature miR-21 (bottom) in WT MDA-MB-231 and RNase L KO- cells. However, in RNase L KO+ cells, RIBOTAC 4's cleavage of pre-miR-21 and reduction of mature miR-21 levels were abated. (D) RIBOTAC 4 inhibits invasion of WT MDA-MB-231 and RNase L KO- cells to a similar extent but has no significant effect on the invasion of RNase $\mathrm{L} \mathrm{KO}+$ cells. Right, quantification of the number of invasive MCF-10A cells from left panel $(\mathrm{n}=3)$. ${ }^{*}, \mathrm{p}<0.05 ; * *, \mathrm{p}<0.01 ;{ }^{* * *} \mathrm{p}<0.001$, as tested by a paired two-tailed Student's t-test. 


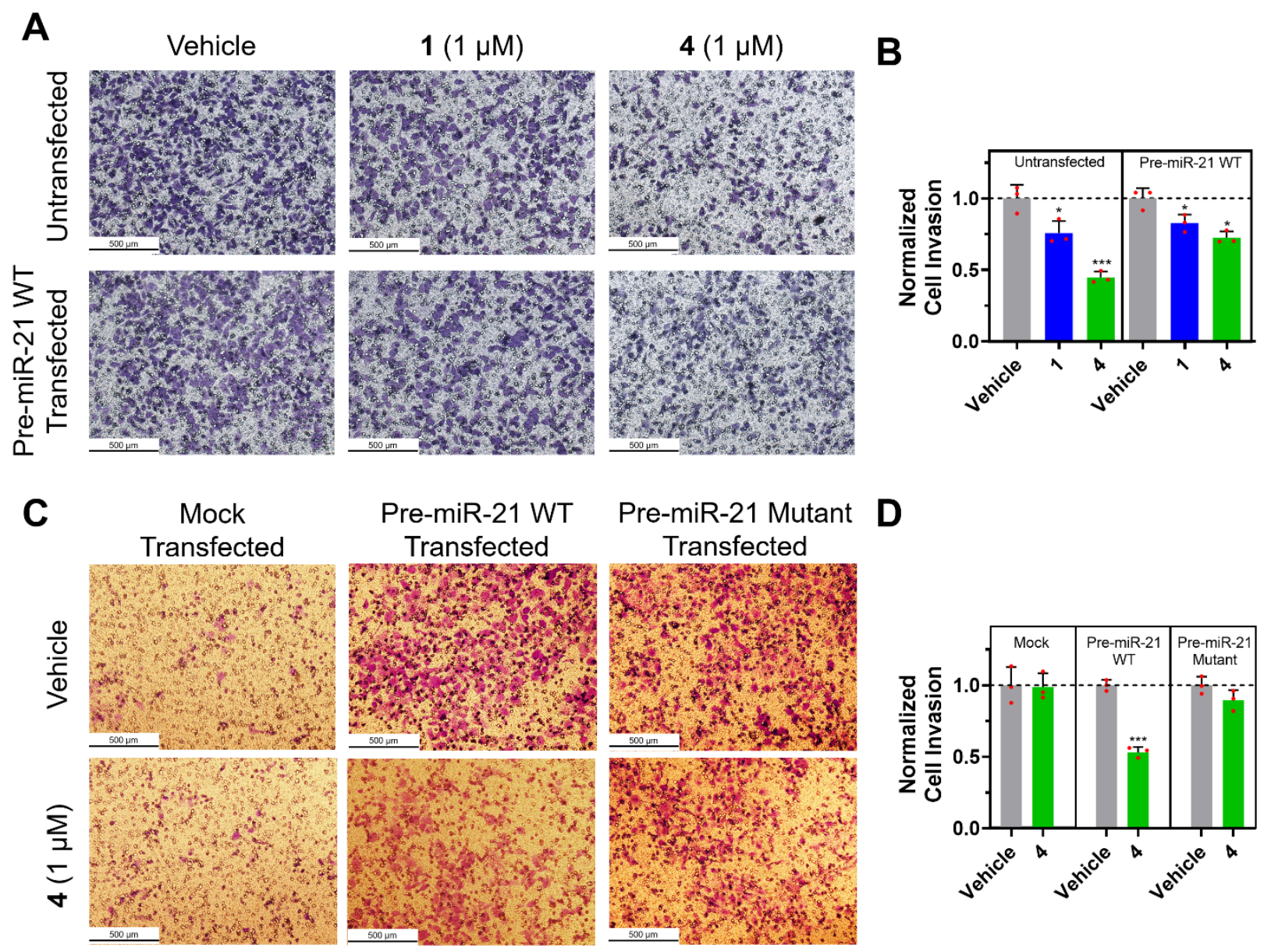

Figure S18. RIBOTAC 4 inhibits the invasive nature (miR-21-mediated phenotype) of MDA-MB231 cells and MCF-10A cells forced to express pre-miR-21. (A) Compound 1 and RIBOTAC 4 reduced the number of invasive MDA-MB-231 cells. This reduction was abated when MDA-MB-231 cells were transfected with wild type pre-miR-21 $(\mathrm{n}=3)$. (B) Quantification of the number of invasive MDA-MB231 cells from $\mathbf{A}(\mathrm{n}=3)$. (C) RIBOTAC 4 inhibited the invasive phenotype of MCF-10A acquired by forced expression of wild type pre-miR-21 from a plasmid $(n=3)$. In contrast, 4 was unable to rescue the invasive phenotype of MCF-10A acquired by transfection of a mutated pre-miR-21 where the binding site of $\mathbf{1}$ is ablated. (D) Quantification of the number of invasive MCF-10A cells from $\mathbf{C}(\mathrm{n}=3)$. These plasmids were the same as those used in Figure S12. *, $\mathrm{p}<0.05 ; * * * \mathrm{p}<0.001$, as tested by a two-tailed Student's t-test. 


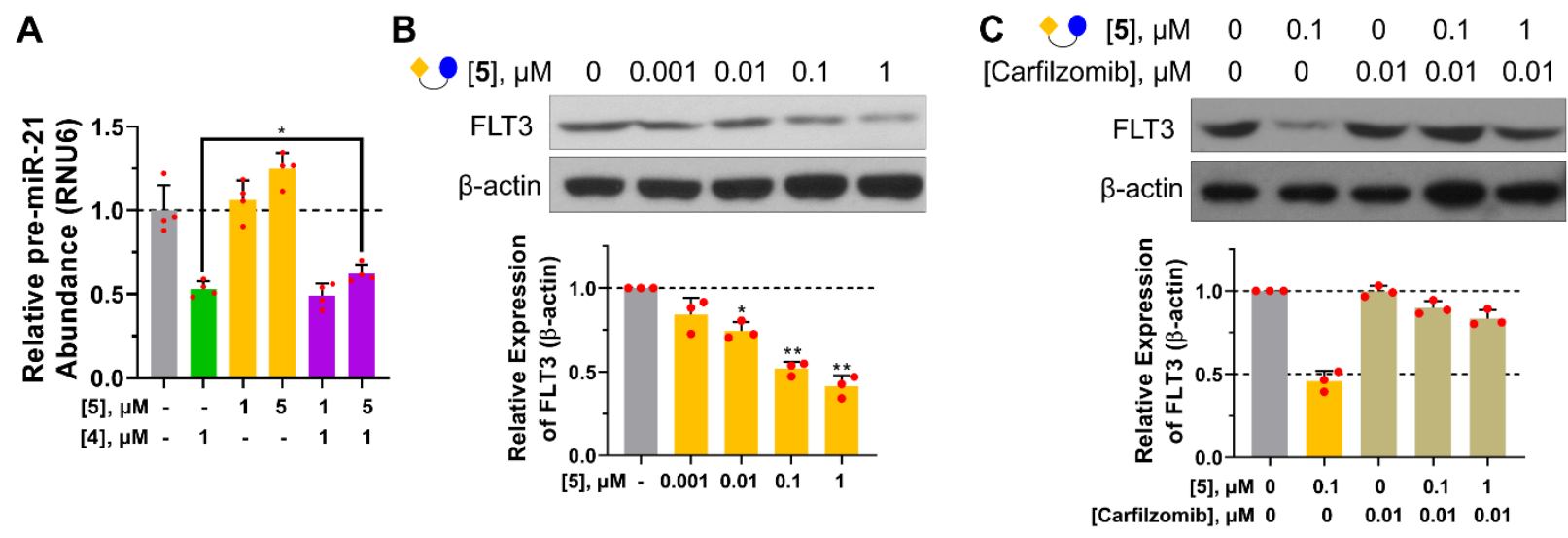

D

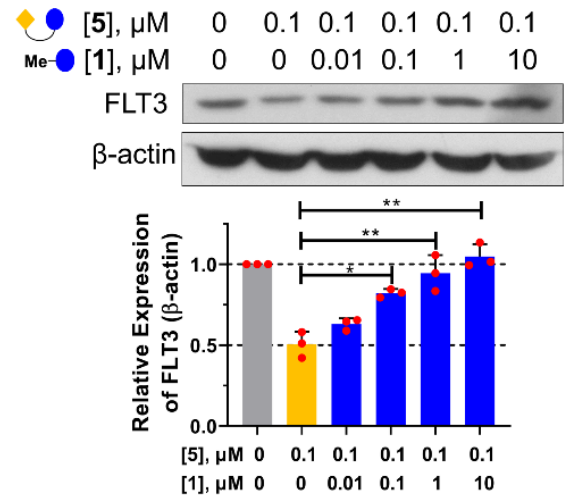

$\mathbf{E}$

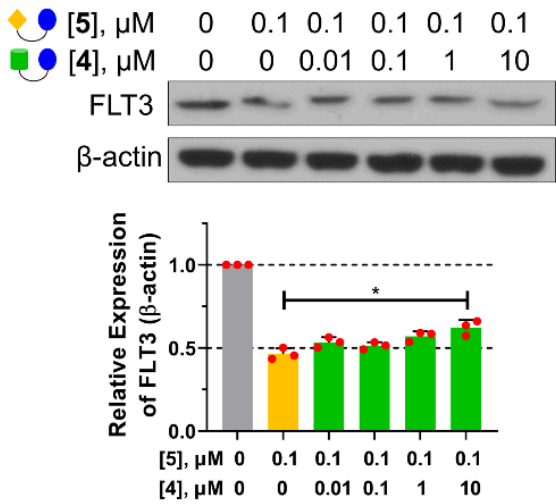

Figure S19. PROTAC 5 inhibits pre-miR-21 biogenesis, in MDA-MB-231 cells, similar to 1 and induces degradation of RTK FLT3 that is competed by 1 and 4. (A) PROTAC 5 boosted pre-miR-21 levels, as determined by RT-qPCR, similar to $\mathbf{1}$, as expected for simple binding compound $(\mathrm{n}=4)$. Further, 5 abated the cleavage of pre-miR-21 by RIBOTAC $\mathbf{4}$ dose dependently $(n=4)$. (B) PROTAC $\mathbf{5}$ induced degradation of FLT3 in a dose dependent manner, and this induction of degradation can be competed by co-treatment with 1 (D) or $4(E)(n=3)$. Interestingly a 100-fold greater concentration of RIBOTAC 4 (10 $\mu \mathrm{M})$ than $1(0.1 \mu \mathrm{M})$ was required to compete the targeted degradation of PROTAC 5. (C) Carfilzomib, a 20S proteasome inhibitor, abated degradation of FLT3 by PROTAC 5, indicating a proteasome-mediated mechanism of action $(\mathrm{n}=3) .^{*}, \mathrm{p}<0.05 ; * *, \mathrm{p}<0.01 *^{* * *} \mathrm{p}<0.001$, as tested by a paired two-tailed Student's t-test. 

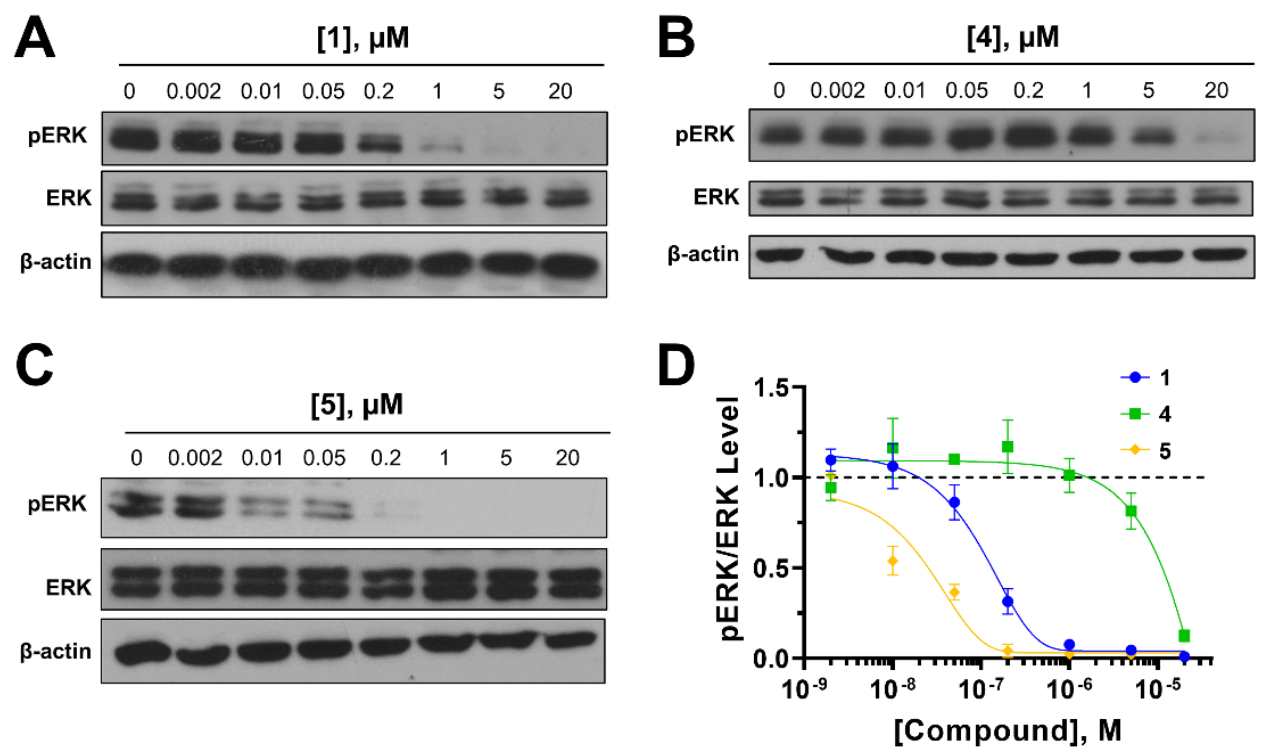

Figure S20. Effect of 1, RIBOTAC 4, and PROTAC 5 on the ERK and phosphorylated (p)ERK levels. (A) Representative Western blot to study the functional inhibition of ERK by 1. (B) Representative Western blot to study the inhibition of ERK phosphorylation by RIBOTAC 4, which has reduced ability to inhibit ERK phosphorylation compared to 1. (C) Representative Western blot to study inhibition of ERK phosphorylation by PROTAC 5, which is more potent than 1. (D) Quantification of the effects of compounds $\mathbf{1}, \mathbf{4}$, and 5 on ERK phosphorylation $(\mathrm{n}=3)$. RIBOTAC $\mathbf{4}$ at $5 \mu \mathrm{M}$ dose inhibited ERK phosphorylation to the similar extent as compound $\mathbf{1}$ at $0.05 \mu \mathrm{M}$ dose, or a 100 -fold difference functional inhibition. 


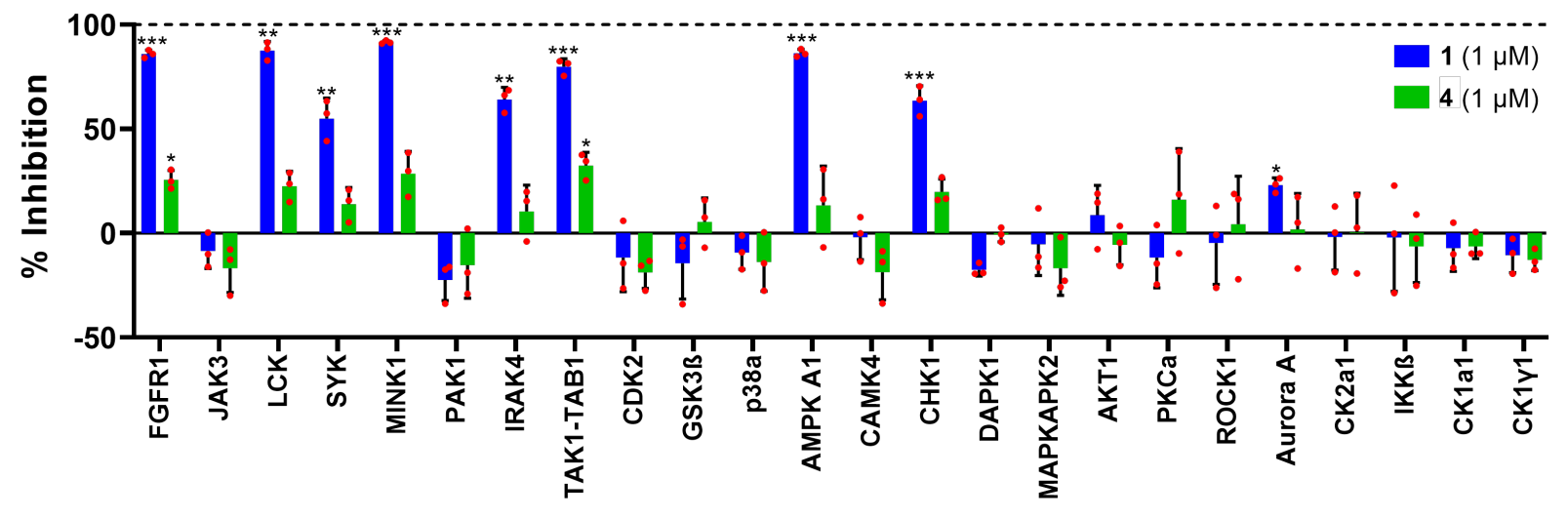

Figure S21. RIBOTAC 4 has significantly less inhibitory activity against 24 kinases in vitro than 1. Compound 1 significantly inhibited $(p<0.01)$ eight kinases and modestly inhibited $(p<0.05)$ one kinase while RIBOTAC $\mathbf{4}$ had no significant inhibitory activity against any kinase and modest inhibition of two ( $\mathrm{n}=3$ for both compounds). ${ }^{*}, \mathrm{p}<0.05 ; * *, \mathrm{p}<0.01 ; * * * \mathrm{p}<0.001$ compared to vehicle, as tested by a paired two-tailed Student's t-test. 


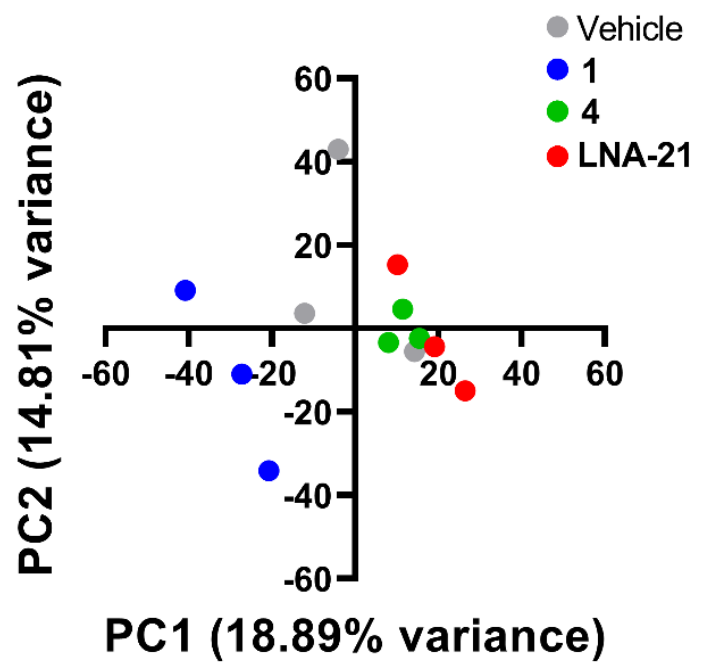

Figure S22. PCA of proteome-wide studies reveals samples treated with RIBOTAC 4 are more similar to LNA-21 than to 1. PCA plot to visualize differences between experimental groups and batch effects. PCA of proteomics studies suggest that samples treated with RIBOTAC $\mathbf{4}$ are more similar to samples treated with LNA-21 than to samples treated with 1 (blue), as expected. 

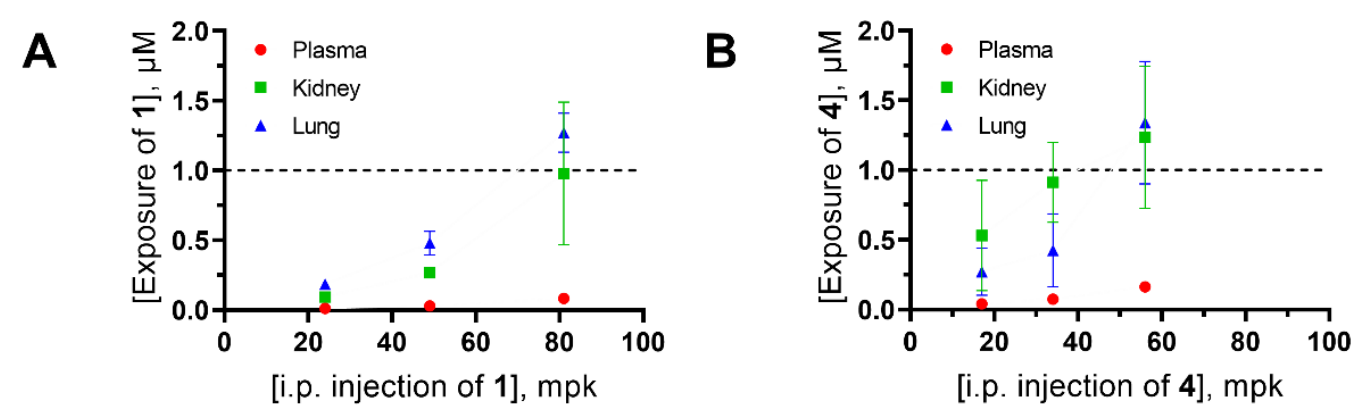

C

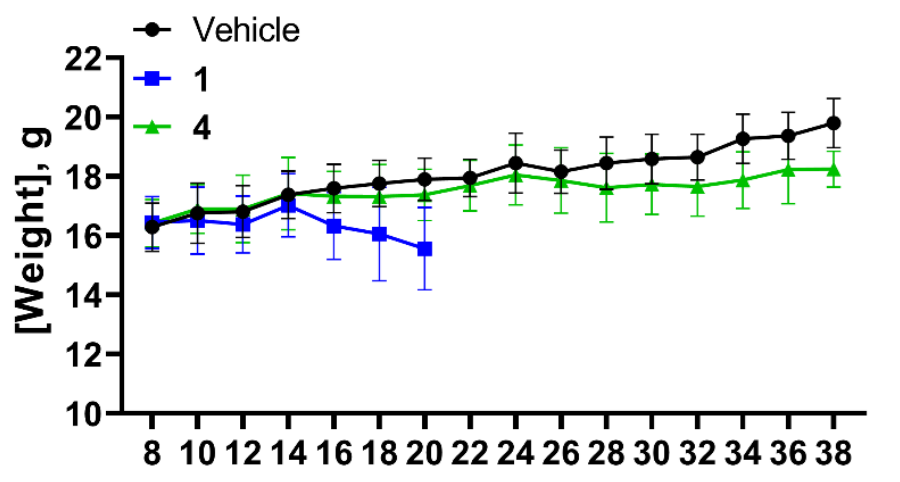

\section{Days after i.v. injection of MDA-MB-231-Luc cells}
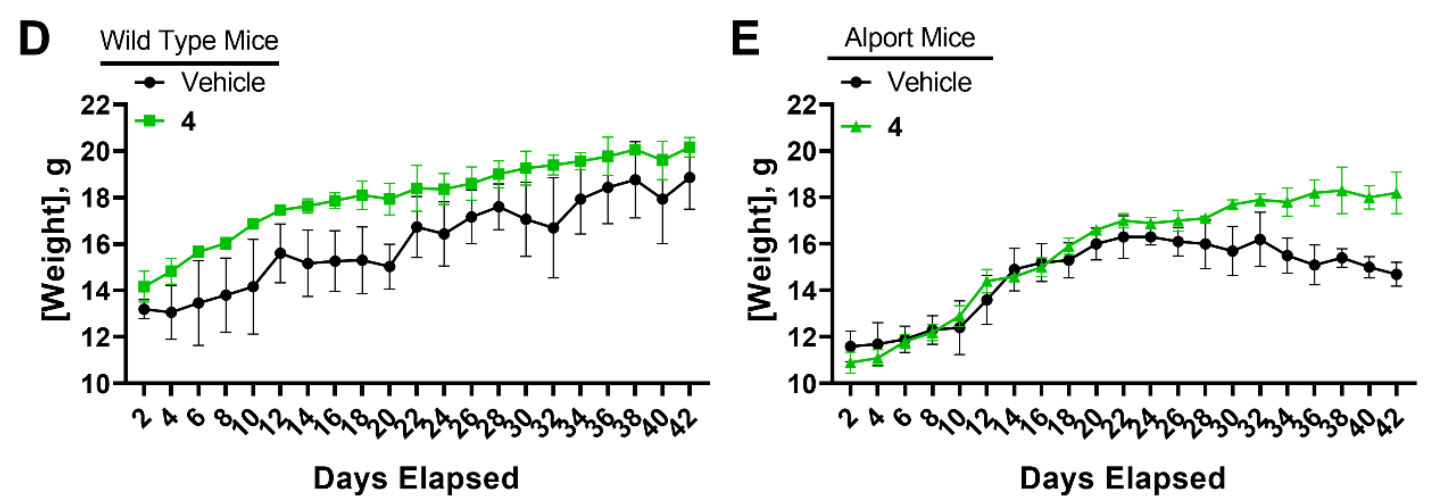

Figure S23. Drug Metabolism and Pharmacokinetics (DMPK) analysis of 1 and RIBOTAC 4 in C57BL/6 mice and weight of xenograft, Alport, and WT mice upon treatment. Mice were i.p. injected with $1(24,49$, or $81 \mathrm{mg} / \mathrm{kg})$ or $\mathbf{4}(17,34$, or $56 \mathrm{mg} / \mathrm{kg})$. Plots show exposure of $\mathbf{1}(\mathbf{A})$ and $\mathbf{2}(\mathbf{B})$ in plasma, ${ }^{13}$ kidney, ${ }^{17}$ or lung (blue) at various doses (mpk), determined $48 \mathrm{~h}$ post-treatment $(\mathrm{n}=3)$. (C) Weight of NOD/Scid mice injected intravenously (i.v., tail vein) with MDA-MB-231-Luc cells, which metastasize to the lung, ${ }^{18}$ upon treatment with $81 \mathrm{mg} / \mathrm{kg}$ of 1 or $56 \mathrm{mg} / \mathrm{kg}$ of RIBOTAC 4 every other day (i.p., q.o.d.), beginning 8 days post MDA-MB-231-Luc cell injection. Over 38 days, 4-treatment did not cause significant changes in weight compared to vehicle treatment. However, 1 treatment could only continue for 12 days due to toxicity. For each treatment, $n=11$ for vehicle; $n=10$ for $1 ; n=11$ for 4 . (D) Treatment of WT Col43 $a^{+/+}$mice (control for Alport Syndrome studies) with 4 over 6 weeks gained weight at a similar rate as vehicle-treated mice $(n=3)$. (E) Alport mice receiving 4-treatment gained more weight than vehicletreated mice and maintained stable weights after one month of treatment, whereas vehicle-treated mice began to lose weight (for vehicle-treated Alport mice, $n=3$; for 4-treated Alport mice, $n=4$ ). Both WT (D) and Alport mice (E) were treated with $56 \mathrm{mg} / \mathrm{kg}$ (q.o.d.) of 4. 
A
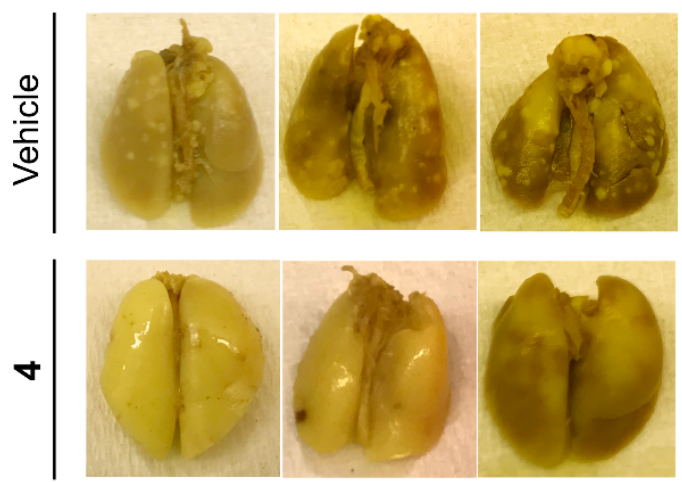

B

Vehicle
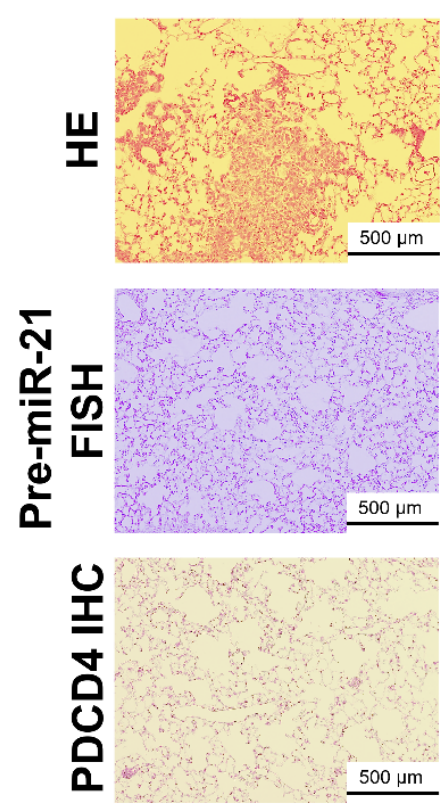

1
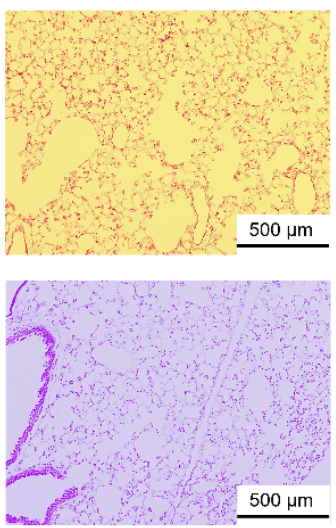

$500 \mu \mathrm{m}$

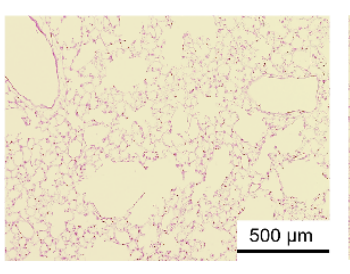

4
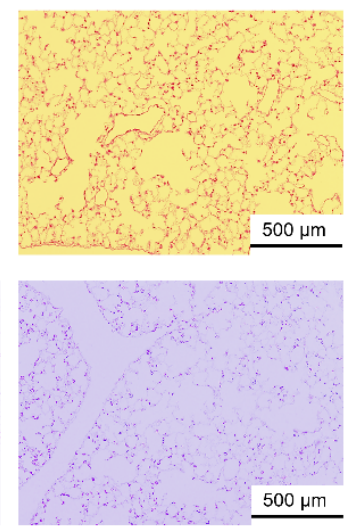

$500 \mu \mathrm{m}$

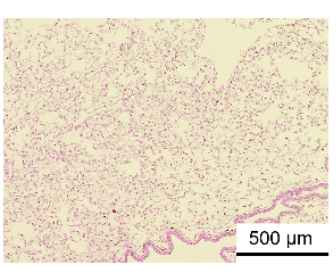

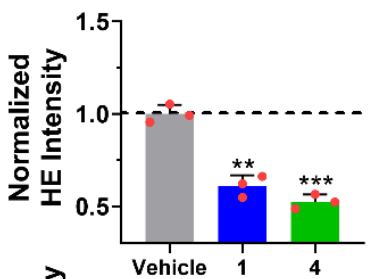
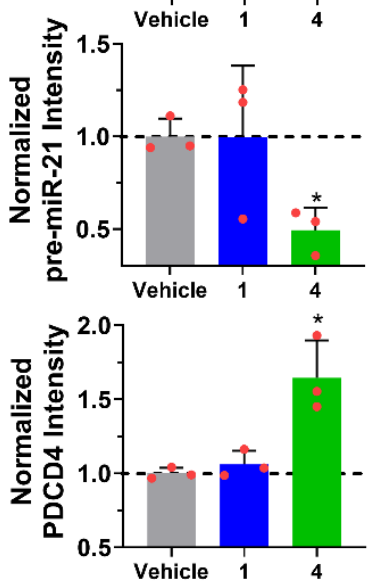

Figure S24. RIBOTAC 4 inhibits MDA-MB-231 metastasis in vivo. (A) Representative lungs from vehicle- and 4-treated mice, perfused with PBS stained with Bouin's solution. Lung metastases were observed as white nodules on the surface of the lungs $(n=11)$. (B) From top to bottom: Hematoxylin and eosin (HE) staining, fluorescent in situ hybridization (FISH) staining of pre-miR-21, and immunohistochemistry (IHC) of PDCD4 of lung tissue from mice treated with vehicle, 1, or RIBOTAC 4. Quantifications are shown to the right of each image $(\mathrm{n}=3)$. ${ }^{*}, \mathrm{p}<0.05 ; * *, \mathrm{p}<0.01 ; * * * \mathrm{p}<0.001$, as tested by a two-tailed Student's t-test. 


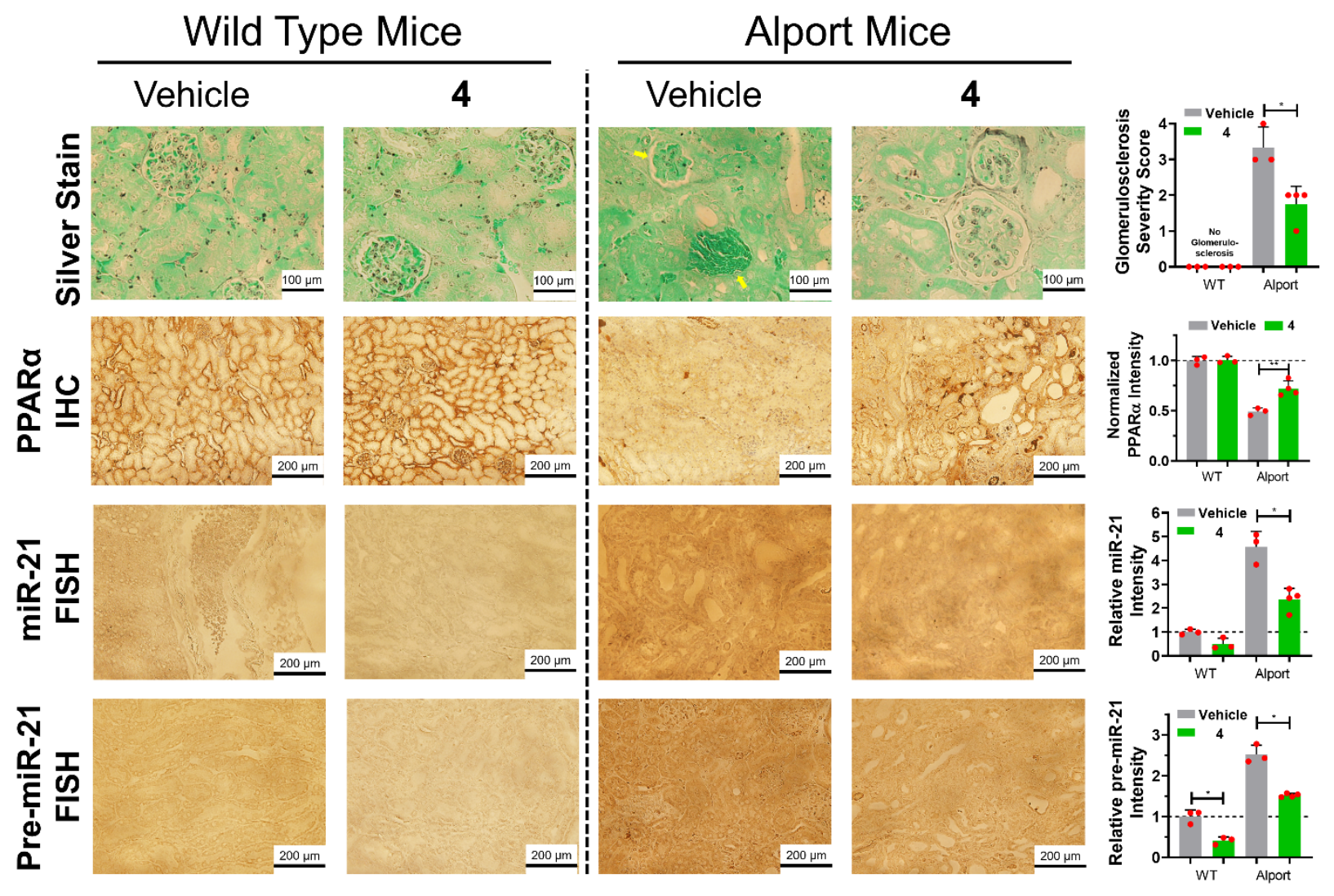

Figure S25. RIBOTAC 4 prevents glomerulosclerosis and tubular atrophy in the kidney of Alport mice. From top to bottom: silver methenamine-stained images, with glomerulosclerosis highlighted with yellow arrows; IHC staining of PPAR $\alpha$; FISH staining of miR-21 and pre-miR-21. Glomerulosclerosis severity was scored from 0 to 4 by extent of sclerosis as previously described, ${ }^{19}$ where 0 is no glomerulosclerosis as observed in wild type mice and 4 is most severe (as observed in untreated Alport mice). Quantifications are shown to the right of each image (for vehicle- and 4-treated WT mice, $\mathrm{n}=3$; for vehicle-treated Alport mice, $\mathrm{n}=3$; for 4-treated Alport mice, $\mathrm{n}=4$ ). ${ }^{*}, \mathrm{p}<0.05$; **, $\mathrm{p}<0.01$, as tested by a two-tailed Student's t-test. 


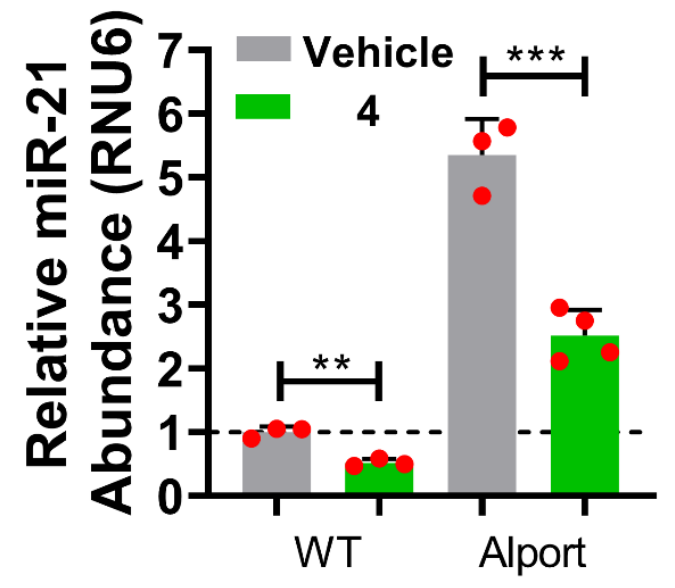

Figure S26. RIBOTAC 4 decreased miR-21 levels in kidneys of both WT and Alport mice. Mature miR-21 levels were measured by RT-qPCR (for vehicle- and 4-treated WT mice, $\mathrm{n}=3$; for vehicle-treated Alport mice, $\mathrm{n}=3$; for 4-treated Alport mice, $\mathrm{n}=4)$; ${ }^{* *}, \mathrm{p}<0.01 ; * * * \mathrm{p}<0.001$, as tested by a two-tailed Student's t-test. 

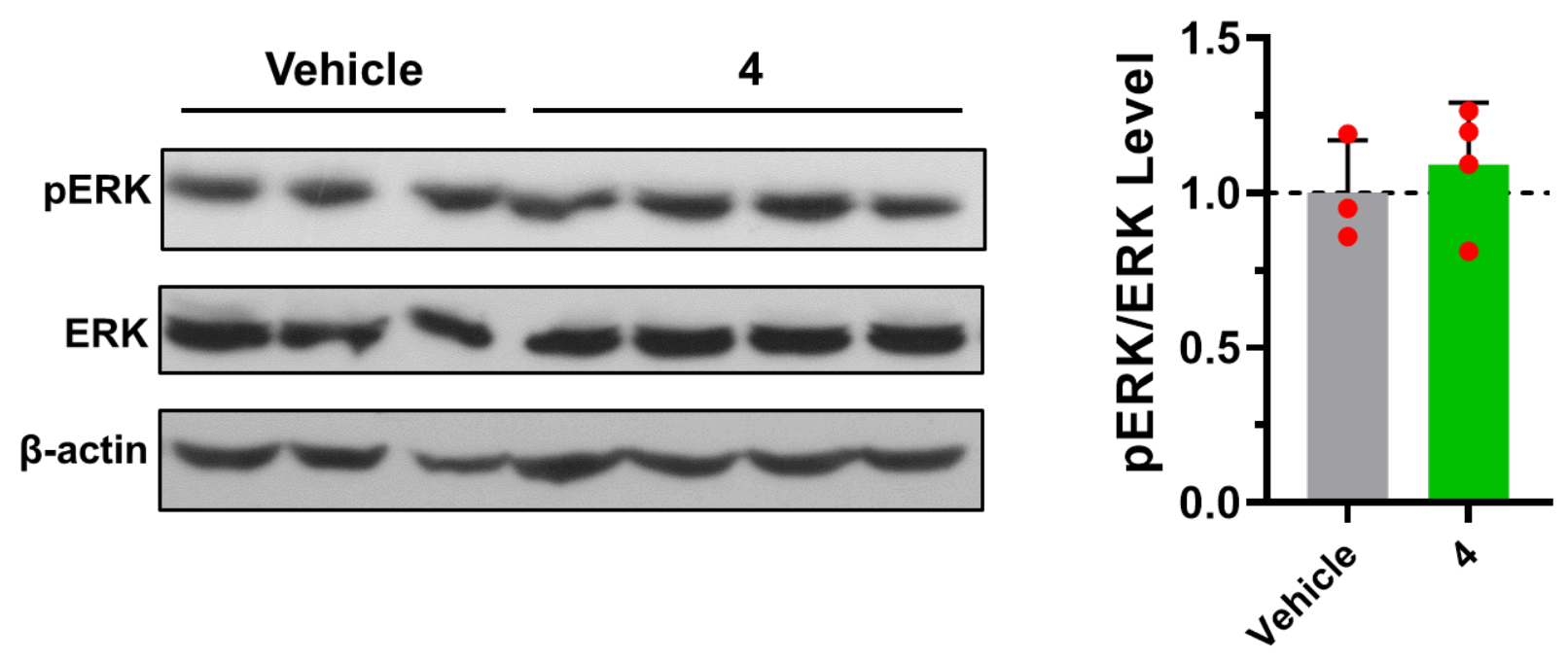

Figure S27. Analysis of ERK and pERK protein levels in kidney tissue from Alport Syndrome mice treated with RIBOTAC 4, as determined by Western blotting. 

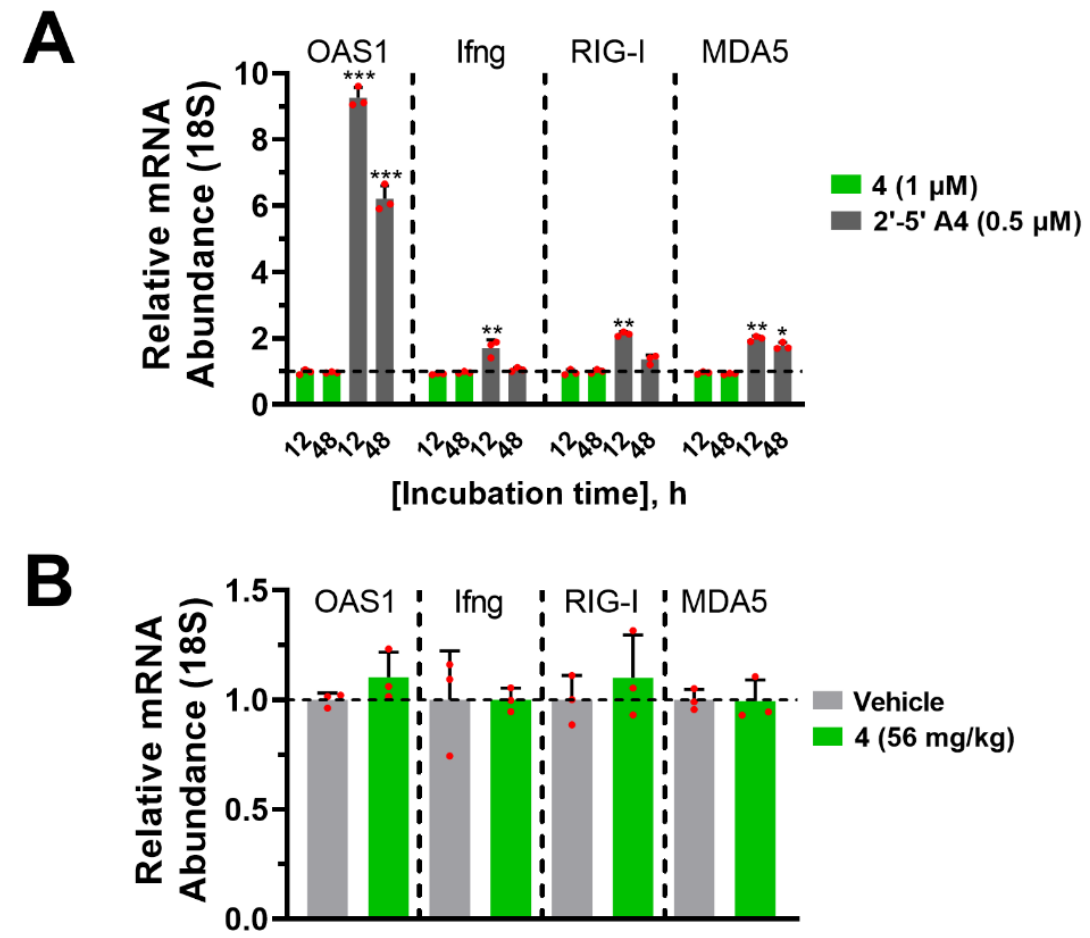

Figure S28. Studying changes in the innate immune response upon of 2'-5' $\mathbf{A}_{4}$ - or 4-treatment in cells and in vivo. (A) Levels of mRNAs associated with the antiviral innate immune response upon treatment with RIBOTAC $4(1 \mu \mathrm{M})$ or transfection of 2' -5 ' $\mathrm{A}_{4}(0.5 \mu \mathrm{M})$ in MDA-MB-231 cells, as determined by RT-qPCR $(n=3)$. No changes in the levels of these markers were observed upon 4-treatment. However, significant upregulation of Ifng (Interferon Gamma), OAS1 (2'-5'-Oligoadenylate Synthetase 1), RIG-I (Retinoic Acid-Inducible Gene 1 Protein), and MDA5 (Melanoma Differentiation-Associated Protein) was observed upon transfection of 2'-5' $\mathrm{A}_{4}$. (B) Levels of mRNAs associated with the antiviral innate immune response upon treatment with RIBOTAC 4 in Alport mice were measured by RT-qPCR $(n=3)$. Similarly, no changes in the levels of these markers were observed upon 4-treatment in mice. ${ }^{*}, \mathrm{p}<0.05 ; * *, \mathrm{p}<$ $0.01 ; * * * \mathrm{p}<0.001$, as tested by a two-tailed Student's t-test. 

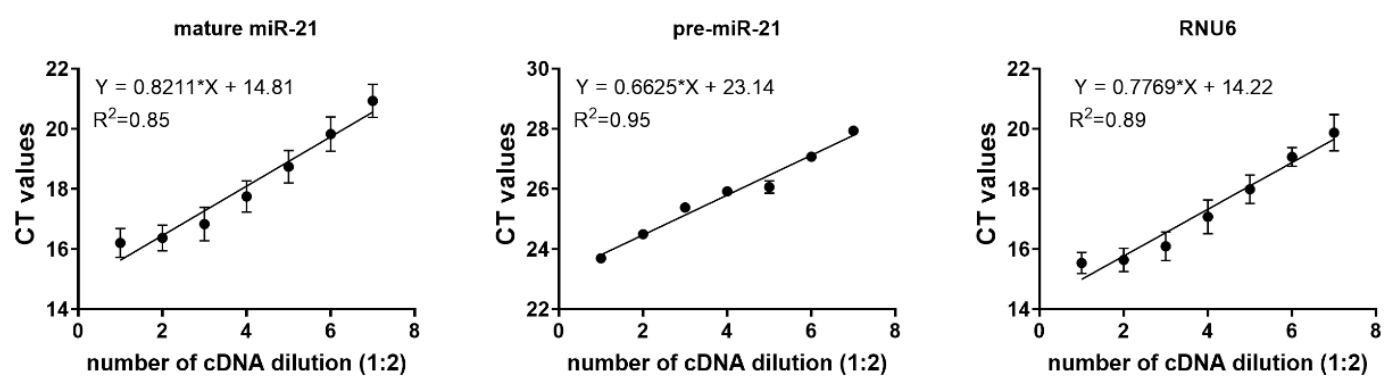

B
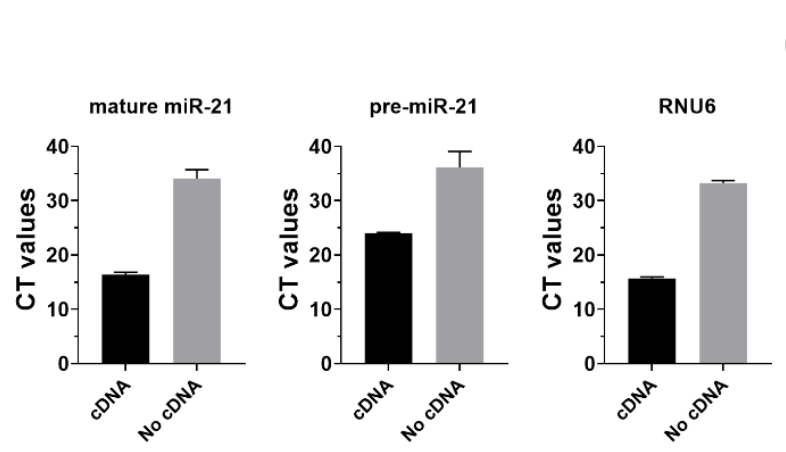

C

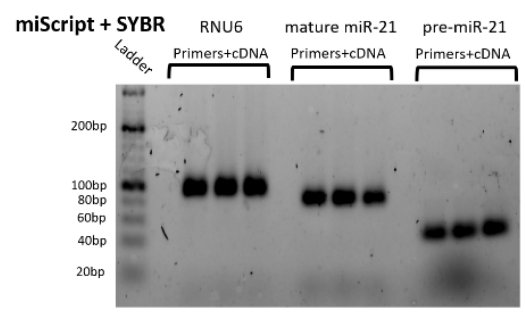

D
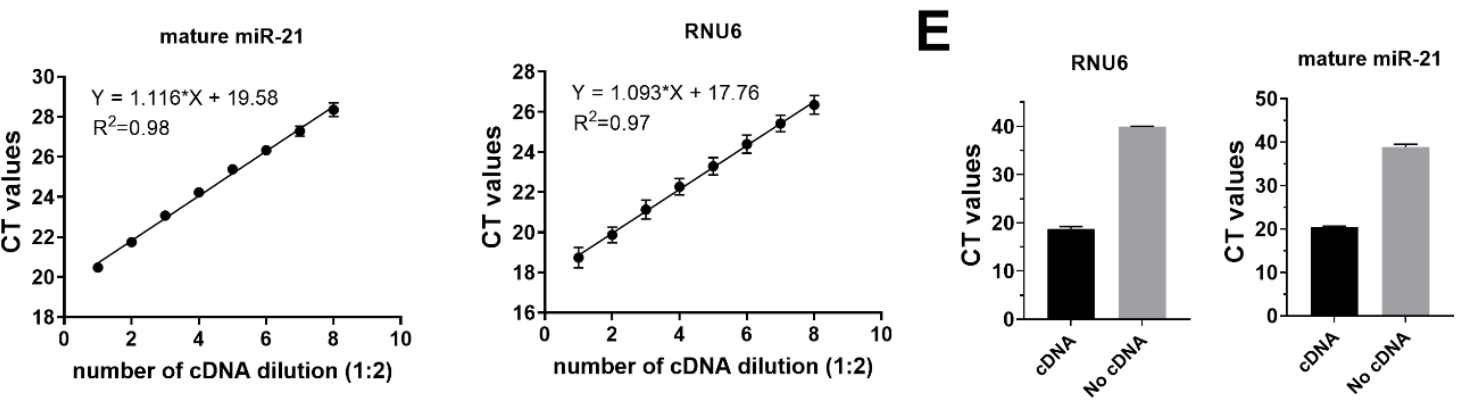

$\mathbf{F}$

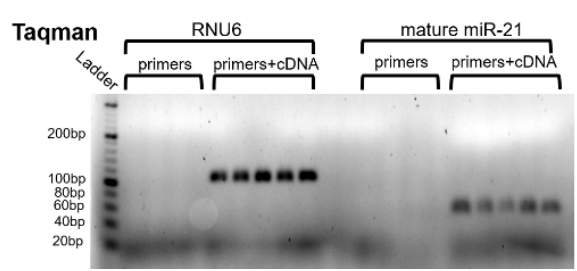

Figure S29. Validation of primers of mature miR-21 and pre-miR-21 used in RT-qPCR analysis. (A) Plot of $C_{t}$ values as function of the number of cDNA dilution for primers to amplify mature miR-21, premiR-21, and RNU6 housekeeping gene by RT-qPCR. RT reaction were completed with miScript kit while qPCR was completed with Power SYBR Master Mix. (B) Primers to amplify mature miR-21, pre-miR-21, and RNU6 control did not amplify no template controls. RT reaction were completed with miScript kit while qPCR was completed with Power SYBR Master Mix. (C) A single RT-qPCR product generated from RT reactions completed with miScript kit and qPCR by Power SYBR Master Mix was observed by electrophoretic analysis $\left(3 \%(\mathrm{w} / \mathrm{v})\right.$ agarose gel). (D) Plot of $\mathrm{C}_{t}$ values as function of the number of cDNA dilution for mature miR-21 and RNU6 housekeeping gene by Taqman analysis. (E) TaqMan primers for mature miR-21 and RNU6 control did not amplify no template controls. (C) A single RT-qPCR product generated from RT reactions completed with TaqMan was observed by electrophoretic analysis (3\% (w/v) agarose gel). 
Table S1: Sequences of oligonucleotides primers used in these studies.

\begin{tabular}{|c|c|c|c|}
\hline $\begin{array}{c}\text { Name of } \\
\text { Oligonucleotide }\end{array}$ & Sequence $\left(5^{\prime} \rightarrow 3^{\prime}\right)$ & Experiment & Supplier \\
\hline RNU6 & ACACGCAAATTCGTGAAGCGTTC & RT-qPCR & IDT \\
\hline Universal Reverse & GAATCGAGCACCAGTTACGC & RT-qPCR & IDT \\
\hline hsa-miR-21 Fwd & TAGCTTATCAGACTGATGTTGA & RT-PCR & IDT \\
\hline pri-miR-21 Fwd & AATCCTGCCTGACTGTVTGC & RT-qPCR & IDT \\
\hline pri-miR-21 Rev & TGAGAACATTGGATATGGATGGTCA & RT-qPCR & IDT \\
\hline pre-miR-21 Fwd & CTGATGTTGACTGTTGAATC & RT-qPCR & IDT \\
\hline pre-miR-21 Rev & GCCCATCGACTGGTGTTGCC & RT-qPCR & IDT \\
\hline $\begin{array}{l}\text { pre-miR-21 } \\
\text { WTtemplate }\end{array}$ & $\begin{array}{l}\text { TAGCTTATCAGACTGATGTTGACTGT } \\
\text { TGAATCTCATGGCAACACCAGTCGAT } \\
\text { GGGCTG }\end{array}$ & RT-PCR & IDT \\
\hline $\begin{array}{l}\text { pre-miR-21 Dicer site } \\
\text { base pair mutant } \\
\text { template }\end{array}$ & $\begin{array}{l}\text { TAGCTTATCAGACTGATGTTGACTGT } \\
\text { TGAATCTCATGGTCAACACCAGTCGA } \\
\text { TGGGCTG }\end{array}$ & RT-PCR & IDT \\
\hline $\begin{array}{l}\text { pre-miR-21 template } \\
\text { Fwd }\end{array}$ & $\begin{array}{l}\text { TAATACGACTCACTATAGTAGCTTAT } \\
\text { CAGACTG }\end{array}$ & RT-PCR & IDT \\
\hline $\begin{array}{l}\text { pre-miR-21 template } \\
\text { Rev }\end{array}$ & CAGCCCATCGACTGG & RT-PCR & IDT \\
\hline RNase L Fwd & GCTCATTTGTACTGCGTTATGC & RT-qPCR & IDT \\
\hline RNase L Rev & CATTTTCTCAAGGAAAAGGC & RT-qPCR & IDT \\
\hline $18 S$ Fwd & GTAACCCGTTGAACCCCATT & RT-qPCR & IDT \\
\hline $18 S \mathrm{Rev}$ & CCATCCAATCGGTAGTAGCG & RT-qPCR & IDT \\
\hline GAPDH Fwd & GTTCGACAGTCAGCCGCATC & RT-qPCR & IDT \\
\hline GAPDH Rev & GGAATTTGCCATGGGTGGA & RT-qPCR & IDT \\
\hline OAS1 Fwd & GAAGGCAGCTCACGAAACC & RT-qPCR & IDT \\
\hline OASI Rev & AGGCCTCAGCCTCTTGTG & RT-qPCR & IDT \\
\hline Ifng Fwd & CGCCTTGGAAGAGTCACTCA & RT-qPCR & IDT \\
\hline Ifng Rev & GAAGCCTCAGGTCCCAATTC & RT-qPCR & IDT \\
\hline$R I G-I F w d$ & GGACGTGGCAAAACAAATCAG & RT-qPCR & IDT \\
\hline RIG-I Rev & GCAATGTCAATGCCTTCATA & RT-qPCR & IDT \\
\hline$M D A 5 F w d$ & CCAGCATTACTAGTCAGAAGGAA & RT-qPCR & IDT \\
\hline MDA5 Rev & CACAGTGCAATCTTGTCATCC & RT-qPCR & IDT \\
\hline
\end{tabular}




\begin{tabular}{|l|l|l|l|}
\hline pre-miR-32 Fwd & $\begin{array}{l}\text { TATTGCACATTACTAAGTTGCATGTT } \\
\text { GTCA }\end{array}$ & RT-qPCR & IDT \\
\hline pre-miR-32 Rev & $\begin{array}{l}\text { AAATATCACACACACTAAATTGCATT } \\
\text { GAGG }\end{array}$ & RT-qPCR & IDT \\
\hline pre-miR-103a Fwd & AGCTTCTTTACAGTGCTGCCTTG & RT-qPCR & IDT \\
\hline pre-miR-103a Rev & TCATAGCCCTGTACAATGCTGCT & RT-qPCR & IDT \\
\hline pre-miR-137 Fwd & GTGACGGGTATTCTTGGGT & RT-qPCR & IDT \\
\hline pre-miR-137 Rev & GACTACGCGTATTCTTAAGCAA & RT-qPCR & IDT \\
\hline pre-miR-187 Fwd & GGCTACAACACAGGACCCGG & RT-qPCR & IDT \\
\hline pre-miR-187 Rev & GCTGCAACACAAGACACGAGG & RT-qPCR & IDT \\
\hline pre-miR-346 Fwd & TGTCTGCCCGCATGCCTG & RT-qPCR & IDT \\
\hline pre-miR-346 Rev & TGCAGGCCCAGCCCC & RT-qPCR & IDT \\
\hline pre-miR-375 Fwd & CCTCGCACAAACCGGACCT & RT-qPCR & IDT \\
\hline pre-miR-375 Rev & GCCTCACGCGAGCCGAAC & RT-qPCR & IDT \\
\hline pre-miR-378d Fwd & ACTGGACTTGGAGTCAGAAAACTTTC & RT-qPCR & IDT \\
\hline pre-miR-378d Rev & ATGGGACTTAGAGCAGGGAATGACT & RT-qPCR & IDT \\
\hline pre-miR-378h Fwd & ACTGGACTTGGTGTCAGATGGGA & RT-qPCR & IDT \\
\hline pre-miR-378h Rev & ACTAGCTCAAGATCAGATTGCTGCT & RT-qPCR & IDT \\
\hline pre-miR-423 Fwd & TGAGGGGCAGAGAGCGAGA & RT-qPCR & IDT \\
\hline pre-miR-423 Rev & ACTGAGGGGCCTCAGACC & RT-qPCR & IDT \\
\hline
\end{tabular}

Sequences for Global miRNA profiling primers were previously described. ${ }^{2}$

Supporting Information Page 47 


\section{Synthetic Experimental Procedures}

\section{General Methods.}

Ethyl 3-ethoxy-3-iminopropionate hydrochloride salt, 1((-2-N-Boc-amino)ethyl)piperazine, and 2Amino-6-fluorobenzonitrile were purchased from Combi-Blocks. Potassium carbonate was purchased from EMD Millipore Corporation. $\quad N, N^{\prime}$-Disuccinimidyl carbonate, Fmoc-15-amino-4,7,10,13tetraoxapentadecanoic acid, and piperidine, were purchased from Chem Impex Intl, Inc. $N, N-$ Diisopropylethylamine, and 3-(3-(But-3-yn-1-yl)-3H-diazirin-3-yl)propanoic acid were purchased from Sigma-Aldrich. Dimethylformamide were purchased from Fisher Chemical. HATU was purchased from Oakwood Products, Inc. Acetic acid was purchased from Avantor Performance Materials. Propylamine, and lithium bis(trimethylsilyl)amide were purchased from Alfa Aesar. Lastly, 5-Chloro-2-nitroaniline was purchased from Acros Organics. Reagents and solvents purchased from commercial suppliers were directly used without further purification.

Reactions were monitored with thin layer chromatography (TLC, Agela Technologies) or by LC-MS. Bands on TLC were visualized under UV light $(254 \mathrm{~nm})$. Products were purified by silica gel column chromatography or by HPLC (waters 2487 and 1525) equipped with a SunFire ${ }^{\circ}$ Prep C18 OBDTM 5 $\mu \mathrm{m}$ column $(19 \times 150 \mathrm{~mm})$ with a flow rate of $5 \mathrm{~mL} / \mathrm{min}$. Product purities were analyzed by HPLC (Waters 2487 and 1525) equipped with a SunFire ${ }^{\circledR}$ C18 $3.5 \mu \mathrm{m}$ column $(4.6 \times 150 \mathrm{~mm})$ with a flow rate of $1 \mathrm{~mL} / \mathrm{min}$. The gradient used for purification and purity analysis is from $100 \%$ of $\mathrm{H}_{2} \mathrm{O}$ (containing $0.1 \%$ TFA) to $100 \% \mathrm{MeOH}$ (containing $0.1 \%$ TFA) in $60 \mathrm{~min}$.

NMR spectra were acquired using an Ascend ${ }^{\mathrm{TM}}$ 600(Bruker) (600 $\mathrm{MHz}$ for ${ }^{1} \mathrm{H}$ and $150 \mathrm{MHz}$ for ${ }^{13} \mathrm{C}$ ) or a 400 UltraShield $^{\mathrm{TM}}$ (Bruker) $\left(400 \mathrm{MHz}\right.$ for ${ }^{1} \mathrm{H}$ and $100 \mathrm{MHz}$ for $\left.{ }^{13} \mathrm{C}\right)$. Chemical shifts are reported in ppm by using residual solvent as internal standards. Coupling constants ( $\mathrm{J}$ values) are reported in hertz.

Mass spectrometry was completed by using an Agilent 1260 Infinity LC system coupled to an Agilent $6230 \mathrm{TOF}(\mathrm{HR}-\mathrm{ESI}$ ) equipped with a Poroshell $120 \mathrm{EC}-\mathrm{C} 18$ column (Agilent, $50 \mathrm{~mm} \times 4.6 \mathrm{~mm}, 2.7$ $\mu \mathrm{m})$ or by using 4800 Plus MALDI TOF/TOF Analyzer. 


\section{Synthetic Schemes, Methods, and Characterizations.}

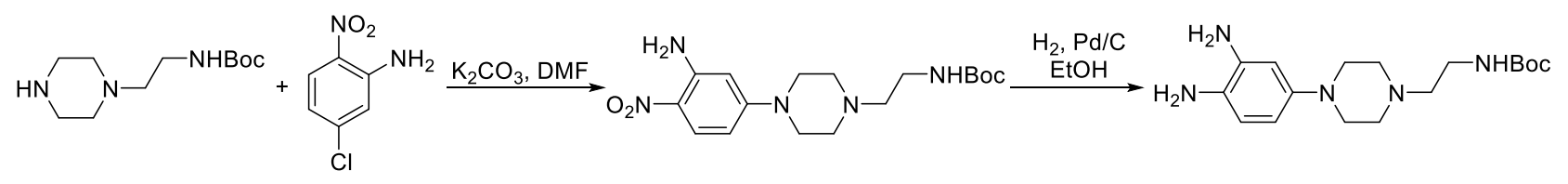

s1

S2

S3

S4

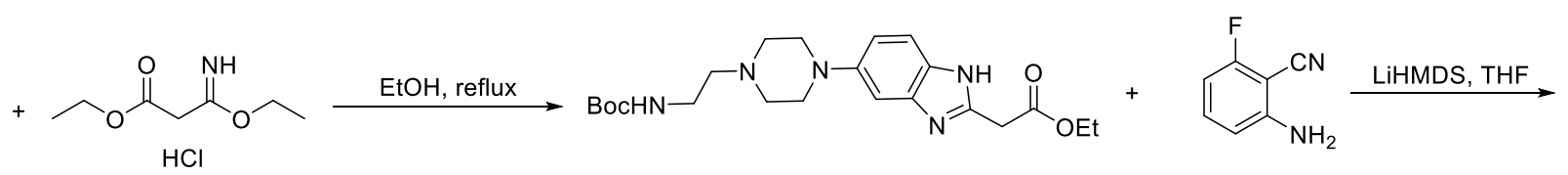

S5

56

S7

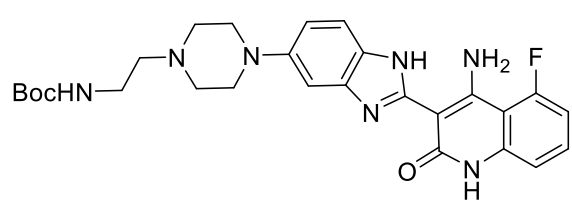

S8

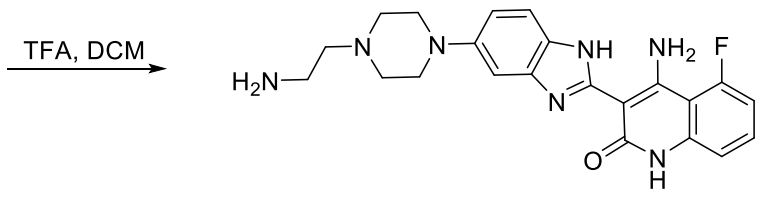

$1 \mathrm{a}$

Compound S3. A solution of the amine S1 (998 mg, $4.36 \mathrm{mmol})$, aniline S2 (500 mg, $2.90 \mathrm{mmol}$ ), and $\mathrm{K}_{2} \mathrm{CO}_{3}(1.91 \mathrm{~g}, 14.5 \mathrm{mmol})$ in $5 \mathrm{~mL}$ of $N, N$-dimethylformamide (DMF) was refluxed with stirring for $24 \mathrm{~h}$. The reaction mixture was then diluted with ethyl acetate and extracted with $\mathrm{H}_{2} \mathrm{O}$. The combined organic layers were washed with brine, dried over anhydrous $\mathrm{Na}_{2} \mathrm{SO}_{4}$ and concentrated in vacuo. The residue was purified by column chromatography (5\%-8\% $\mathrm{MeOH}$ in DCM) to give $\mathbf{S 3}$ as a yellow solid (550 mg, $1.51 \mathrm{mmol}, 52.3 \%) .{ }^{1} \mathbf{H}$ NMR (400 MHz, CD $\left.3 \mathrm{OD}\right) \delta(\mathrm{ppm}) 7.92(\mathrm{~d}, J=9.8$ $\mathrm{Hz}, 1 \mathrm{H}), 6.36(\mathrm{dd}, J=9.8,2.7 \mathrm{~Hz}, 1 \mathrm{H}), 6.17(\mathrm{~d}, J=2.6 \mathrm{~Hz}, 1 \mathrm{H}), 3.41-3.38(\mathrm{~m}, 4 \mathrm{H}), 3.23(\mathrm{t}, J=6.7 \mathrm{~Hz}$, 2H), 2.62-2.60 (m, 4H), $2.50(\mathrm{t}, J=6.7 \mathrm{~Hz}, 2 \mathrm{H}), 1.44(\mathrm{~s}, 9 \mathrm{H}) .{ }^{13} \mathbf{C} \mathbf{N M R}\left(100 \mathrm{MHz}, \mathrm{CD}_{3} \mathrm{OD}\right) \delta(\mathrm{ppm})$ $158.4,157.1,149.9,128.6,125.1,106.7,99.1,80.1,58.7,53.8,47.6,38.4,28.8$. HRMS (m/z): calculated for $\mathrm{C}_{17} \mathrm{H}_{28} \mathrm{~N}_{5} \mathrm{O}_{4}[\mathrm{M}+\mathrm{H}]^{+} 366.2136$, found: 366.2074 .

Compound S6. A solution of $\mathbf{S 3}(500 \mathrm{mg}, 1.37 \mathrm{mmol})$ and $50 \mathrm{mg}$ of $10 \% \mathrm{Pd} / \mathrm{C}$ in $30 \mathrm{~mL}$ of ethanol $(\mathrm{EtOH})$ was stirred at room temperature under an atmosphere of $\mathrm{H}_{2}$ overnight until all the starting material converted to amine by TLC (10\% MeOH in DCM) and then the $\mathrm{Pd} / \mathrm{C}$ was filtered off. The filtrate was concentrated in vacuo to $\sim 20 \mathrm{~mL}$, and to the mixture was added the amidate $\mathbf{S 5}$ (1.34 g, $6.85 \mathrm{mmol})$. The final solution was then stirred under reflux for $1 \mathrm{~h}$. After cooling down to room temperature, the mixture was quenched with saturated $\mathrm{NH}_{4} \mathrm{Cl}$ and extracted with ethyl acetate. The combined organic layer was washed with brine, dried over anhydrous $\mathrm{Na}_{2} \mathrm{SO}_{4}$ and concentrated in vacuo. The residue was purified by column chromatography (6\% EtOH in DCM) to give $\mathbf{S 6}$ as a grey solid (300 mg, $0.7 \mathrm{mmol}, 51 \%$ ). ${ }^{1} \mathbf{H}$ NMR (400 MHz, DMSO- $\left.d^{6}\right) \delta(\mathrm{ppm}) 12.05(\mathrm{br}, 1 \mathrm{H}), 7.34(\mathrm{~d}, J=8.7$ $\mathrm{Hz}, 1 \mathrm{H}), 6.89-6.93(\mathrm{~m}, 2 \mathrm{H}), 6.70(\mathrm{~m}, 1 \mathrm{H}), 4.11(\mathrm{q}, J=7.1 \mathrm{~Hz}, 2 \mathrm{H}), 3.89(\mathrm{~s}, 2 \mathrm{H}), 3.08(\mathrm{~m}, 6 \mathrm{H}), 2.57(\mathrm{~m}$, 4H), 2.39(m, 2H), 1.38(s, 9H), 1.22(t, $J=7.1 \mathrm{~Hz}, 3 \mathrm{H}) .{ }^{13} \mathbf{C}$ NMR (150 MHz, DMSO-d $\left.d^{6}\right) \delta(\mathrm{ppm}) 168.9$, 155.6, 147.6, 146.4, 137.1, 135.3, 118.4, 113.0, 97.5, 77.5, 60.8, 57.4, 52.9, 50.2, 37.4, 35.1, 28.3, 14.1. HRMS (m/z): calculated for $\mathrm{C}_{22} \mathrm{H}_{34} \mathrm{~N}_{5} \mathrm{O}_{4}[\mathrm{M}+\mathrm{H}]^{+} 432.2605$, found: 432.2536 . 
Compound S8. To a solution of S6 (1 g, $2.32 \mathrm{mmol})$ and $\mathbf{S 7}(473 \mathrm{mg}, 3.48 \mathrm{mmol})$ in $10 \mathrm{~mL}$ of tetrahydrofuran (THF) was added a solution of lithium bis(trimethylsilyl)amide (LiHMDS; $1.0 \mathrm{M}$ in THF, $11.6 \mathrm{~mL}$ ) dropwise at $0{ }^{\circ} \mathrm{C}$. The mixture was stirred at room temperature overnight. To the reaction mixture was added saturated $\mathrm{NH}_{4} \mathrm{Cl}$. The mixture was extracted with ethyl acetate, washed with brine and concentrated in vacuo. The residue was purified by column chromatography $(6 \%-8 \%$ $\mathbf{M e O H}$ in DCM) to give $\mathbf{S 8}$ as a brown solid (560 mg, $1.07 \mathrm{mmol}, 46 \%) .{ }^{\mathbf{1}} \mathbf{H}$ NMR (400 MHz, DMSO$\left.d^{6}\right) \delta(\mathrm{ppm}) 12.74(\mathrm{~m}, 1 \mathrm{H}), 11.61(\mathrm{~s}, 1 \mathrm{H}), 11.38(\mathrm{~m}, 1 \mathrm{H}), 7.74(\mathrm{~m}, 2 \mathrm{H}), 7.18(\mathrm{~m}, 1 \mathrm{H}), 7.43$ 2-7.60(m, 2H), 7.06-7.25(m, 2H), 7.04(dd, $J=14,8 \mathrm{~Hz}, 1 \mathrm{H}), 6.94(\mathrm{~m}, 1 \mathrm{H}), 3.08(\mathrm{~m}, 6 \mathrm{H}), 2.57(\mathrm{~m}, 4 \mathrm{H}), 2.39(\mathrm{t}, J=6.4$ $\mathrm{Hz}, 2 \mathrm{H}), 1.39(\mathrm{~s}, 9 \mathrm{H}) .{ }^{13} \mathrm{C}$ NMR (100 MHz, DMSO- $\left.d^{6}\right) \delta(\mathrm{ppm}) 161.9,161.9,160.2(\mathrm{~d}, J=248.3 \mathrm{~Hz})$, $151.7,151.4,151.3,150.5,147.7,147.4,141.9,139.6,135.3,132.7,132.2,132.0,126.2,117.2,114.1$, 113.0, 112.3, 111.9, 107.9(d, $J=23.6 \mathrm{~Hz}), 103.5,102.7(\mathrm{~d}, J=10.14 \mathrm{~Hz}), 98.2,91.0,90.9,77.6,57.4$, 53.0, 52.9, 50.3, 49.4, 37.4, 28.3. HRMS (m/z): calculated for $\mathrm{C}_{27} \mathrm{H}_{33} \mathrm{FN}_{7} \mathrm{O}_{3}[\mathrm{M}+\mathrm{H}]^{+}$522.2623, found: 522.2556 .

Compound 1a. A solution of $\mathbf{S 8}(1 \mathrm{~g}, 1.91 \mathrm{mmol})$ in $5 \mathrm{~mL}$ of trifluoracetic acid/dichloromethane (TFA/DCM; 30/70) was stirred at room temperature for $1 \mathrm{~h}$, and the solution was concentrated in vacuo to give compound 1a without further purification.

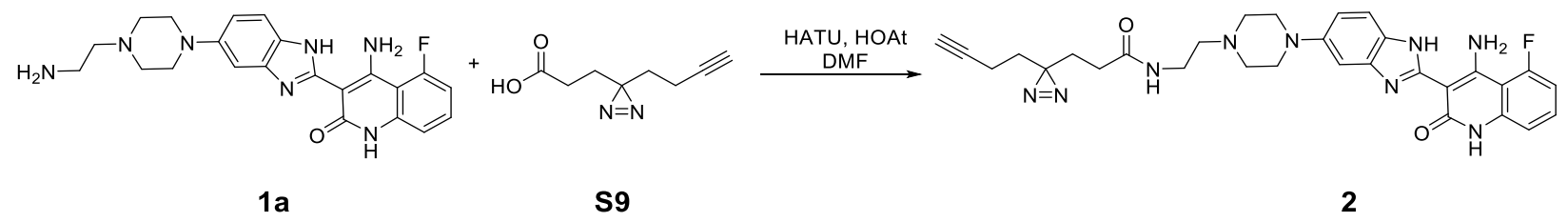

Chem-CLIP Probe 2. A solution of 1a $(2.1 \mathrm{mg}, 0.005 \mathrm{mmol})$, S9 (1.2 mg, $0.0075 \mathrm{mmol})$, HATU (2.9 mg, $0.0075 \mathrm{mmol}$ ), 1-hydroxy-7-azabenzotriazole (HOAt; $1 \mathrm{mg}, 0.0075 \mathrm{mmol}$ ) and triethylamine (TEA; $1.52 \mathrm{mg}, 0.015 \mathrm{mmol}$ ) in $0.2 \mathrm{~mL}$ of DMF was stirred at room temperature for $2 \mathrm{~h}$ in dark. The reaction mixture was then purified by HPLC to afford 2 as a TFA salt. ${ }^{1} \mathbf{H}$ NMR (400 MHz, CD $\left.{ }_{3} \mathrm{OD}\right)$ $\delta(\mathrm{ppm}) 7.53-7.62(\mathrm{~m}, 2 \mathrm{H}), 7.26(\mathrm{~s}, 1 \mathrm{H}), 7.13-7.22(\mathrm{~m}, 2 \mathrm{H}), 6.97-7.05(\mathrm{~m}, 1 \mathrm{H}), 3.55-3.98(\mathrm{~m}, 6 \mathrm{H}), 3.00-$ $3.40(\mathrm{~m}, 6 \mathrm{H}), 2.30(\mathrm{t}, J=2.7 \mathrm{~Hz}, 1 \mathrm{H}), 2.10(\mathrm{t}, J=7.2 \mathrm{~Hz}, 2 \mathrm{H}), 2.04(\mathrm{td}, J=7.4 \mathrm{~Hz}, 2.6 \mathrm{~Hz}, 2 \mathrm{H}), 1.81(\mathrm{t}, J=7.2$ $\mathrm{Hz}, 2 \mathrm{H}), 1.64(\mathrm{t}, J=7.4 \mathrm{~Hz}, 2 \mathrm{H}) .{ }^{13} \mathbf{C} \mathbf{N M R}\left(150 \mathrm{MHz}, \mathrm{CD}_{3} \mathrm{OD}\right) \delta(\mathrm{ppm}) 176.4,163.6,162.3(\mathrm{~d}, J=248.3$ Hz), 154.9, 150.6, 148.5, 141.5, 136.4, 132.0, 134.1(d, J=12.0 Hz), 117.1, 116.0, 113.6, 109.7(d, $J=24.3 \mathrm{~Hz}), 104.4,102.5,91.4,83.6,70.4,58.1,53.7,49.5,35.6,33.3,30.7,29.3,29.0,13.8$. HRMS $(\mathrm{m} / \mathrm{z})$ : calculated for $\mathrm{C}_{30} \mathrm{H}_{33} \mathrm{FN}_{9} \mathrm{O}_{2}[\mathrm{M}+\mathrm{H}]^{+}$570.2736, found: 570.2655 . 


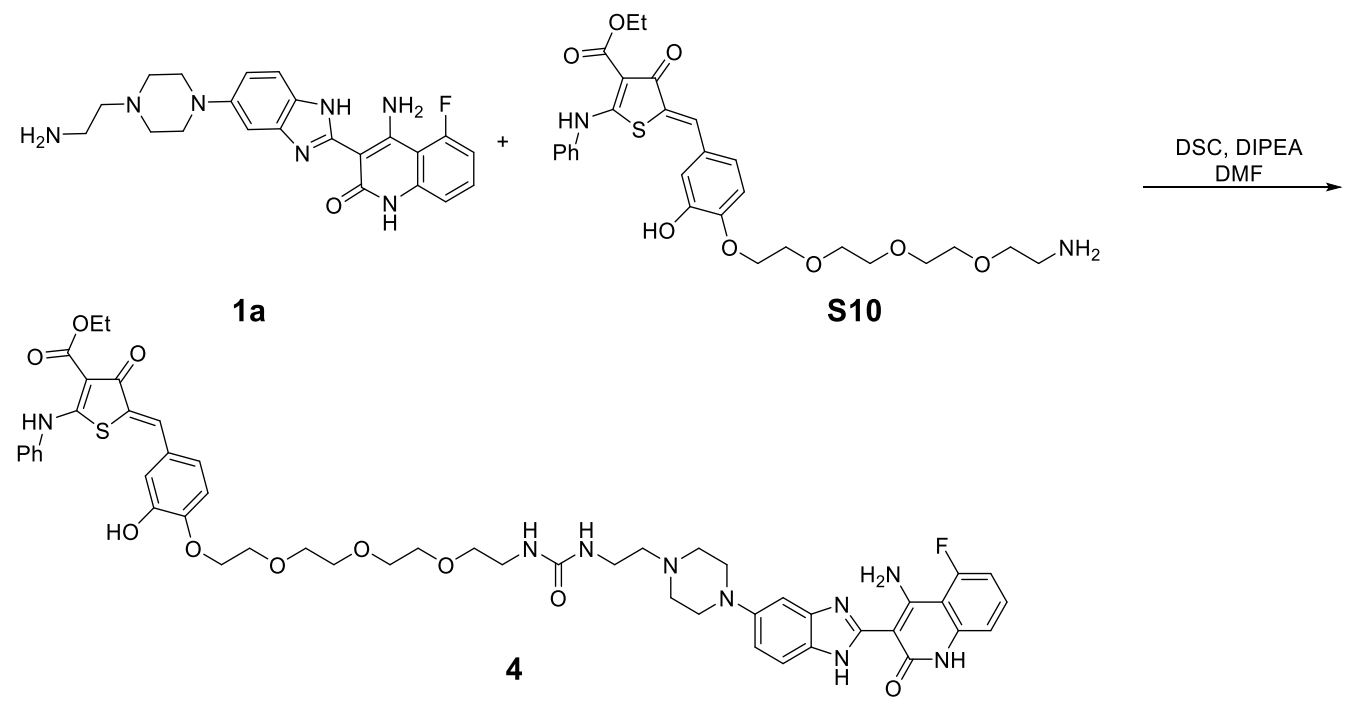

RIBOTAC 4. To a solution of 1a (168 mg, $0.4 \mathrm{mmol}$ ) and $N, N^{\prime}$-disuccinimidyl carbonate (DSC; 123 $\mathrm{mg}, 0.48 \mathrm{mmol}$ ) in $3 \mathrm{~mL}$ of DMF was added $N, N$-diisopropylethylamine (DIPEA; $198 \mathrm{~mL}, 1.2 \mathrm{mmol}$ ), and the mixture was stirred at room temperature After $20 \mathrm{~min}$, compound $\mathbf{S 1 0}{ }^{2}(268 \mathrm{mg}, 0.48 \mathrm{mmol})$ was added to the solution, and the mixture was stirred at room temperature until $1 \mathbf{a}$ was consumed completely, as determined by LC-MS. The final reaction mixture was concentrated in vacuo and purified by HPLC to give 4 as a TFA salt (168 mg, $0.167 \mathrm{mmol}, 42 \%) .{ }^{1} \mathbf{H} \mathbf{~ N M R}\left(400 \mathrm{MHz}, \mathrm{CD}_{3} \mathrm{OD}\right)$ $\delta(\mathrm{ppm}) 7.50-7.65(\mathrm{~m}, 5 \mathrm{H}), 7.40-7.45(\mathrm{~m}, 3 \mathrm{H}), 7.16-7.20(\mathrm{~m}, 3 \mathrm{H}), 6.96-7.05(\mathrm{~m}, 1 \mathrm{H}), 6.87-6.95(\mathrm{~m}, 3 \mathrm{H})$, $4.28(\mathrm{q}, J=7.0 \mathrm{~Hz}, 2 \mathrm{H}), 4.13-4.20(\mathrm{~m}, 2 \mathrm{H}), 3.82-3.88(\mathrm{~m}, 2 \mathrm{H}), 3.48-3.80(\mathrm{~m}, 16 \mathrm{H}), 3.29-3.31(\mathrm{~m}, 2 \mathrm{H})$, $3.27(\mathrm{t}, J=5.1 \mathrm{~Hz}, 2 \mathrm{H}), 2.98-3.26(\mathrm{~m}, 4 \mathrm{H}), 1.33(\mathrm{t}, J=7.1 \mathrm{~Hz}, 3 \mathrm{H}) .{ }^{13} \mathbf{C}$ NMR $\left(100 \mathrm{MHz}, \mathrm{CD}_{3} \mathrm{OD}\right) \delta$ (ppm) 184.2, 177.6, 166.8, 162.9, 162.2 (d, $J=249.2 \mathrm{~Hz}), 161.2,161.9,150.1,149.2,148.2$, 141.9, $138.7,134.5(\mathrm{~d}, J=12.8 \mathrm{~Hz}), 132.8,130.9,129.4,128.4,126.1,125.9,124.9,117.8,117.6,115.6,114.2$, $113.8,109.8(\mathrm{~d}, J=24.2 \mathrm{~Hz}), 101.5,98.8,71.6,71.4,71.2,70.5,69.3,61.4,59.9,53.5,36.6,14.8$. HRMS (m/z): calculated for $\mathrm{C}_{51} \mathrm{H}_{57} \mathrm{FN}_{9} \mathrm{O}_{10} \mathrm{~S}[\mathrm{M}+\mathrm{H}]^{+} 1006.3928$, found: 1006.3857 .
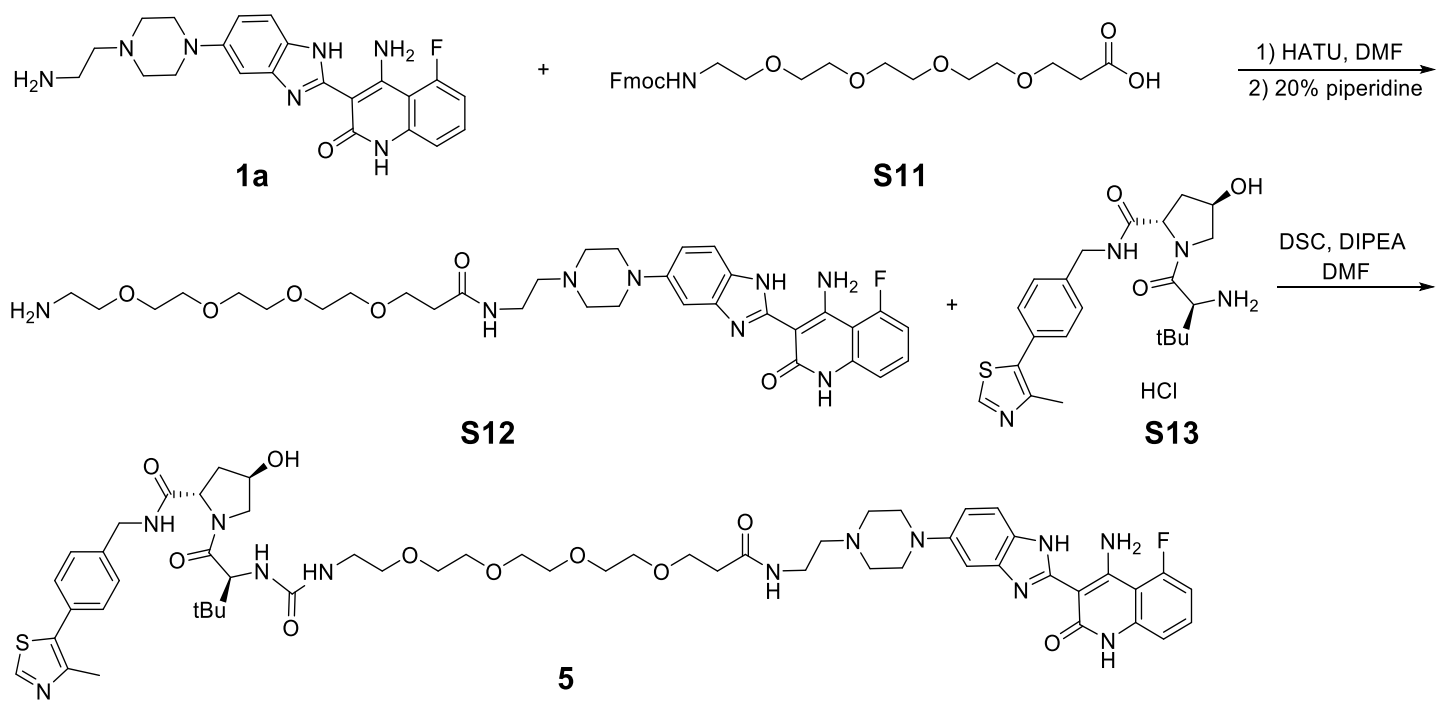

PROTAC 5. A solution of 1a (14 mg, $0.33 \mathrm{mmol})$, S11 (16 mg, $0.033 \mathrm{mmol})$, and 1[bis(dimethylamino)methylene]-1H-1,2,3-triazolo[4,5-b]pyridinium 3-oxid hexafluorophosphate 
(HATU; $15.2 \mathrm{mg}, 0.04 \mathrm{mmol}$ ) in $0.5 \mathrm{~mL}$ of DMF was stirred at room temperature for $30 \mathrm{~min}$. Then, $0.1 \mathrm{~mL}$ of piperidine was added to the mixture. The mixture was stirred at room temperature for another $30 \mathrm{~min}$ and then concentrated in vacuo. To the final slurry was added DSC (9.2 mg, 0.036 mmol) and DIPEA (55 mL, $0.3 \mathrm{mmol})$, and the mixture was stirred at room temperature for $20 \mathrm{~min}$, followed by the addition of $\mathbf{S 1 3}(17 \mathrm{mg}, 0.036 \mathrm{mmol})$. The mixture was stirred at room temperature for $24 \mathrm{~h}$. The final mixture was purified by HPLC to give PROTAC 5 as a TFA salt $(2.3 \mathrm{mg}, 0.002$ mmol, 6\%). ${ }^{1} \mathbf{H}$ NMR $\left(600 \mathrm{MHz}, \mathrm{CD}_{3} \mathrm{OD}\right) \delta(\mathrm{ppm})$ 8.94(s, 1H), 7.64(d, $\left.J=8.9 \mathrm{~Hz}, 1 \mathrm{H}\right), 7.55-7.63(\mathrm{~m}$, $1 \mathrm{H}), 7.44(\mathrm{~d}, J=8.9 \mathrm{~Hz}, 2 \mathrm{H}), 7.37(\mathrm{~d}, J=8.4 \mathrm{~Hz}, 2 \mathrm{H}), 7.28(\mathrm{~d}, J=2.0 \mathrm{~Hz}, 1 \mathrm{H}), 7.25(\mathrm{dd}, J=8.9 \mathrm{~Hz}, 2.2 \mathrm{~Hz}$, $1 \mathrm{H}), 7.18(\mathrm{~d}, J=8.3 \mathrm{~Hz}, 1 \mathrm{H}), 6.99-7.05(\mathrm{~m}, 1 \mathrm{H}), 4.58(\mathrm{t}, J=7.7 \mathrm{~Hz}, 2 \mathrm{H}), 4.47-4.53(\mathrm{~m}, 2 \mathrm{H}), 4.43(\mathrm{~s}, 1 \mathrm{H})$, $4.36(\mathrm{~d}, J=15.5 \mathrm{~Hz}, 1 \mathrm{H}), 3.72-4.00(\mathrm{~m}, 7 \mathrm{H}), 3.52-3.70(\mathrm{~m}, 15 \mathrm{H}), 3.47(\mathrm{~m}, 2 \mathrm{H}), 3.40(\mathrm{~m}, 2 \mathrm{H}), 3.27(\mathrm{~m}, 2 \mathrm{H})$, $2.52(\mathrm{t}, J=5.7 \mathrm{~Hz}, 2 \mathrm{H}), 2.45(\mathrm{~s}, 3 \mathrm{H}), 2.22(\mathrm{~m}, 1 \mathrm{H}), 2.08(\mathrm{~m}, 1 \mathrm{H}), 1.03(\mathrm{~s}, 9 \mathrm{H}) .{ }^{13} \mathrm{C}$ NMR $(150 \mathrm{MHz}$, $\left.\mathrm{CD}_{3} \mathrm{OD}\right) \delta(\mathrm{ppm}) 176.1,174.5,173.7,162.2(\mathrm{~d}, J=248.6 \mathrm{~Hz}), 160.8,160.5,155.3,153.1,149.1,148.5$, $140.4,134.5(\mathrm{~d}, J=12.0 \mathrm{~Hz}), 133.7,131.2,130.3,129.0,117.7,115.9,113.8,109.8(\mathrm{~d}, J=23.8 \mathrm{~Hz})$, 104.3, 101.9, 90.9, 71.5, 71.4, 71.3, 71.1, 67.9, 60.9, 59.6, 58.5, 58.0, 53.7, 43.7, 41.0, 39.0, 37.3, 36.6, 35.8, 27.0, 15.6. MALDI $(\mathrm{m} / \mathrm{z})$ : calculated for $\mathrm{C}_{56} \mathrm{H}_{74} \mathrm{FN}_{12} \mathrm{O}_{10} \mathrm{~S}[\mathrm{M}+\mathrm{H}]^{+} 1125.5350$, found: 1125.5300 .
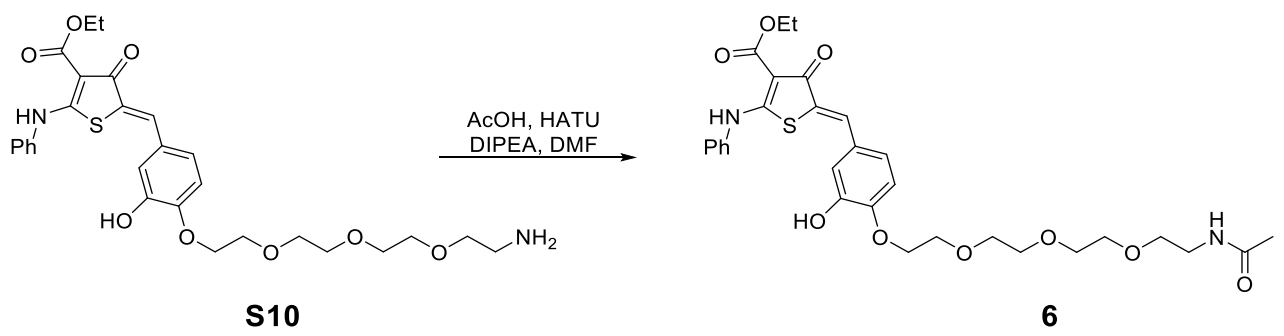

Compound 6. To a solution of HATU ( $5.7 \mathrm{mg}, 0.015 \mathrm{mmol})$ and DIPEA ( $5 \mathrm{uL}, 0.03 \mathrm{mmol})$ in 0.5 $\mathrm{mL}$ of DMF was added $10 \mathrm{~mL}$ of acetic acid solution (AcOH; $1 \mathrm{M}$ in DMF). The mixture was stirred at room temperature for $10 \mathrm{~min}$, followed by the addition of $\mathbf{S 1 0}(5.6 \mathrm{mg}, 0.01 \mathrm{mmol})$. After stirring at room temperature overnight, the reaction was purified by HPLC to afford 6 as a TFA salt (3.4 mg, $0.0056 \mathrm{mmol}, 56 \%) .{ }^{1} \mathbf{H}$ NMR $\left(600 \mathrm{MHz}, \mathrm{CD}_{3} \mathrm{OD}\right)$ 7.66(s, 1H), 7.53-7.58(m, 2H), 7.44-7.53(m, 3H), 6.99-7.07(m, 3H), 4.38(q, J=7.1 Hz, 2H), 4.18-4.23(m, 2H), 3.82-3.90(m, 2H), 3.69-3.74(m, 2H), 3.65-3.68(m, 2H), 3.56-3.60(m, 2H), 3.50(t, J=5.6 Hz, 2H), 1.91(s, 3H), 1.39(t, J=7.1 Hz, 3H). ${ }^{13} \mathrm{C}$ NMR $\left(150 \mathrm{MHz}, \mathrm{CD}_{3} \mathrm{OD}\right) \delta(\mathrm{ppm}) 183.1,176.9,172.0,148.8,147.1,137.4,131.7,129.6,128.1$, $127.1,125.0,124.9,123.4,116.1,113.0,97.5,70.2,70.1,69.8,69.2,69.1,67.9,60.0,39.1,21.1,13.4$. HRMS (m/z): calculated for $\mathrm{C}_{30} \mathrm{H}_{37} \mathrm{~N}_{2} \mathrm{O}_{9} \mathrm{~S}[\mathrm{M}+\mathrm{H}]^{+}$601.2214, found: 601.2122. 


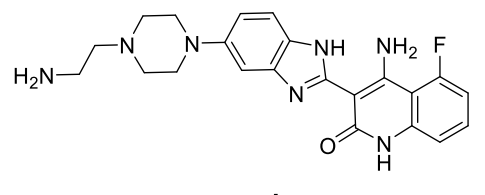

$1 \mathrm{a}$

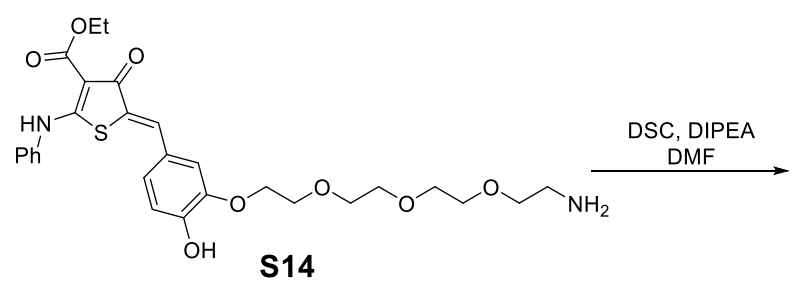

S14

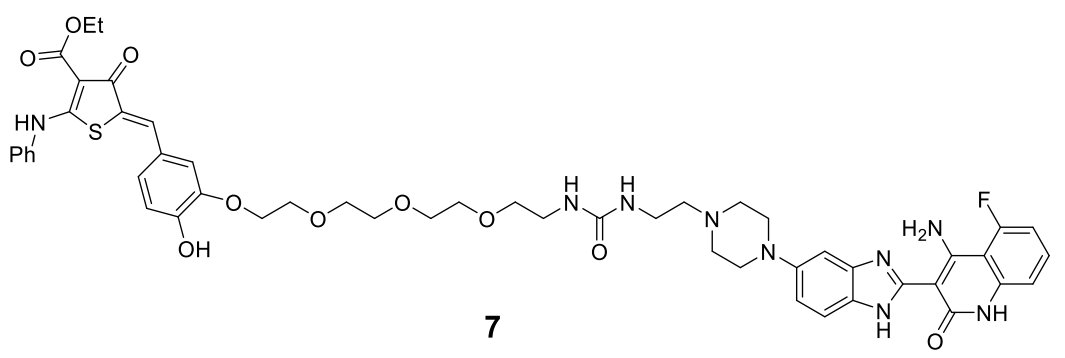

Compound 7. To a solution of 1a $(2.1 \mathrm{mg}, 0.005 \mathrm{mmol})$ and DSC ( $3.8 \mathrm{mg}, 0.015 \mathrm{mmol})$ in $0.2 \mathrm{~mL}$ of DMF was added DIPEA $(2.5 \mathrm{~mL}, 0.015 \mathrm{mmol})$, and the mixture was stirred at room temperature. After $20 \mathrm{~min}$, compound $\mathbf{S 1 4}{ }^{2}(5.6 \mathrm{mg}, 0.01 \mathrm{mmol})$ was added to the solution, and the mixture was stirred at room temperature overnight. The final reaction mixture was concentrated in vacuo and purified by HPLC to give 7 as a TFA salt $(1.0 \mathrm{mg}, 0.001 \mathrm{mmol}, 20 \%) .{ }^{1} \mathbf{H} \mathbf{~ N M R}\left(400 \mathrm{MHz}, \mathrm{CD}_{3} \mathrm{OD}\right)$ $\delta(\mathrm{ppm}) 7.48-7.63(\mathrm{~m}, 5 \mathrm{H}), 7.38-7.45(\mathrm{~m}, 3 \mathrm{H}), 7.06-7.16(\mathrm{~m}, 3 \mathrm{H}), 6.95-7.05(\mathrm{~m}, 3 \mathrm{H}), 6.81(\mathrm{~d}, J=8.3 \mathrm{~Hz}$, $1 \mathrm{H}), 4.31(\mathrm{q}, J=7.1 \mathrm{~Hz}, 2 \mathrm{H}), 4.08-4.14(\mathrm{~m}, 2 \mathrm{H}), 3.57-3.86(\mathrm{~m}, 14 \mathrm{H}), 3.50-3.56(\mathrm{~m}, 4 \mathrm{H}), 3.0-3.3(\mathrm{~m}, 8 \mathrm{H})$, $1.35(\mathrm{t}, J=7.1 \mathrm{~Hz}, 3 \mathrm{H}) .{ }^{13} \mathbf{C}$ NMR $\left(150 \mathrm{MHz}, \mathrm{CD}_{3} \mathrm{OD}\right) \delta(\mathrm{ppm}) 184.4,171.5,166.9,163.5,162.4(\mathrm{~d}$, $J=248.4 \mathrm{~Hz}), 162.2$, , 154.9, 150.7, 148.5, 148.3, 141.5, 138.7, 134.1(d, $J=12.0 \mathrm{~Hz}), 133.2,130.9$, 129.3, 126.9, 125.8, 125.6, 125.5, 117.2, 117.1, 113.6, 109.7(d, $J=24.0 \mathrm{~Hz}), 104.4,102.2$, 98.9, 91.3, 71.6, 71.4, 71.3, 71.2, 70.7, 69.6, 61.4, 60.0, 53.6, 49.6, 41.2, 36.6, 14.8. HRMS (m/z): calculated for $\mathrm{C}_{51} \mathrm{H}_{57} \mathrm{FN}_{9} \mathrm{O}_{10} \mathrm{~S}[\mathrm{M}+\mathrm{H}]^{+}$1006.3928, found: 1006.3837 .

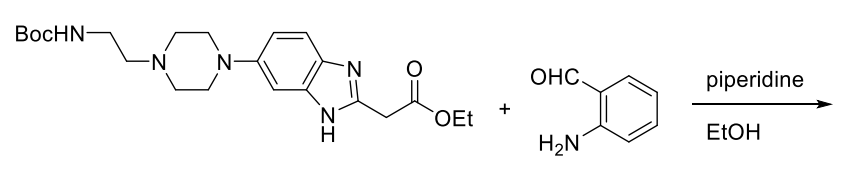

S6

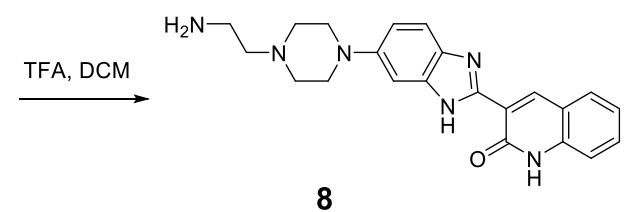

Compound S15: To a solution of 2-aminobenzaldehyde (140 mg, $1.16 \mathrm{mmol})$ and $\mathbf{S 6}$ (500 $\mathrm{mg}, 1.16$ $\mathrm{mmol})$ in EtOH $(6 \mathrm{~mL})$ was added piperidine $(0.114 \mathrm{~mL}, 1.16 \mathrm{mmol})$. The solution was heated at 70 ${ }^{\circ} \mathrm{C}$ overnight. After cooling to room temperature, the precipitate was collected by filtration, washed with EtOH, and dried under vacuum to afford $\mathbf{S 1 5}(419 \mathrm{mg}, 0.858 \mathrm{mmol}, 74 \%$ yield) as dark yellow solid. ${ }^{1}$ H NMR (400 MHz, DMSO- $\left.d^{6}\right) \delta(\mathrm{ppm}) 12.4-12.1(\mathrm{~m}, 2 \mathrm{H}), 9.02-9.00(\mathrm{~m}, 1 \mathrm{H}), 7.94-7.91(\mathrm{~m}$, $1 \mathrm{H}), 7.59-7.41(\mathrm{~m}, 3 \mathrm{H}), 7.30-7.08(\mathrm{~m}, 2 \mathrm{H}), 6.98-6.96(\mathrm{~m}, 1 \mathrm{H}), 6.70(\mathrm{~m}, 1 \mathrm{H}), 3.10(\mathrm{~m}, 6 \mathrm{H}), 2.57(\mathrm{~m}, 4 \mathrm{H})$, 
2.40-2.39(m, 2H), 1.38(s, 9H). ${ }^{13} \mathbf{C}$ NMR (150 MHz, DMSO- $\left.d^{6}\right) \delta(\mathrm{ppm}) 160.9,160.8,155.6,148.0$, $147.8,147.4,146.5,143.7,138.5,138.4,138.3,137.7,137.2,135.2,131.4,131.2,128.9,128.9,122.6$, $120.3,120.2,119.3,119.2,118.4,115.2,115.0,114.1,112.7,104.0,98.4,77.5,57.4,53.0,52.9,50.3$, 49.9, 37.4, 28.3. HRMS (m/z): calculated for $\mathrm{C}_{27} \mathrm{H}_{32} \mathrm{~N}_{6} \mathrm{O}_{3}[\mathrm{M}-\mathrm{H}]^{-} 487.2463$, found: 487.2459.

Compound 8: A solution of $\mathbf{S 1 5}(0.419 \mathrm{~g}, 0.85 \mathrm{mmol})$ in $5 \mathrm{~mL}$ of $30 / 70 \mathrm{TFA} / \mathrm{DCM}$ was stirred at room temperature for $1 \mathrm{~h}$ and then concentrated in vacuo to give $\mathbf{8}$, which was used without further purification. ${ }^{1} \mathrm{H}$ NMR $\left(400 \mathrm{MHz}, \mathrm{CD}_{3} \mathrm{OD}\right) \delta(\mathrm{ppm}) 8.82(\mathrm{~s}, 1 \mathrm{H}), 7.74(\mathrm{~d}, J=7.8 \mathrm{~Hz}, 1 \mathrm{H}), 7.65-7.61(\mathrm{~m}$, 2H), 7.32-7.24(m, 3H), 7.17(s, 1H), 3.56-3.55(m, 4H), 3.52-3.51(m, 8H). ${ }^{13} \mathbf{C}$ NMR (100 MHz, $\left.\mathrm{CD}_{3} \mathrm{OD}\right) \delta(\mathrm{ppm}) 160.9,150.7,145.5,143.8,140.9,135.4,133.5,130.9,126.7,124.9,119.8,119.4$, $116.8,115.8,113.9,100.3,54.5,53.5,48.2,35.3$. HRMS (m/z): calculated for $\mathrm{C}_{22} \mathrm{H}_{24} \mathrm{~N}_{6} \mathrm{O}[\mathrm{M}-\mathrm{H}]^{-}$ 387.1939, found: 387.1956 .
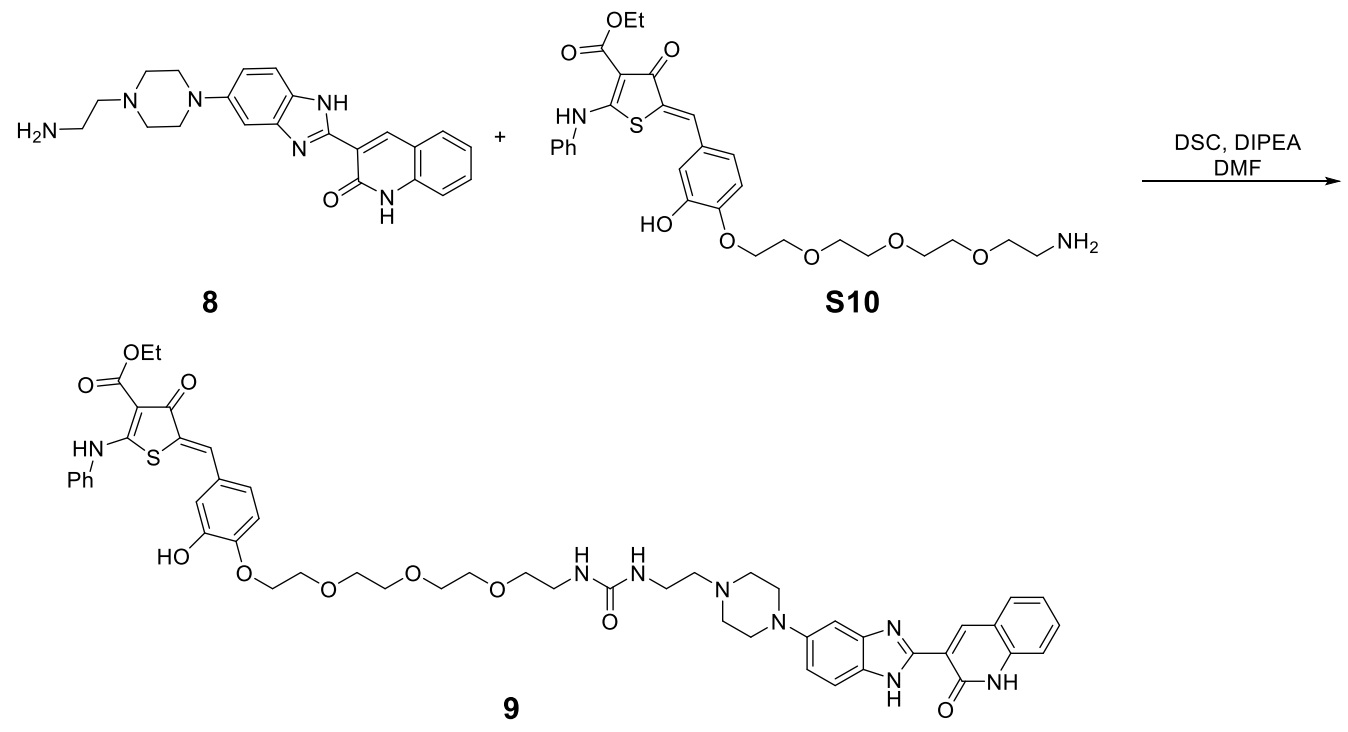

Compound 9: To a solution of 9 (20 mg, $0.051 \mathrm{mmol})$ and $N, N^{\prime}$-disuccinimidyl carbonate (DSC; 19.8 $\mathrm{mg}, 0.077 \mathrm{mmol}$ ) in $1 \mathrm{~mL}$ of DMF was added $N, N$-diisopropylethylamine (DIPEA; $44.8 \mu \mathrm{L}, 0.26$ $\mathrm{mmol})$, and the mixture was stirred at room temperature for $20 \mathrm{~min}$. Next, $\mathbf{S 1 0}^{2}(28.8 \mathrm{mg}, 0.051$ $\mathrm{mmol}$ ) was added to the solution, and the mixture was stirred at room temperature overnight. This final reaction mixture was concentrated in vacuo and purified by HPLC to give $\mathbf{1 0}$ as a TFA salt $(2.2 \mathrm{mg}$, $0.0017 \mathrm{mmol}, 3.2 \%) .{ }^{1} \mathbf{H}$ NMR (600 MHz, DMSO- $\left.d^{6}\right) \delta(\mathrm{ppm}) 12.5(\mathrm{br}, 1 \mathrm{H}), 11.2(\mathrm{~s}, 1 \mathrm{H}), 9.70(\mathrm{br}$, $1 \mathrm{H}), 9.44(\mathrm{br}, 1 \mathrm{H}), 9.03(\mathrm{~s}, 1 \mathrm{H}), 7.92(\mathrm{~d}, J=7.7 \mathrm{~Hz}, 1 \mathrm{H}), 7.64-7.63(\mathrm{~m}, 2 \mathrm{H}), 7.55-7.43(\mathrm{~m}, 7 \mathrm{H}), 7.31(\mathrm{t}$, $J=7.5 \mathrm{~Hz}, 1 \mathrm{H}), 7.24(\mathrm{br}, 1 \mathrm{H}), 7.11-7.10(\mathrm{~m}, 1 \mathrm{H}), 7.02-7.00(\mathrm{~m}, 1 \mathrm{H}), 6.98-6.97(\mathrm{~m}, 2 \mathrm{H}), 6.33-6.29(\mathrm{~m}$, $2 \mathrm{H}), 4.27(\mathrm{q}, J=7.1 \mathrm{~Hz}, 2 \mathrm{H}), 4.11-4.10(\mathrm{~m}, 2 \mathrm{H}), 3.79-3.77(\mathrm{~m}, 2 \mathrm{H}), 3.74-3.73(\mathrm{~m}, 2 \mathrm{H}), 3.70-3.69(\mathrm{~m}, 2 \mathrm{H})$, $3.59-3.57(\mathrm{~m}, 2 \mathrm{H}), 3.54-3.49(\mathrm{~m}, 8 \mathrm{H}), 3.22(\mathrm{~m}, 5 \mathrm{H}), 3.19-3.16(\mathrm{~m}, 2 \mathrm{H}), 3.03-3.00(\mathrm{~m}, 2 \mathrm{H}) 1.29(\mathrm{t}, J=7.1$ $\mathrm{Hz}, 3 \mathrm{H}) .{ }^{13} \mathrm{C}$ NMR $\left(150 \mathrm{MHz}, \mathrm{CD}_{3} \mathrm{OD}\right) \delta(\mathrm{ppm}) 184.1,177.4,166.8,162.4,150.3,150.1,148.2$, 143.2, 141.0, 138.6, 135.2, 132.7, 131.0, 130.9, 129.4, 128.1, 126.0, 125.8, 125.0, 124.8, 120.2, 119.1, 117.6, 117.0, 114.2, 98.7, 71.6, 71.6 71.4, 71.2, 70.5, 69.3, 61.4, 60.0, 53.4, 49.8, 40.4, 36.7, 14.8 . HRMS (m/z): calculated for $\mathrm{C}_{51} \mathrm{H}_{56} \mathrm{~N}_{8} \mathrm{O}_{10} \mathrm{~S}$ [M-H] ${ }^{-} 971.3767$, found: 971.3761 . 


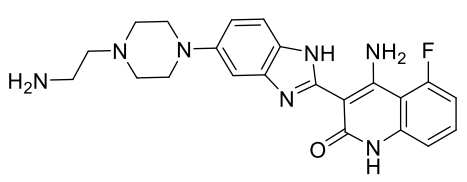

$1 \mathbf{a}$

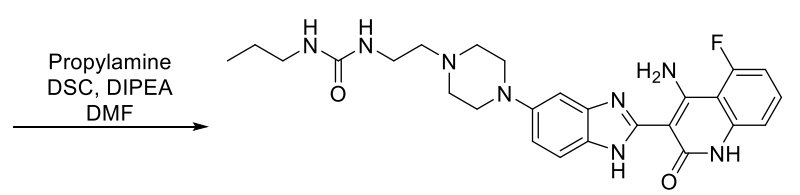

10

Compound 10. A solution of 1a (12.8 mg, $0.03 \mathrm{mmol})$, DSC (8.4 mg, $0.033 \mathrm{mmol})$ and DIPEA (15 $\mathrm{mL}, 0.09 \mathrm{mmol}$ ) was stirred at room temperature for $10 \mathrm{~min}$, followed by the addition of propylamine $(1.8 \mathrm{mg}, 0.03 \mathrm{mmol})$. The mixture was stirred at room temperature overnight and then purified by HPLC to give $\mathbf{1 0}$ as a TFA salt $(3.1 \mathrm{mg}, 0.006 \mathrm{mmol}, 20 \%)$. ${ }^{1} \mathbf{H}$ NMR (400 MHz, CD $\left.{ }_{3} \mathrm{OD}\right)$ 7.557.78(m, 2H), 7.22-7.28(m, 2H), 7.14(d, J=8.4 Hz, 1H), 6.96-7.05(m, 1H), 3.68-4.02(m, 4H), 3.56(m, $2 \mathrm{H}), 3.33(\mathrm{~m}, 2 \mathrm{H}), 3.14-3.31(\mathrm{~m}, 4 \mathrm{H}), 3.10(\mathrm{t}, J=7.0 \mathrm{~Hz}, 2 \mathrm{H}), 1.45-1.58(\mathrm{~m}, 2 \mathrm{H}), 0.93(\mathrm{t}, J=7.4 \mathrm{~Hz}, 3 \mathrm{H})$. ${ }^{13}$ C NMR (100 MHz, CD $\left.{ }_{3} \mathrm{OD}\right) \delta(\mathrm{ppm}) 161.7,160.8(\mathrm{~d}, J=248.8 \mathrm{~Hz}), 160.7,154.0,148.1,146.9,140.5$, 133.7, 133.2(d, $J=12.0 \mathrm{~Hz}), 128.4,116.6,114.3,112.4,108.4(\mathrm{~d}, J=24.1 \mathrm{~Hz}),. 102.8(\mathrm{~d}, J=10.7 \mathrm{~Hz})$, 100.3 , 89.3, 58.4, 52.1, 41.7, 35.1, 22.9, 10.2. HRMS (m/z): calculated for $\mathrm{C}_{26} \mathrm{H}_{32} \mathrm{FN}_{8} \mathrm{O}_{2}[\mathrm{M}+\mathrm{H}]^{+}$ 507.2627, found: 507.2566 . 
NMR spectra

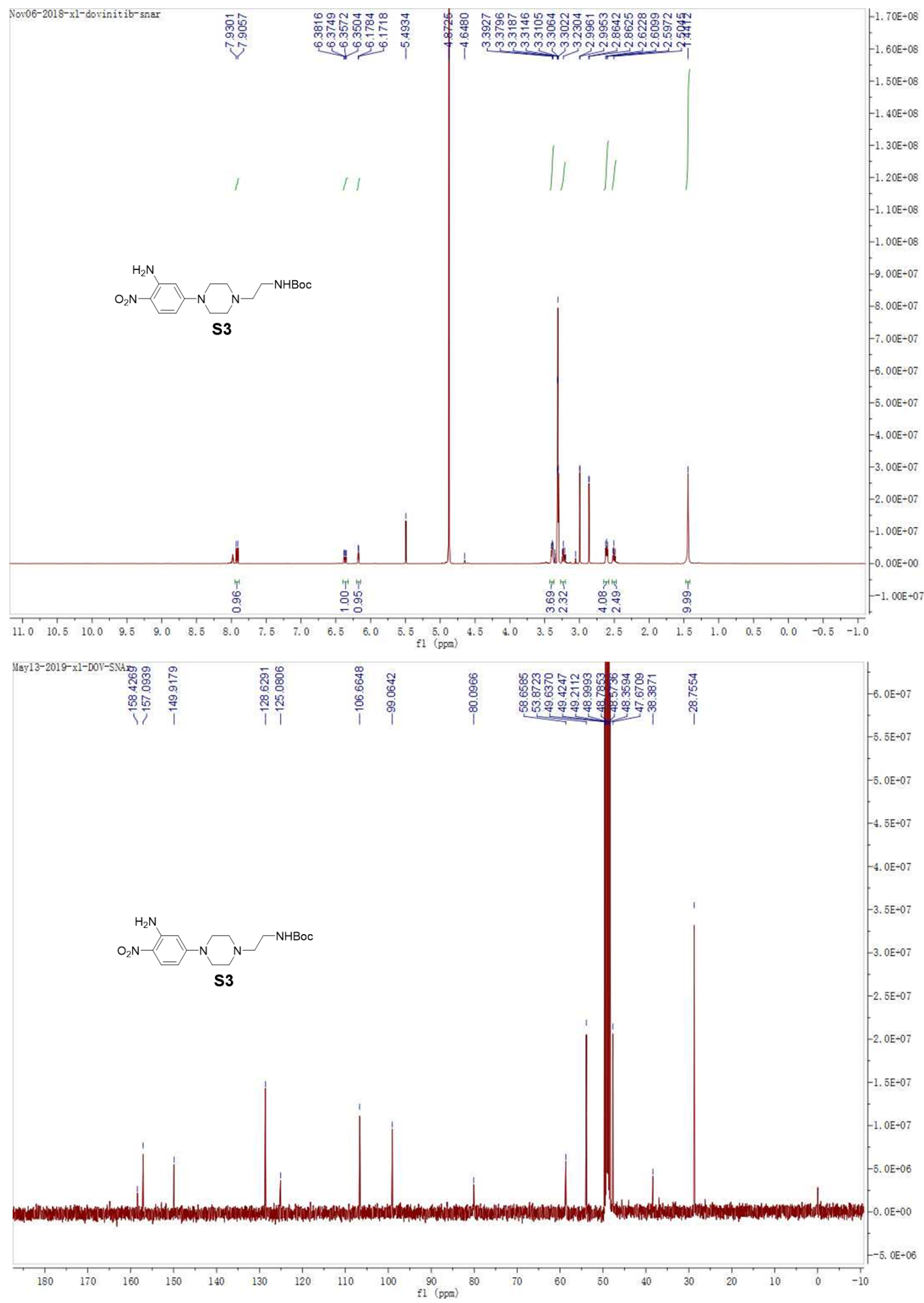




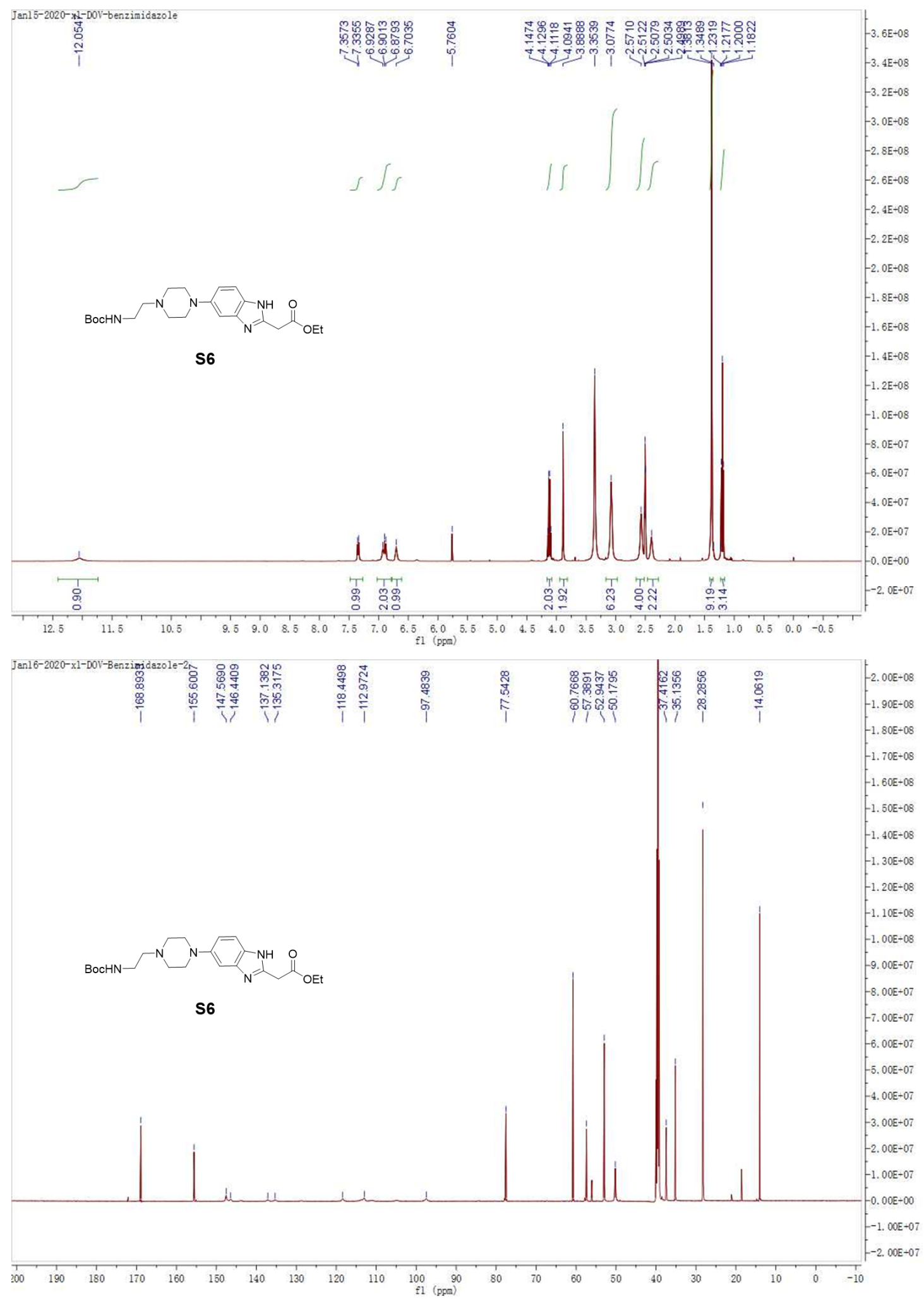




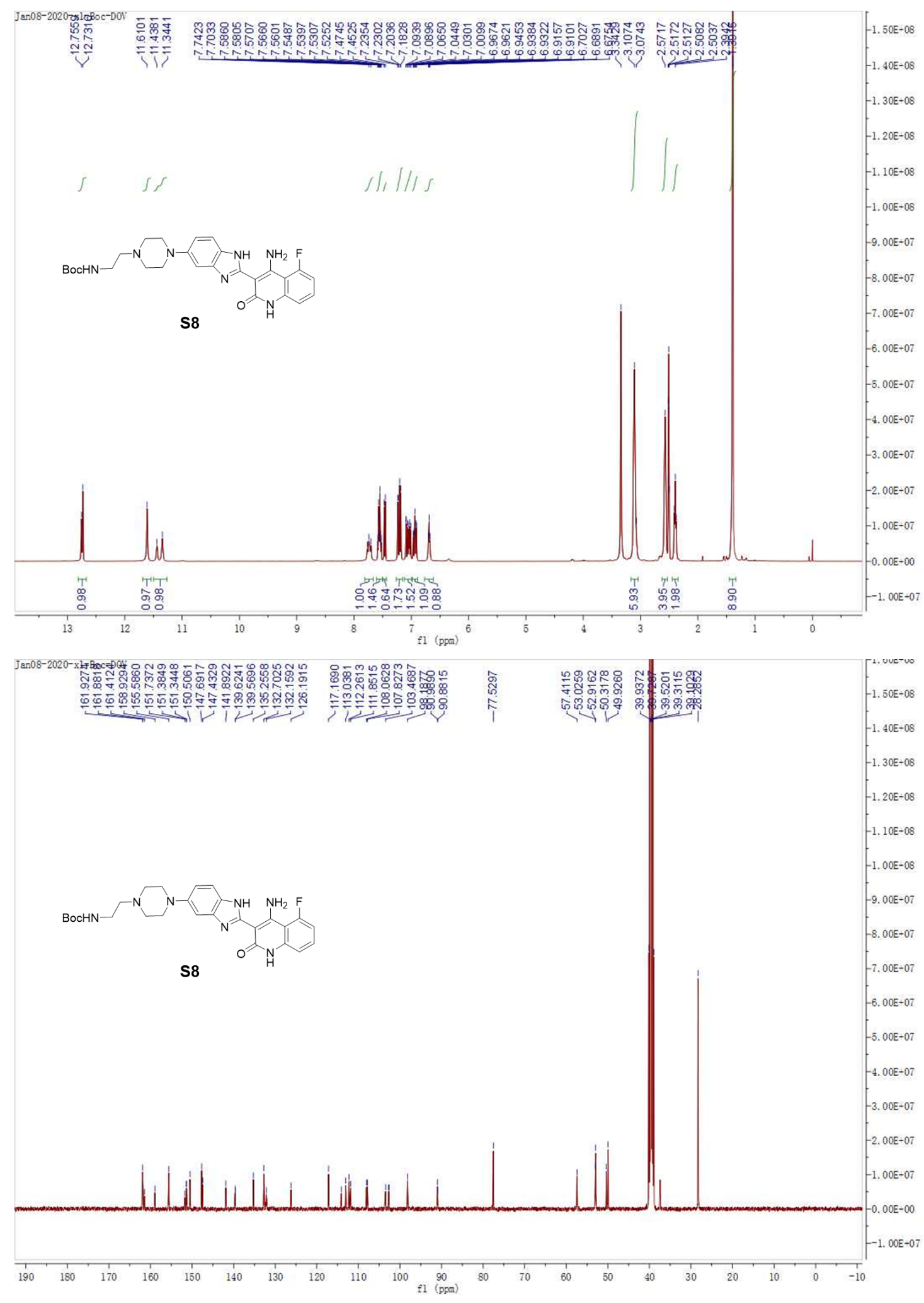




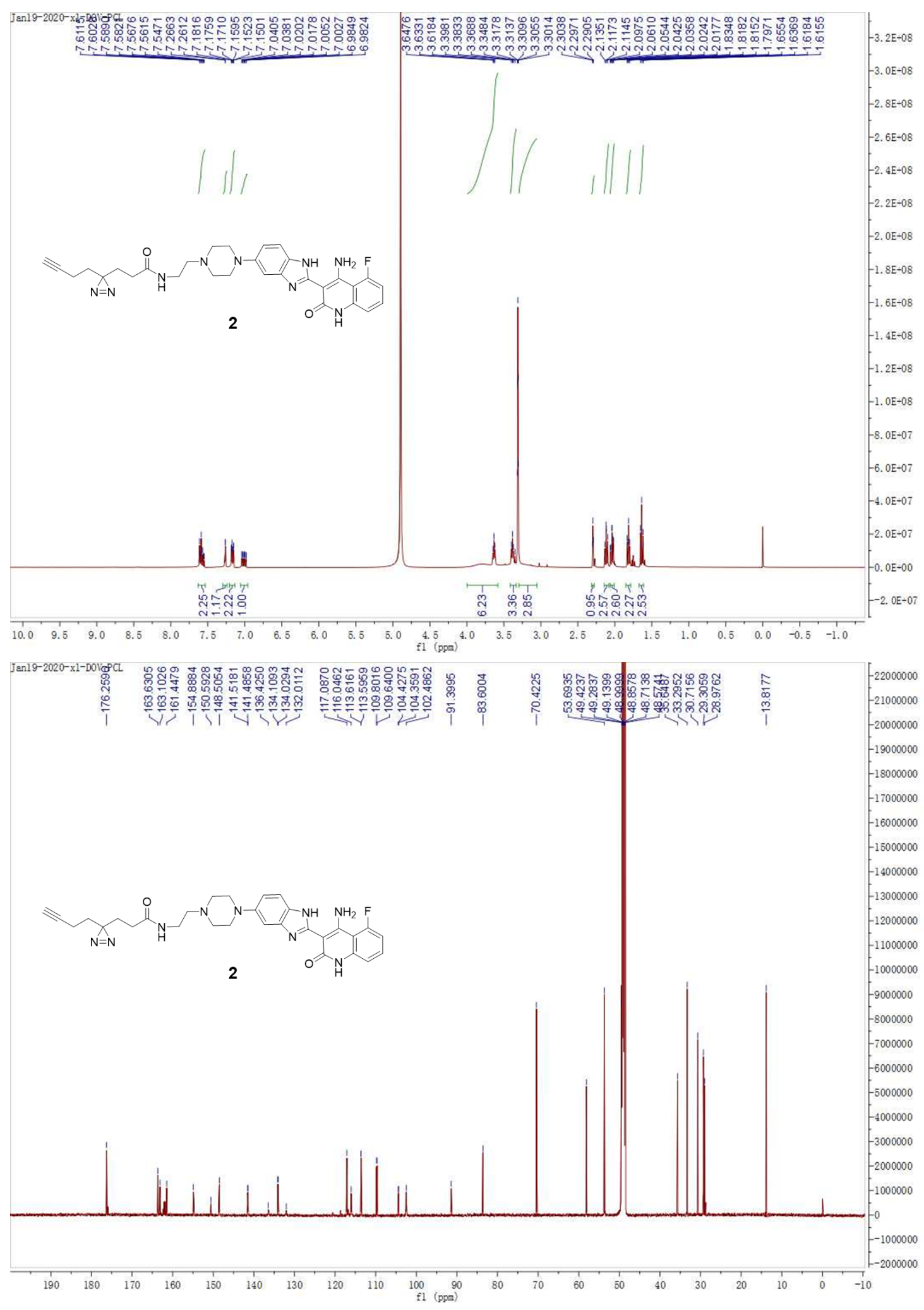




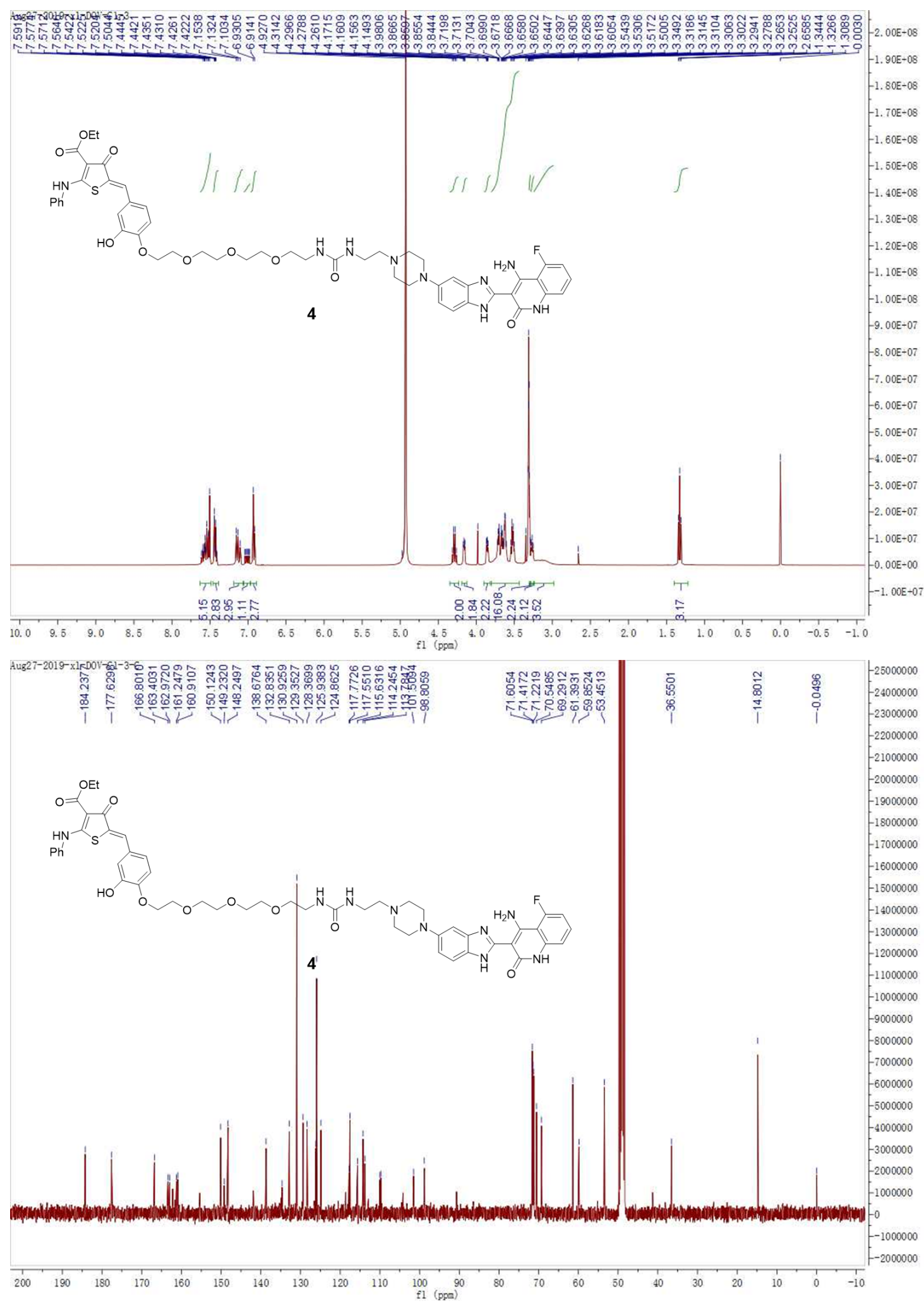




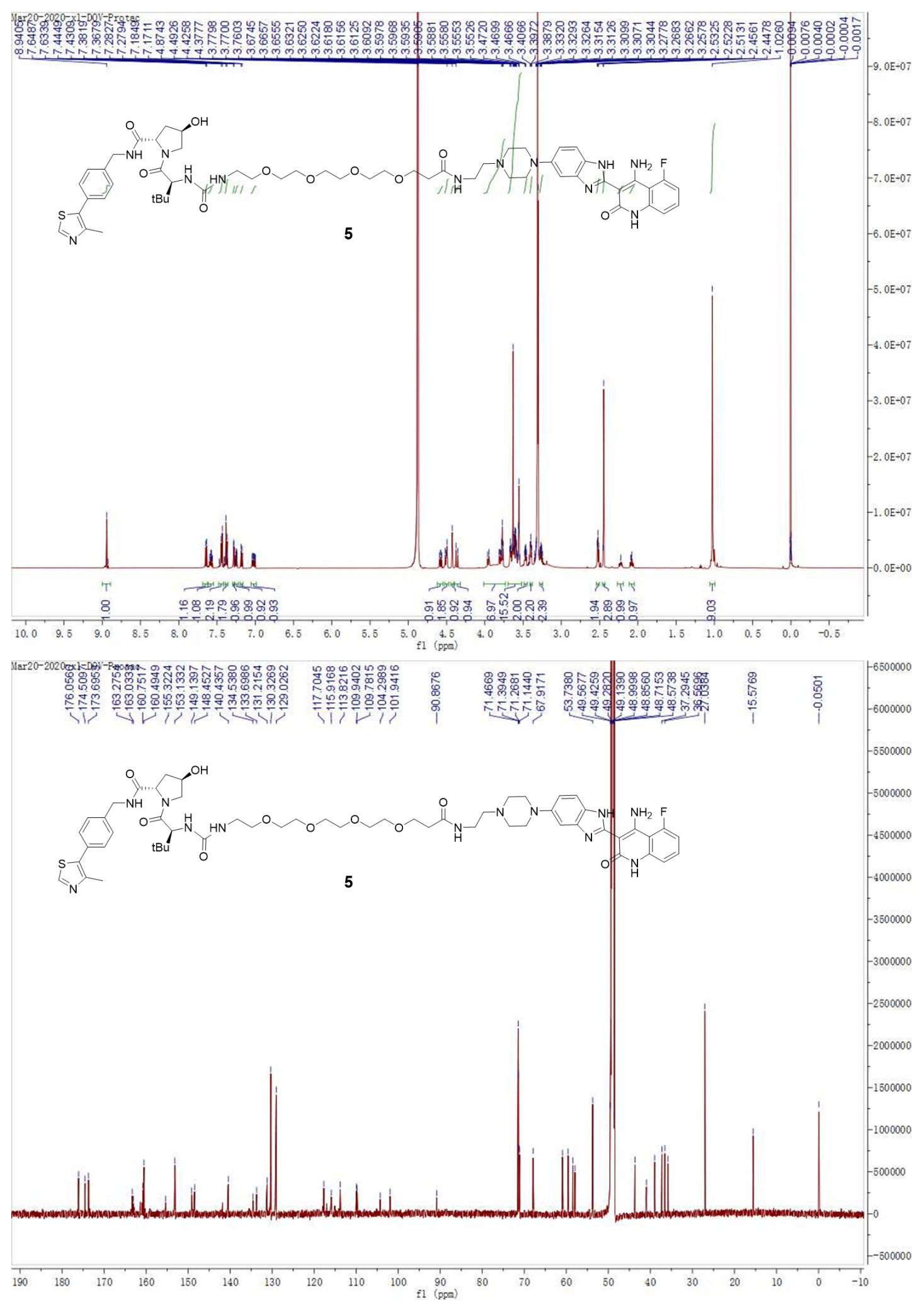




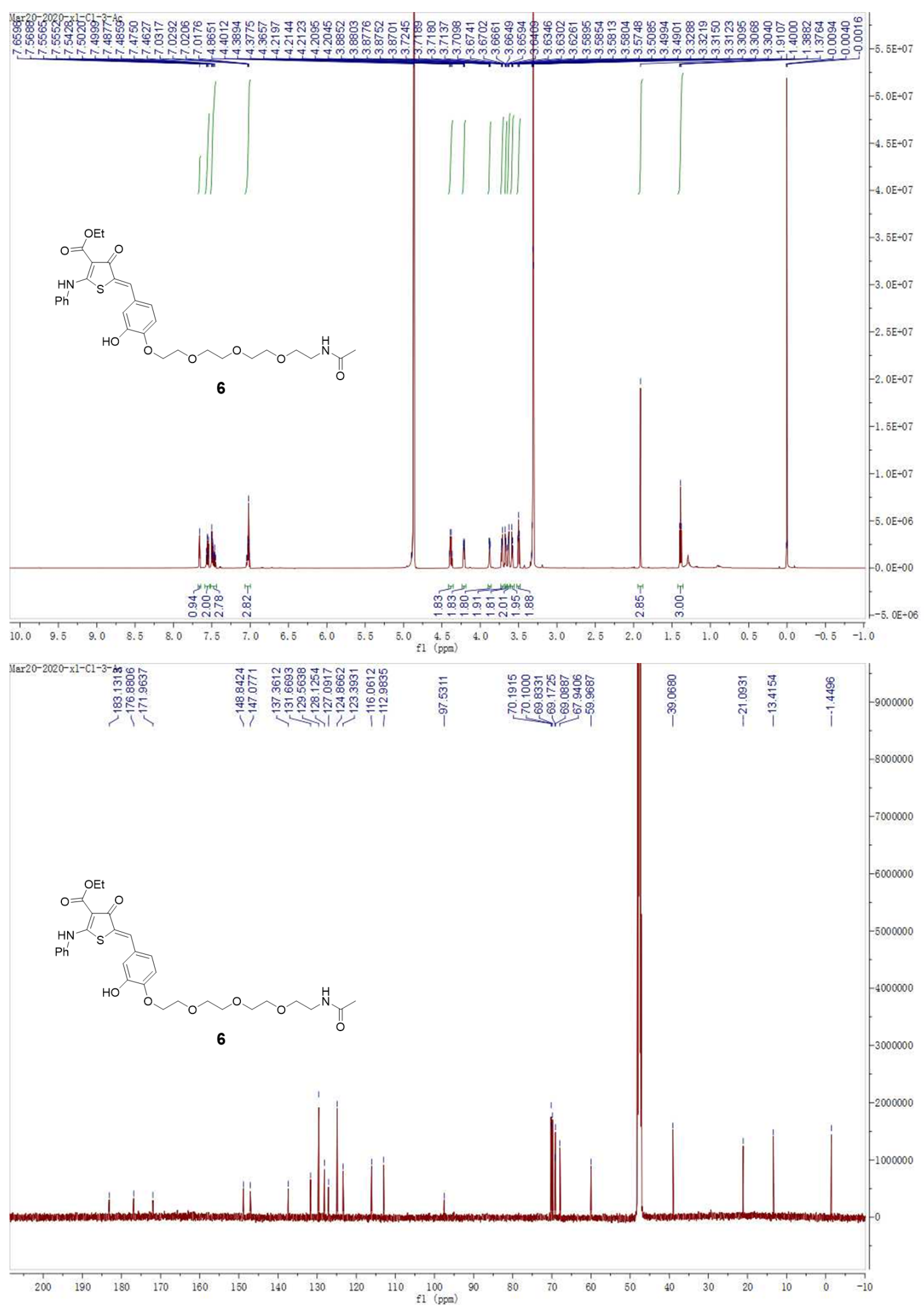



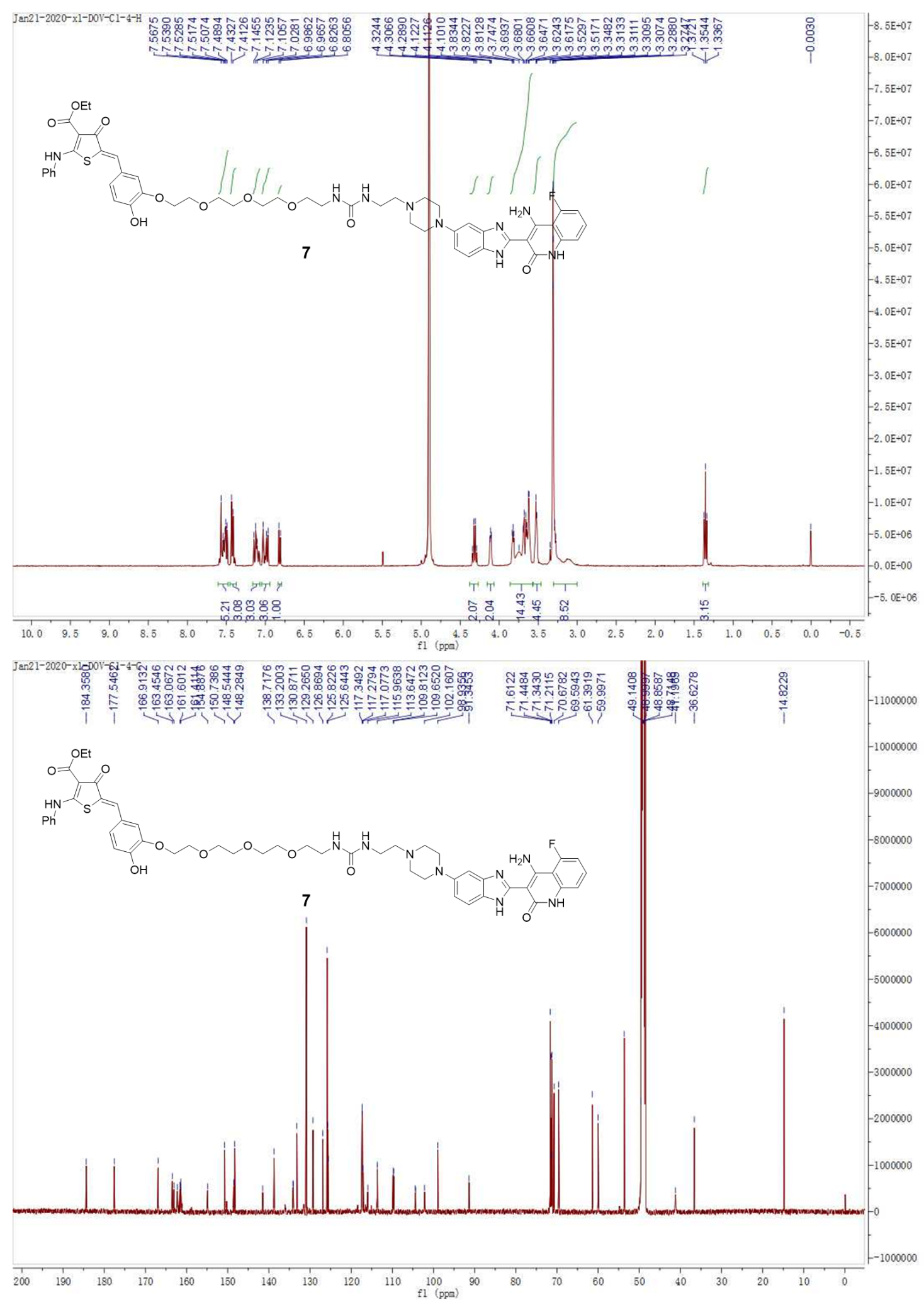


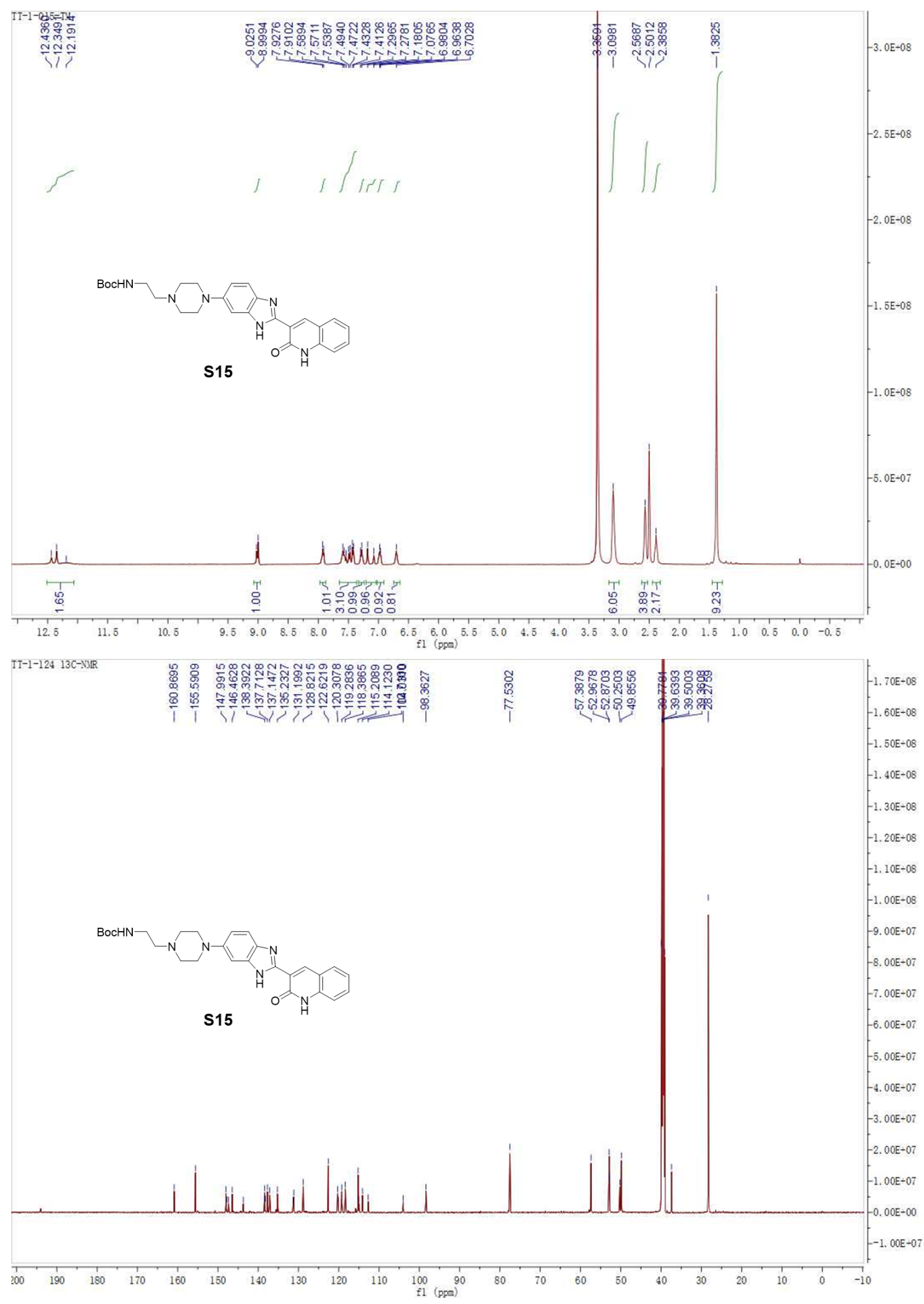




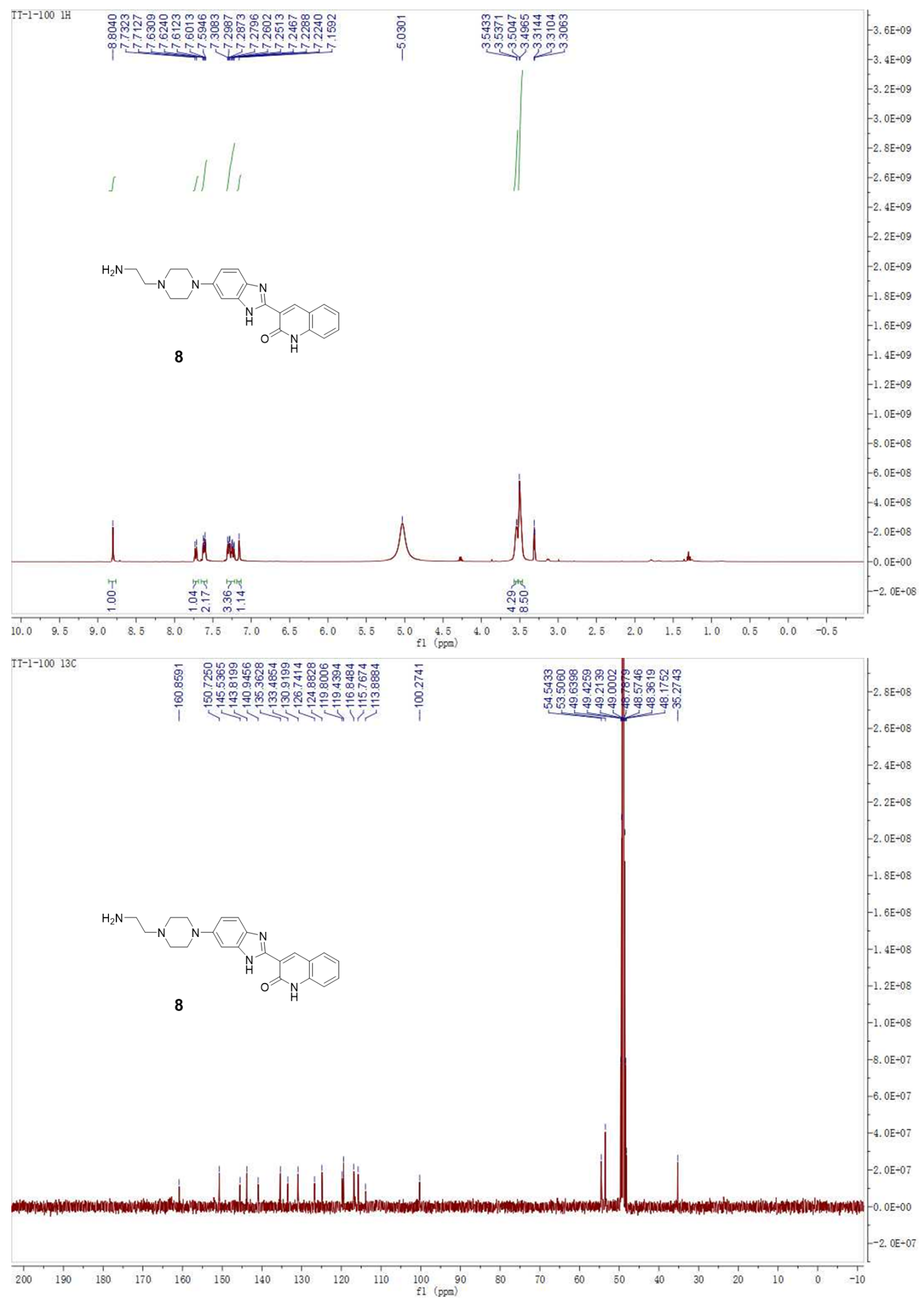




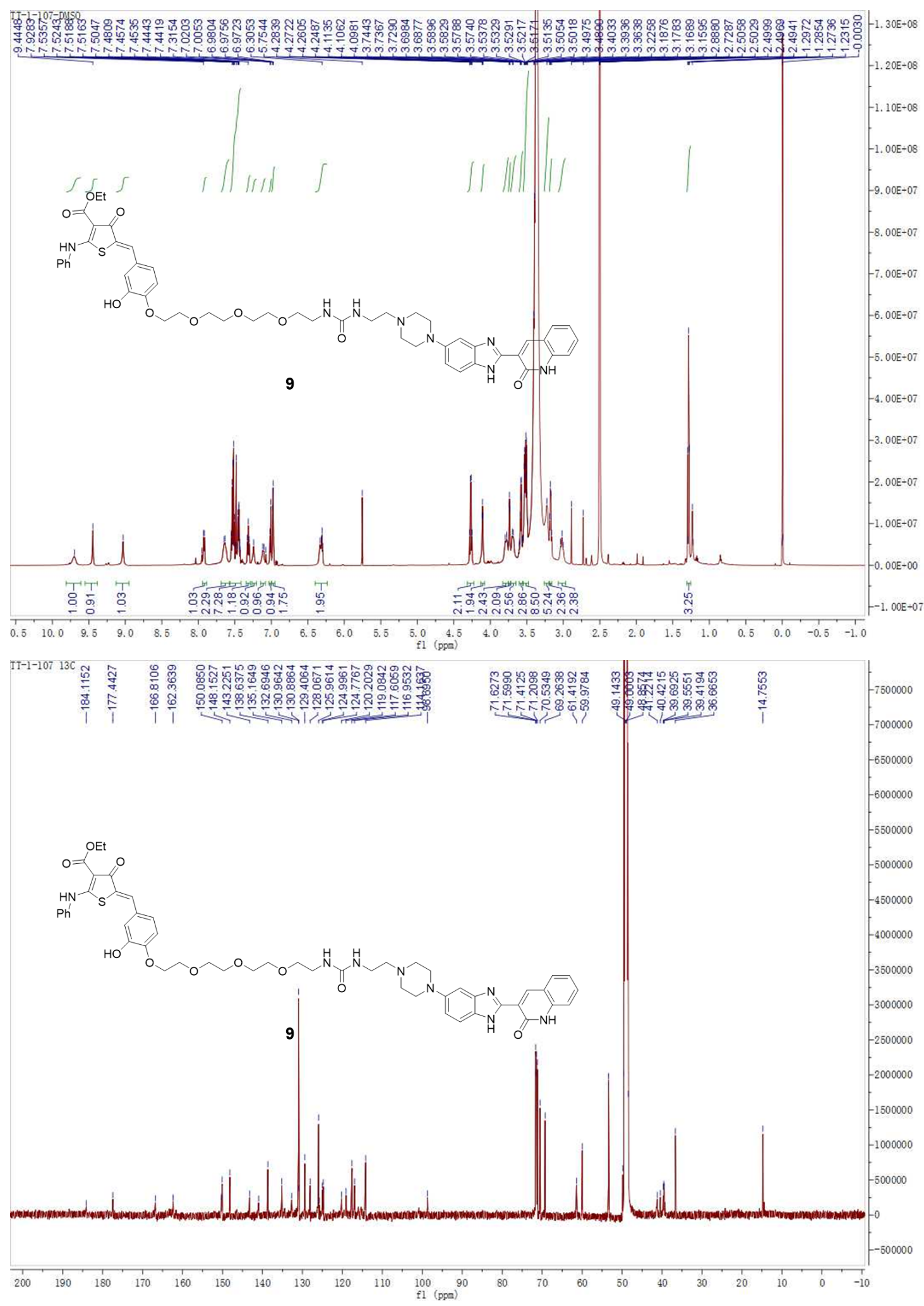




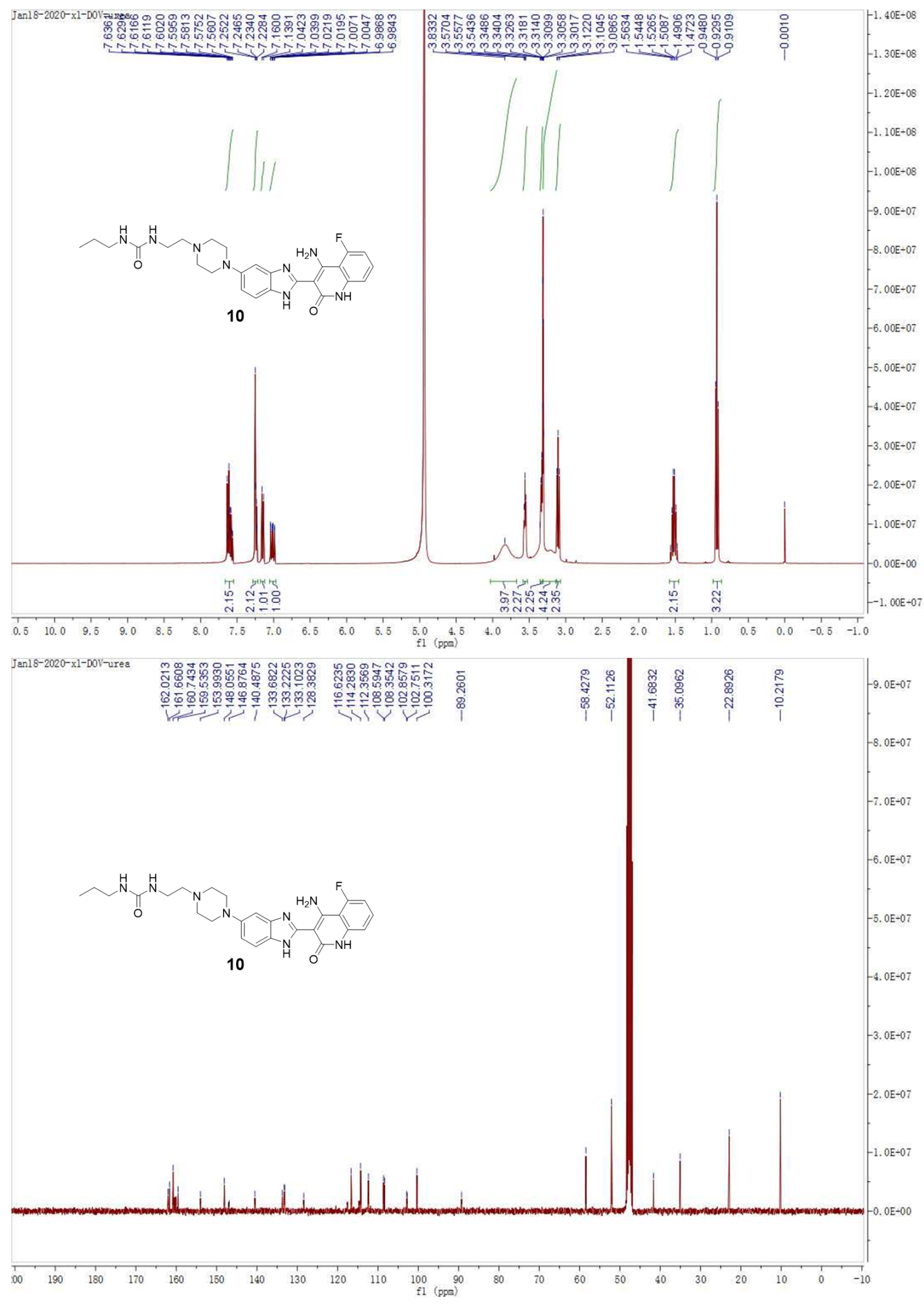




\section{Analytical HPLC trace of 2 and 3}
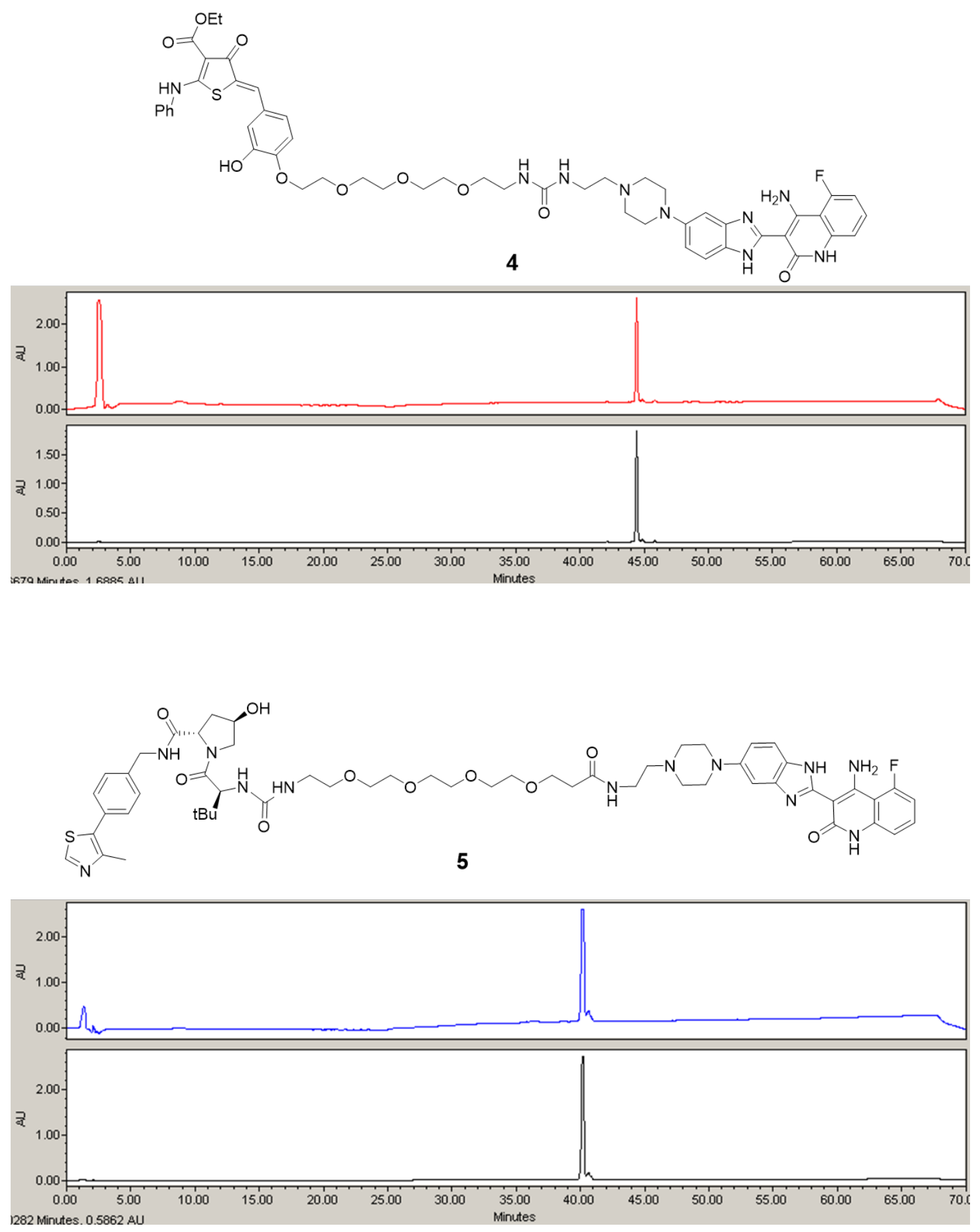
HRMS spectra

$$
\text { S3 }
$$
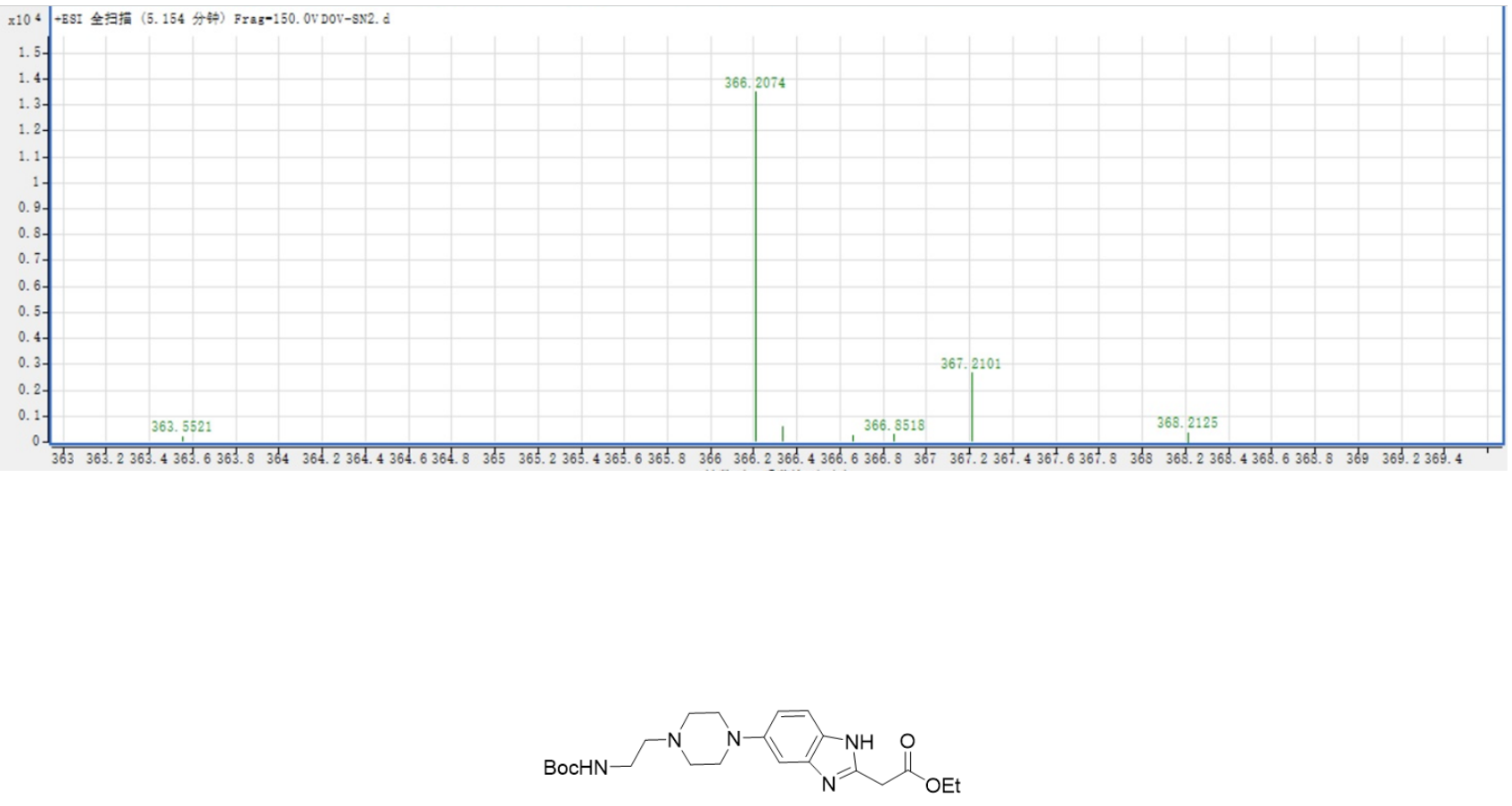

S6

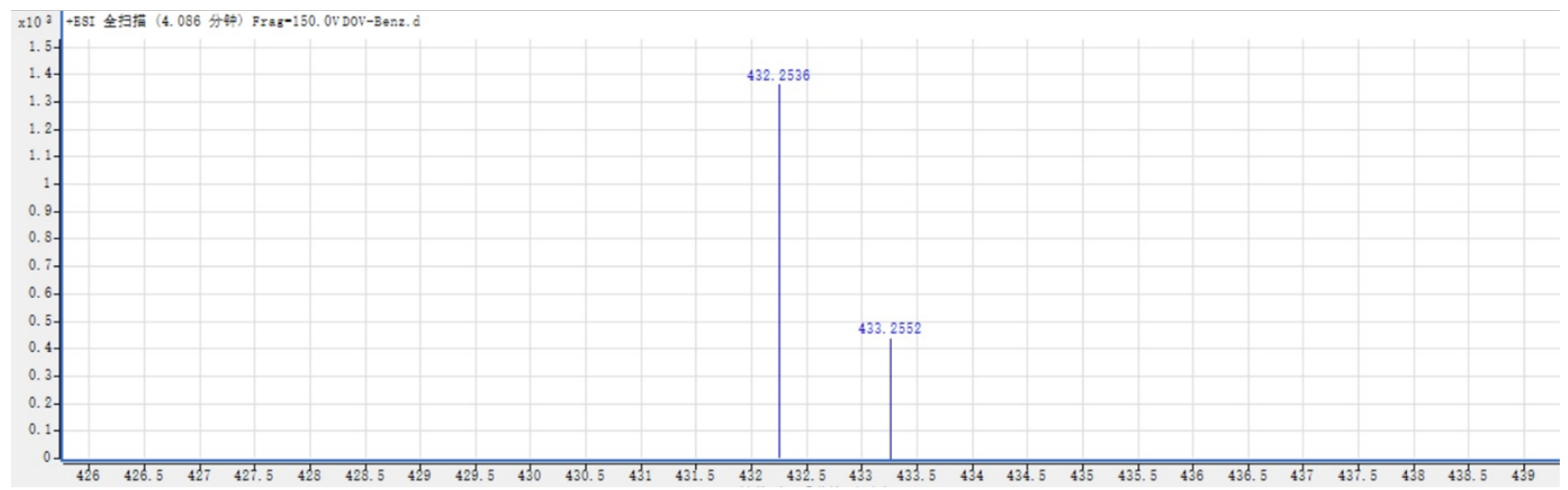



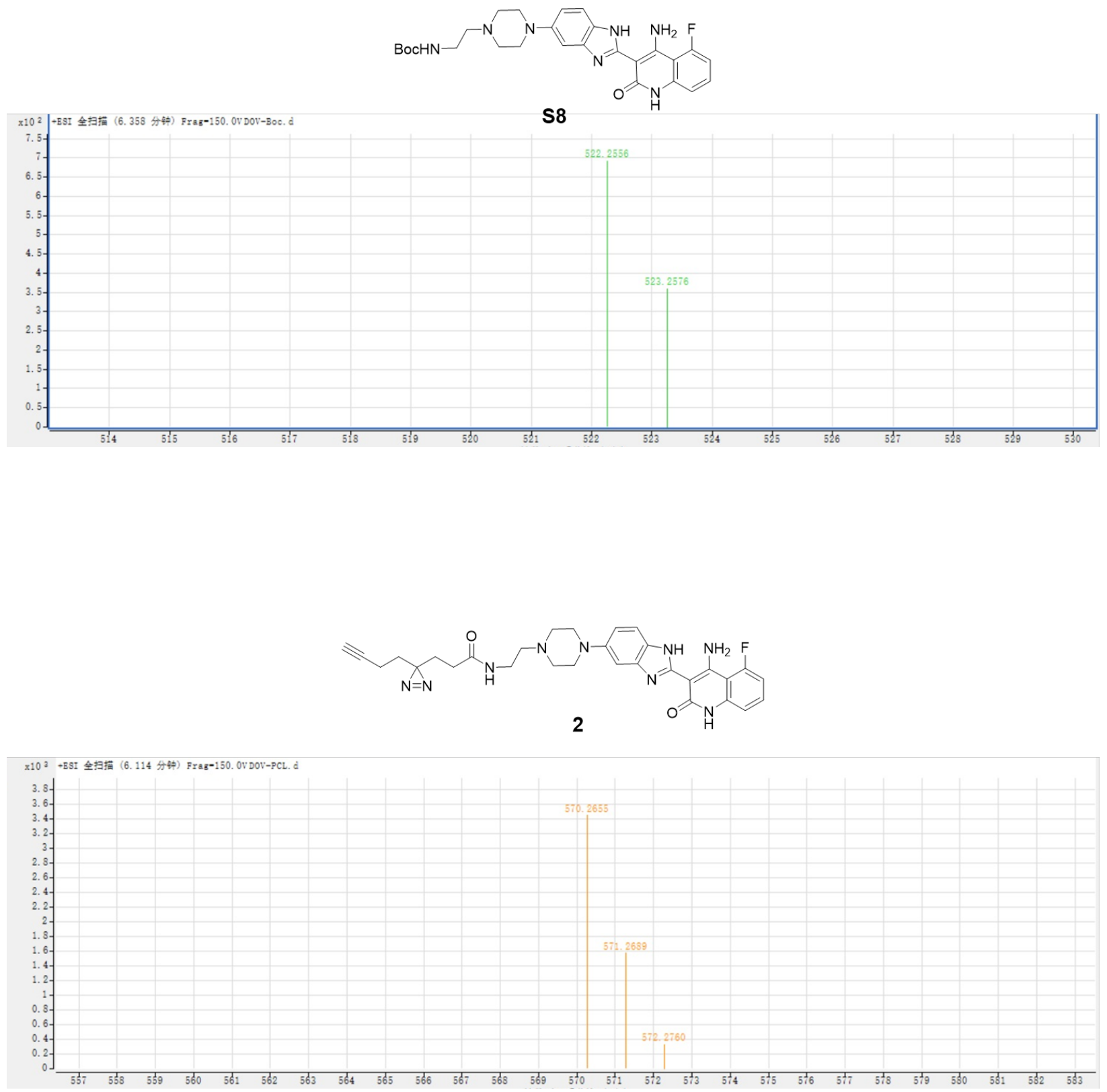

70 

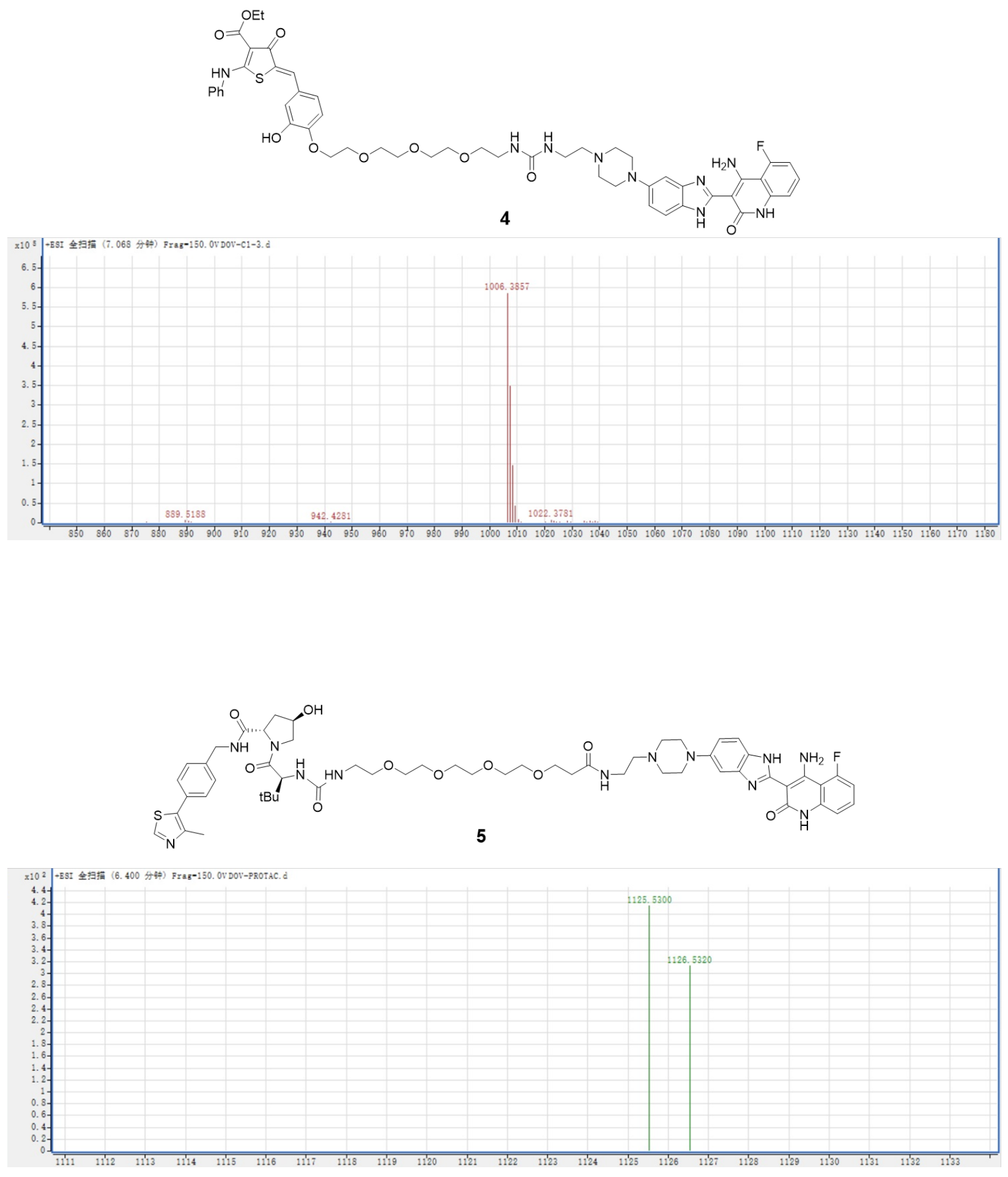

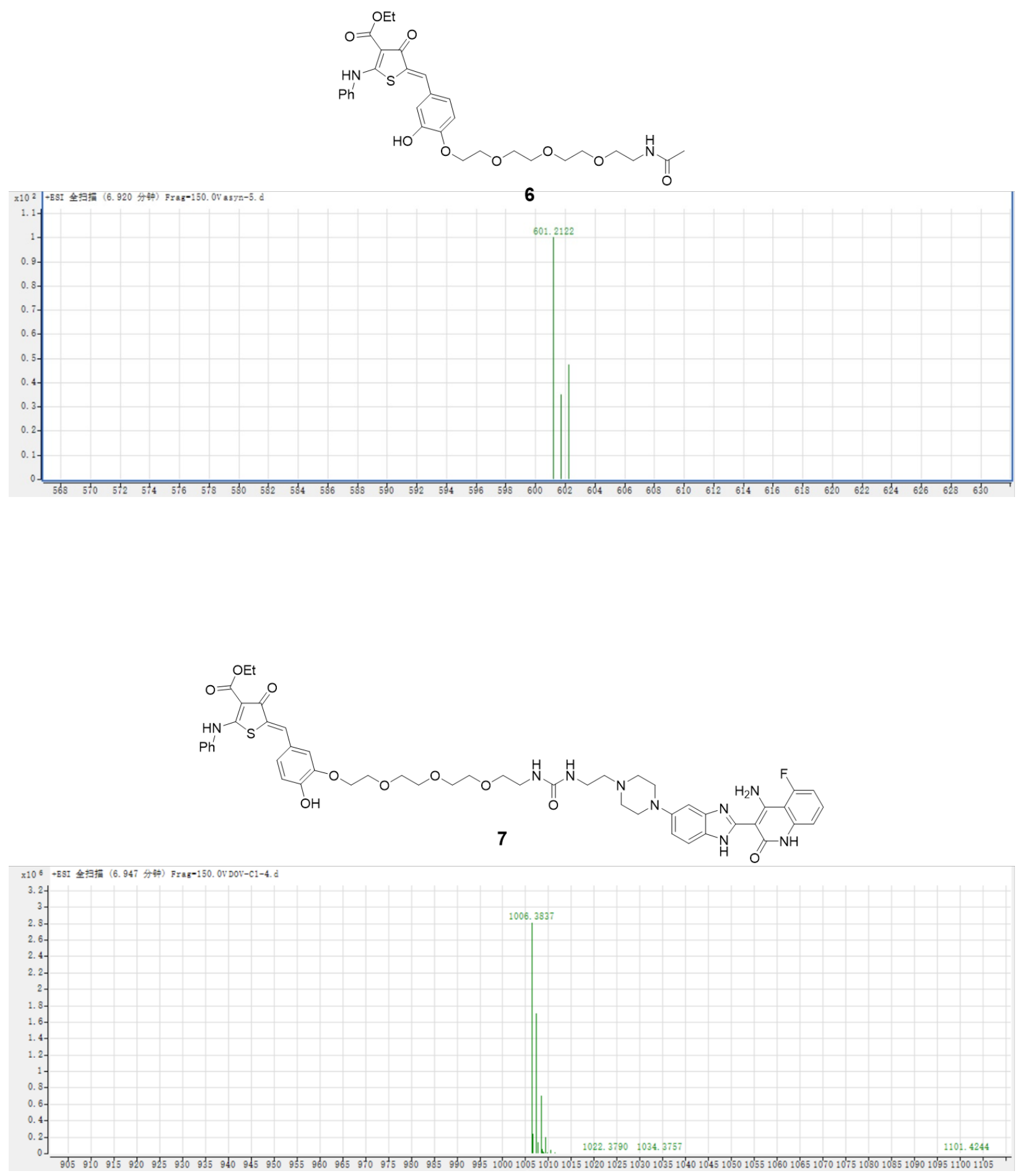

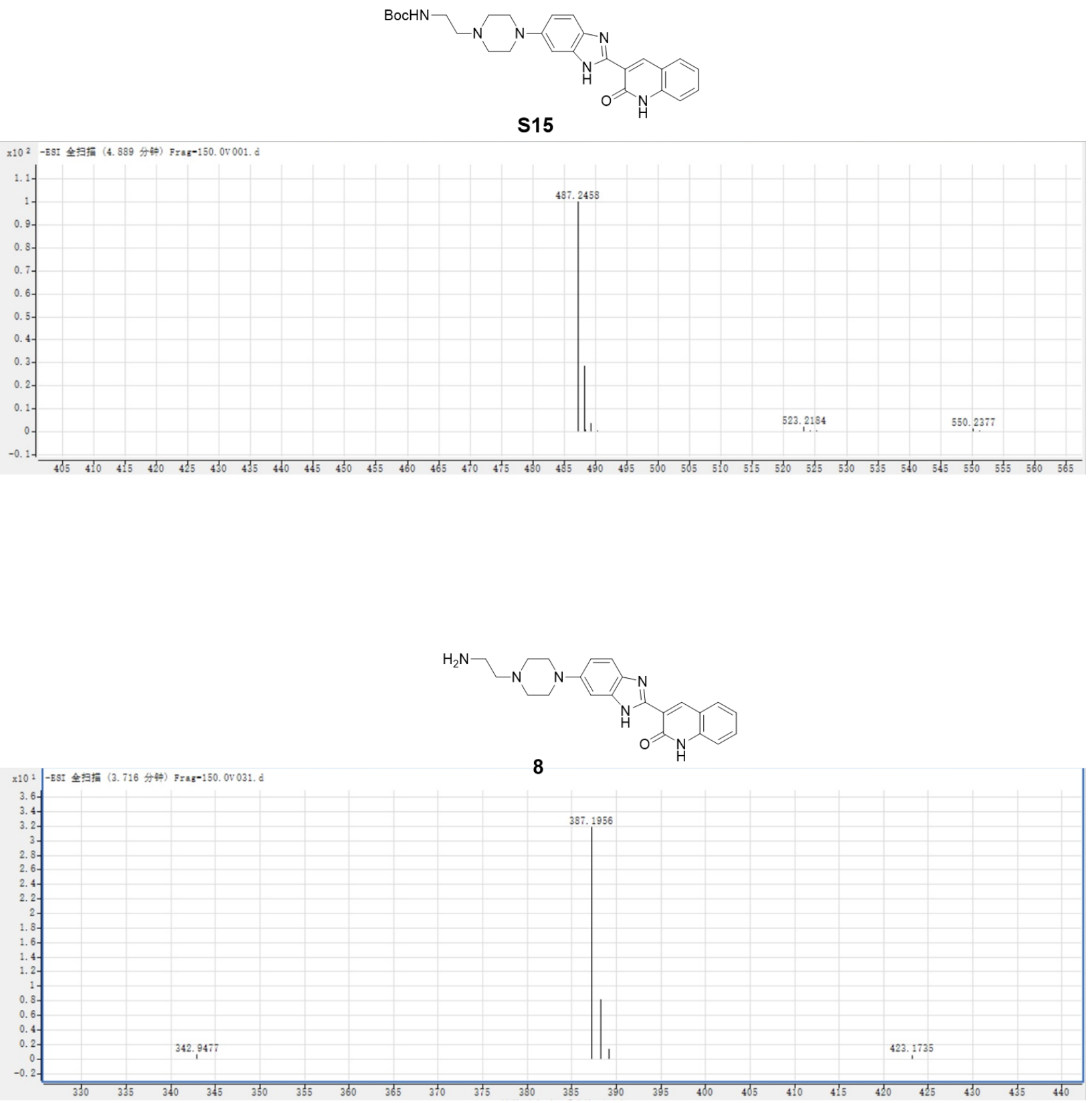

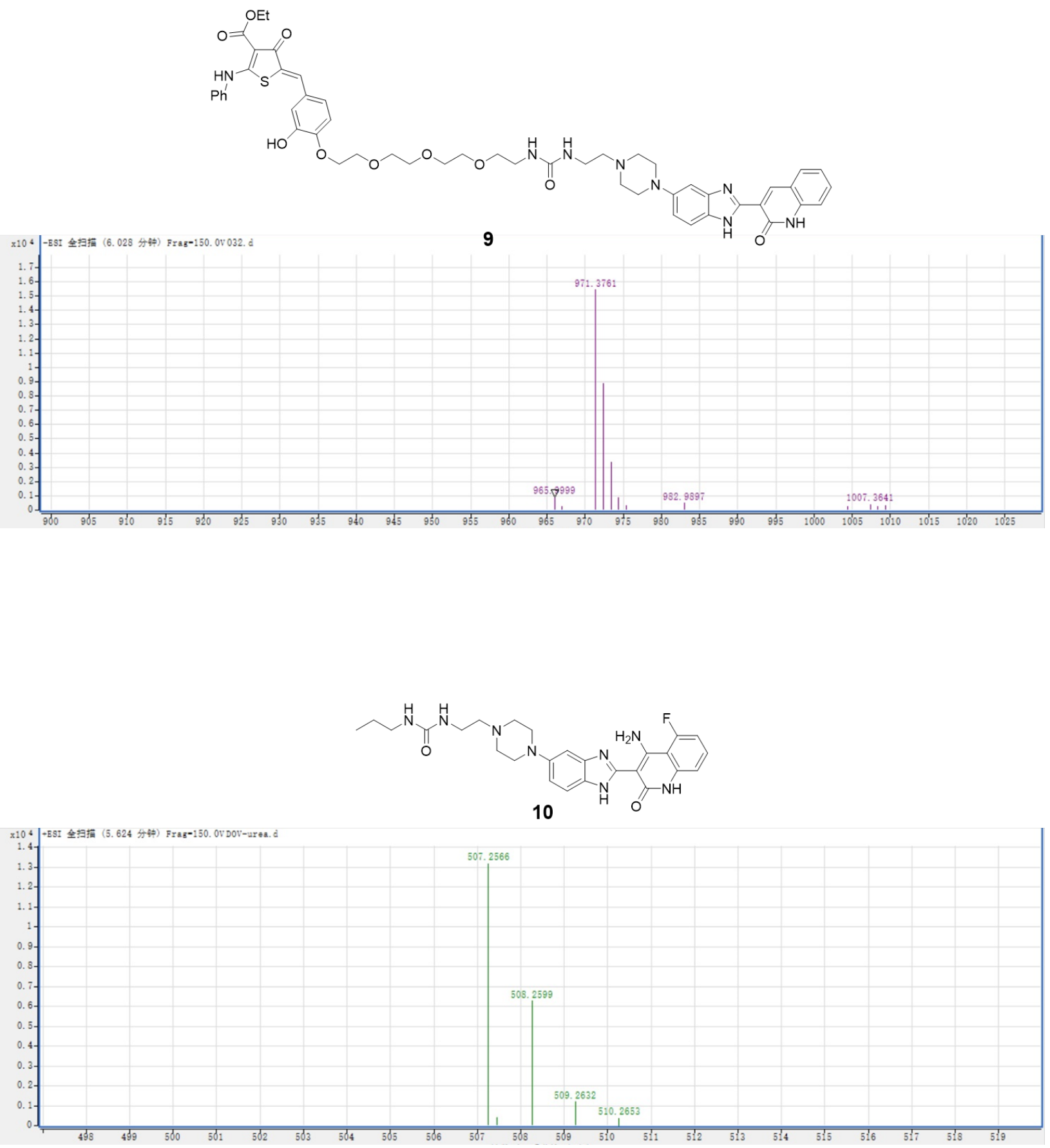
Data S1: Results of global proteomic analysis of MDA-MB-231 cells treated with $1(1 \mu \mathrm{M}), 4(1$ $\mu \mathrm{M})$, or LNA-21 $(0.1 \mu \mathrm{M})$ and untreated cells.

Columns A-C include all proteins (protein ID, protein names, and gene names, respectively) measured and identified by proteomics and associated metadata.

Columns D-G (blue) include protein changes affected by $\mathbf{1}$ as compared with untreated and reported as $\log _{2}$ (Fold Change) (column D), statistical significance, reported as $-\log (\mathrm{P}$ value) (column E), if the change is statistically significant, as indicated with a "+" (above 5\% FDR curves; column F), and if significantly affected proteins are involved in ERK pathway, as indicated with a “+” (column G).

Columns I-L in green include protein changes affected by RIBOTAC 4 as compared with untreated and reported as $\log _{2}$ (Fold Change) (column I), statistical significance, reported as $-\log (\mathrm{P}$ value $)$ (column J), if the change is statistically significant, as indicated with a "+" (above 5\% FDR curves; column K), and if significantly affected proteins are involved in ERK pathway, as indicated with a "+" (column L).

Columns N-Q in red include protein changes affected by LNA-21, as compared with untreated and reported as $\log _{2}$ (Fold Change) (column $\left.\mathrm{N}\right)$, statistical significance, reported as $-\log (\mathrm{P}$ value) (column $\mathrm{O}$ ), if the change is statistically significant, as indicated with a "+" (above 5\% FDR curves; column P), and if significantly affected proteins are involved in ERK pathway, as indicated with a "+" (column Q).

Column S denotes proteins with mRNA are potentially regulated by miR-21-5p (Context Score $<$ $-0.1)$ with a "+".

" $\log _{2}$ (Fold Change)" indicates the fold change of protein expression of compound-treated $(\mathbf{1}, \mathbf{4}$ or LNA-21) relative to untreated samples, and " $-\log (\mathrm{P}$-value)" indicates the significance of the fold change as measured by $p$-value. 
Data S2: Results of total RNA-seq analysis of MDA-MB-231 cells treated with $1(1 \mu \mathrm{M}), 4(1$ $\mu \mathrm{M})$, or LNA-21 $(0.1 \mu \mathrm{M})$ and untreated cells.

Column A (gene names) includes all genes measured and identified by RNA-seq that were commonly found in all samples.

Column B-D include genes affected by 1 as compared with untreated and reported as $\log _{2}($ Fold Change) (column B), statistical significance, reported as - $\log _{10}$ (adjusted P-value) (column C), if the change is statistically significant, as indicated with a "+" (adjusted P-value $<0.05$; column D).

Column F-H include genes affected by 4 as compared with untreated and reported as $\log _{2}$ (Fold Change) (column F), statistical significance, reported as - $\log _{10}$ (adjusted P-value) (column G), if the change is statistically significant, as indicated with a "+" (adjusted P-value $<0.05$; column $\mathrm{H}$ ).

Column J-L include genes affected by LNA-21 as compared with untreated and reported as $\log _{2}$ (Fold Change) (column J), statistical significance, reported as - $\log _{10}$ (adjusted P-value) (column K), if the change is statistically significant, as indicated with a "+" (adjusted P-value < 0.05; column L). 


\section{REFERENCES}

1. Janes, J.; Young, M. E.; Chen, E.; Rogers, N. H.; Burgstaller-Muehlbacher, S.; Hughes, L. D.; Love, M. S.; Hull, M. V.; Kuhen, K. L.; Woods, A. K.; Joseph, S. B.; Petrassi, H. M.; McNamara, C. W.; Tremblay, M. S.; Su, A. I.; Schultz, P. G.; Chatterjee, A. K. The ReFRAME library as a comprehensive drug repurposing library and its application to the treatment of cryptosporidiosis. Proc. Natl. Acad. Sci. U. S. A. 2018, 115 (42), 10750-10755.

2. Costales, M. G.; Aikawa, H.; Li, Y.; Childs-Disney, J. L.; Abegg, D.; Hoch, D. G.; Pradeep Velagapudi, S.; Nakai, Y.; Khan, T.; Wang, K. W.; Yildirim, I.; Adibekian, A.; Wang, E. T.; Disney, M. D. Small-molecule targeted recruitment of a nuclease to cleave an oncogenic RNA in a mouse model of metastatic cancer. Proc. Natl. Acad. Sci. U. S. A. 2020, 117 (5), 2406-2411.

3. Tran, T.; Disney, M. D. Identifying the preferred RNA motifs and chemotypes that interact by probing millions of combinations. Nat. Commun. 2012, 3, 1125.

4. Zhang, J. H.; Chung, T. D.; Oldenburg, K. R. A simple statistical parameter for use in evaluation and validation of high throughput screening assays. J. Biomol. Screen 1999, 4 (2), 6773.

5. Velagapudi, S. P.; Costales, M. G.; Vummidi, B. R.; Nakai, Y.; Angelbello, A. J.; Tran, T.; Haniff, H. S.; Matsumoto, Y.; Wang, Z. F.; Chatterjee, A. K.; Childs-Disney, J. L.; Disney, M. D. Approved anti-cancer drugs target oncogenic non-coding RNAs. Cell Chem. Biol. 2018, 25 (9), 1086-1094.

6. $\quad$ Velagapudi, S. P.; Luo, Y.; Tran, T.; Haniff, H. S.; Nakai, Y.; Fallahi, M.; Martinez, G. J.; Childs-Disney, J. L.; Disney, M. D. Defining RNA-small molecule affinity landscapes enables design of a small molecule inhibitor of an oncogenic noncoding RNA. ACS Cent. Sci. 2017, 3 (3), 205-216.

7. Disney, M. D.; Labuda, L. P.; Paul, D. J.; Poplawski, S. G.; Pushechnikov, A.; Tran, T.; Velagapudi, S. P.; Wu, M.; Childs-Disney, J. L. Two-dimensional combinatorial screening identifies specific aminoglycoside-RNA internal loop partners. J. Am. Chem. Soc. 2008, 130 (33), 11185-11194.

8. Schneider, T. D.; Stephens, R. M. Sequence logos: a new way to display consensus sequences. Nucleic Acids Res. 1990, 18 (20), 6097-6100.

9. Nettling, M.; Treutler, H.; Grau, J.; Keilwagen, J.; Posch, S.; Grosse, I. DiffLogo: a comparative visualization of sequence motifs. BMC Bioinformatics 2015, 16, 387. 
10. R Core Team. R: A language and environment for statistical computing. 2013, Available online at: https://www.R-project.org/.

11. Parker, C. G.; Galmozzi, A.; Wang, Y.; Correia, B. E.; Sasaki, K.; Joslyn, C. M.; Kim, A. S.; Cavallaro, C. L.; Lawrence, R. M.; Johnson, S. R.; Narvaiza, I.; Saez, E.; Cravatt, B. F. Ligand and target discovery by fragment-based screening in human cells. Cell 2017, 168 (3), 527-541.

12. Hampf, M.; Gossen, M. A protocol for combined Photinus and Renilla luciferase quantification compatible with protein assays. Anal. Biochem. 2006, 356 (1), 94-99.

13. Kolling, M.; Kaucsar, T.; Schauerte, C.; Hubner, A.; Dettling, A.; Park, J. K.; Busch, M.; Wulff, X.; Meier, M.; Scherf, K.; Bukosza, N.; Szenasi, G.; Godo, M.; Sharma, A.; Heuser, M.; Hamar, P.; Bang, C.; Haller, H.; Thum, T.; Lorenzen, J. M. Therapeutic miR-21 silencing ameliorates diabetic kidney disease in mice. Mol. Ther. 2017, 25 (1), 165-180.

14. Costales, M. G.; Suresh, B.; Vishnu, K.; Disney, M. D. Targeted degradation of a hypoxiaassociated non-coding RNA enhances the selectivity of a small molecule interacting with RNA. Cell Chem. Biol. 2019, 26 (8), 1180-1186.

15. Velagapudi, S. P.; Gallo, S. M.; Disney, M. D. Sequence-based design of bioactive small molecules that target precursor microRNAs. Nat. Chem. Biol. 2014, 10 (4), 291-297.

16. Hayakawa, N.; Noguchi, M.; Takeshita, S.; Eviryanti, A.; Seki, Y.; Nishio, H.; Yokoyama, R.; Noguchi, M.; Shuto, M.; Shima, Y.; Kuribayashi, K.; Kageyama, S.; Eda, H.; Suzuki, M.; Hatta, T.; Iemura, S.-i.; Natsume, T.; Tanabe, I.; Nakagawa, R.; Shiozaki, M.; Sakurai, K.; Shoji, M.; Andou, A.; Yamamoto, T. Structure-activity relationship study, target identification, and pharmacological characterization of a small molecular IL-12/23 inhibitor, APY0201. Bioorg. Med. Chem. 2014, 22 (11), 3021-3029.

17. Zhu, M.; Yi, M.; Kim, C. H.; Deng, C.; Li, Y.; Medina, D.; Stephens, R. M.; Green, J. E. Integrated miRNA and mRNA expression profiling of mouse mammary tumor models identifies miRNA signatures associated with mammary tumor lineage. Genome Biol. 2011, 12 (8), R77.

18. Yang, S.; Zhang, J. J.; Huang, X. Y. Mouse models for tumor metastasis. Methods Mol. Biol. 2012, 928, 221-228.

19. Gomez, I. G.; MacKenna, D. A.; Johnson, B. G.; Kaimal, V.; Roach, A. M.; Ren, S.; Nakagawa, N.; Xin, C.; Newitt, R.; Pandya, S.; Xia, T. H.; Liu, X.; Borza, D. B.; Grafals, M.; Shankland, S. J.; Himmelfarb, J.; Portilla, D.; Liu, S.; Chau, B. N.; Duffield, J. S. Anti-microRNA21 oligonucleotides prevent Alport nephropathy progression by stimulating metabolic pathways. 
J. Clin. Invest. 2015, 125 (1), 141-156. 